\title{
Programmatic Need for a Zero Emission Steam Technology (ZEST) Research Facility
}

\author{
R. Smith, M. Meltzer, F. Followill, J. Johnson
}

\section{June 30, 2001}

U.S. Department of Energy

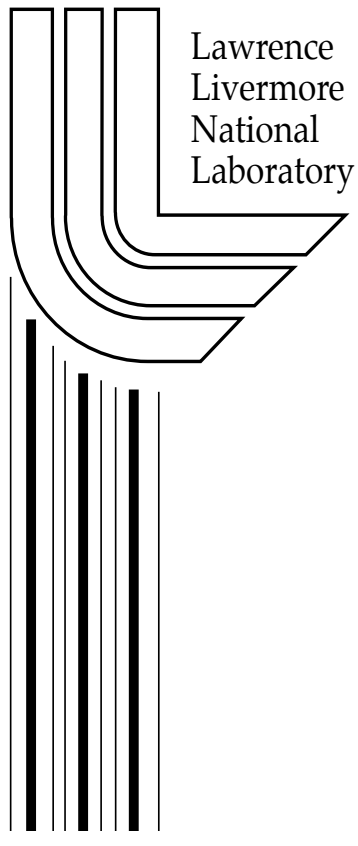




\section{DISCLAIMER}

This document was prepared as an account of work sponsored by an agency of the United States Government. Neither the United States Government nor the University of California nor any of their employees, makes any warranty, express or implied, or assumes any legal liability or responsibility for the accuracy, completeness, or usefulness of any information, apparatus, product, or process disclosed, or represents that its use would not infringe privately owned rights. Reference herein to any specific commercial product, process, or service by trade name, trademark, manufacturer, or otherwise, does not necessarily constitute or imply its endorsement, recommendation, or favoring by the United States Government or the University of California. The views and opinions of authors expressed herein do not necessarily state or reflect those of the United States Government or the University of California, and shall not be used for advertising or product endorsement purposes.

This work was performed under the auspices of the U. S. Department of Energy by the University of California, Lawrence Livermore National Laboratory under Contract No. W-7405-Eng-48.

This report has been reproduced directly from the best available copy.

Available electronically at http://www.doc.gov/bridge

Available for a processing fee to U.S. Department of Energy

And its contractors in paper from

U.S. Department of Energy

Office of Scientific and Technical Information

P.O. Box 62

Oak Ridge, TN 37831-0062

Telephone: (865) 576-8401

Facsimile: (865) 576-5728

E-mail: reports@adonis.osti.gov

Available for the sale to the public from

U.S. Department of Commerce

National Technical Information Service

5285 Port Royal Road

Springfield, VA 22161

Telephone: (800) 553-6847

Facsimile: (703) 605-6900

E-mail: orders@ntis.fedworld.gov

Online ordering: http://www.ntis.gov/ordering.htm

OR

Lawrence Livermore National Laboratory

Technical Information Department's Digital Library

http:/ / www.llnl.gov/tid/Library.html 
Technical Support Document

\section{Programmatic Need for a Zero Emission Steam Technology (ZEST) Research Facility}

Prepared by

Energy and Environment Directorate

Lawrence Livermore National Laboratory

June 2001

R. Smith, M. Meltzer, F. Followill, J. Johnson 



\section{Contents}

Executive Summary

1. The ZEST Concept

2. Why a ZEST Research Facility Needs to Be Built

3. What is New and Innovative About ZEST?

Page

3.1 The Gas Generator: Modular Rocket-Engine-Inspired Design and Independent Parameter Control

3.2 Coupling Oilfield Production Facilities with Distributed Electric Power Generation Plants

3.3 Establishing a Research Facility for Geologic Carbon Dioxide Sequestration

4. How ZEST Supports the National Energy Policy

5. How ZEST Supports the DOE Fossil Energy Mission

6. ZEST Technical Details

6.1 Oxygen Separation

6.2 Control System

6.3 Gas Generator

6.4 Turbines

6.5 Condenser

6.6 Water Treatment

7. Carbon Dioxide Sequestration

7.1 Injection for Enhanced Oil Recovery (EOR)

7.2 Injection for Environmental Isolation

8. Why LLNL is the Best Site for This Project 33

8.1 Ceramic Membrane Oxygen Separation 33

8.2 Thermal Barrier Coating Technology for High-Temperature Turbines and Gas Generator

8.3 Computational Capabilities: Gas Generator Combustion Region

8.4 Computational Modeling Capabilities: Geologic Carbon Dioxide Sequestration

8.5 Geophysical Imaging and Geochemical Sampling and Analytic Capabilities

8.6 Carbon Dioxide Injection and Enhanced Oil Recovery in Seismically Active Oil Basins

9. Competitive Technologies

9.1 Combined-Cycle Gas and Steam Turbines $\quad 41$

9.2 Solid Oxide Fuel Cells

9.3 Los Alamos National Laboratory (LANL) Zero Emission Coal (ZEC) Power Plant

10. Facility Design, Engineering Services, and Construction Plan 43

10.1 Project Participants

10.2 Facility Construction Budget Estimates

10.3 Proposed Funding Schedule and Milestones

11. ZEST Research and Operations Management Plan 47

11.1 Organizational Structure $\quad 47$

11.2 Annual Research Activities 48

Appendices $\quad 49$

A. Discussion of Factors Affecting the Cost of Carbon Dioxide Sequestration $\quad 51$

B. Bechtel Preliminary Design Study and Cost Estimate 57 


\section{Executive Summary}

Lawrence Livermore National Laboratory (LLNL) is proposing to construct an on-site research facility for a novel electric power generation system that exploits clean-burning fossil fuels. This system, termed Zero Emission Steam Technology (ZEST), offers unique economic and environmental benefits, including:

- Highly efficient power generation using the most advanced combustion and turbine technologies.

- Ability to burn a range of fossil fuels, including natural gas, synthetic gas from coal ("coal syngas"), and coal-bed methane.

- No oxides of nitrogen generated that would contribute to air pollution.

- No greenhouse gases emitted.

- Secure geologic sequestration of the carbon dioxide $\left(\mathrm{CO}_{2}\right)$ combustion product.

- Use of the $\mathrm{CO}_{2}$ combustion product to enhance oil recovery in mature fields.

The proposed research facility will provide a necessary step toward commercialization of ZEST. Despite the technology's promise, it will not be implemented by the U.S. electric power industry unless an agency such as DOE takes on the task of demonstrating its scientific and economic viability. The U.S. electric power industry typically requires 50,000 hours of operational datanearly six years of continuous duty-before investing in a major new technology. ${ }^{1}$ Hence, there is a strong programmatic need for DOE to provide such data for ZEST, to accelerate commercial investment in this technology.

The ZEST combustion process is based on rocket engine technology. It burns pure oxygen with a hydrocarbon fuel under stoichiometric conditions to produce power with virtually no oxides of nitrogen generated. The flexibility of ZEST's gas generator, which has independent temperature and pressure control, will allow modular upgrading of turbine systems as new, more efficient technology becomes available. It is envisioned that the ZEST research facility will serve as a testing laboratory for new turbine technology being designed by the U.S. Department of Energy (DOE) National Energy Technology Laboratory (NETL) Next Generation Turbine Program.

\footnotetext{
${ }^{1}$ Personal communication between Clean Energy Systems and General Electric Power Systems.
} 
In its initial phase, ZEST is expected to operate at 35\% efficiency, using commercially available turbine technology, while future phases of the ZEST system should approach an operating efficiency of $60 \%$ and, based on $\$ 6$ per GJ of natural gas, should generate electricity for less than 6 cents per kilowatt-hour. ZEST is expected to be competitive with or surpass all other fossil fuel power generation technologies in efficiency and economy of operation when $\mathrm{CO}_{2}$ sequestration is included. When the sequestration is carried out in a mature oil field, significant additional energy can be derived from the supplementary oil recovered. For every Btu of energy generated through combustion in the ZEST gas generator, sufficient oil to produce as much as five Btu of energy can possibly be recovered. ${ }^{2}$

The ZEST research facility will demonstrate the advantages of building multi-objective power plants that not only generate emission-free electricity but that also use their $\mathrm{CO}_{2}$ combustion products to enhance oil recovery at combined power and fuel production sites around the United States. LLNL is the logical host for such a research facility for several reasons, including staff expertise in research areas that are key to successful development of ZEST. These areas include ceramic membrane oxygen separation, thermal barrier coating development for high-temperature steam turbines, computational simulation of combustion processes and geologic $\mathrm{CO}_{2}$ sequestration, geophysical imaging and analysis, and $\mathrm{CO}_{2}$ injection to enhance oil production in seismically active basins. Equally important, LLNL has an impressive track record of successfully translating complex systems from benchscale proof-of-concept to field-scale prototype.

LLNL also has a valuable combination of site and regional attributes, including close proximity to both a mature oil field and deep saline aquifers. This setting presents an opportunity to establish - as an integral component of ZEST - a U.S. geologic sequestration research facility that explicitly integrates advanced modeling and field studies of $\mathrm{CO}_{2}$ injection for both enhanced oil recovery and pure environmental isolation. Important regional attributes include strong San Francisco Bay Area support for clean energy and environmental technologies, ready access to multiple power grid feeds, a controllable nearby base load, and a highly stressed local grid that will benefit from a nominal 10-MW addition. LLNL also enjoys an established collaboration with the larg-

\footnotetext{
${ }^{2}$ Based on LLNL calculation, which assumes that two barrels of oil can be recovered for each barrel of $\mathrm{CO}_{2}$ injected.
} 
est research university in the country and has geographical proximity to many important technology developers.

Collaborations with other DOE national laboratories will be important for the success of ZEST. LLNL will draw upon NETL's Next Generation Turbine (NGT) Program and its industrial partners as resources for the design and testing of high-temperature steam turbines, which are critical for achieving ZEST's high efficiency potential. NETL will provide vital expertise and testing facilities for expanding ZEST's capabilities to include the use of coal syngas fuel, and will lead the design and testing effort for a syngas-compatible reheater. In addition, Oak Ridge National Laboratory's High Temperature Materials Laboratory (HTML) capabilities will be critical for evaluating LLNL thermal barrier coatings for corrosion rates at elevated temperatures.

The goal of the proposed project is to exploit the unique convergence of LLNL's research capabilities and its geologic and geographic setting to:

- Demonstrate ZEST's performance, thus enabling its emergence in the marketplace.

- Establish a U.S. research facility for geologic $\mathrm{CO}_{2}$ sequestration, which will provide a much-needed testbed for evaluating DOE-proposed sequestration strategies.

ZEST research facility design and construction activities will span six years and will cost a total of about $\$ 70.2$ million (see Table E.1).

Table ES-1. Major ZEST Funding Elements (3Q FY01 \$ Million)

\begin{tabular}{|c|c|}
\hline Total estimated cost (TEC) & \$ Million \\
\hline Design and engineering & 7.6 \\
\hline Project management & 4.1 \\
\hline Construction management & 4.7 \\
\hline Construction & 48.9 \\
\hline Subtotal TEC & 65.4 \\
\hline \multicolumn{2}{|l|}{ Other project costs (OPC) } \\
\hline Conceptual design & 0.6 \\
\hline Hazards, analysis, NEPA (EA), \& permits & 0.3 \\
\hline Risk reduction engineering & 3.0 \\
\hline Misc. other costs & 0.9 \\
\hline Subtotal OPC & 4.8 \\
\hline Total project cost (TPC) & 70.2 \\
\hline
\end{tabular}


In addition to constructing and operating the power plant research facility, critical activities will include development of the novel technologies, simulations, and analyses important for the success of ZEST. The estimated budget for these activities in FY05 is $\$ 4.75$ million. 


\section{The ZEST Concept}

Lawrence Livermore National Laboratory (LLNL) is proposing to construct a Zero Emission Steam Technology (ZEST) research facility on site that will implement advanced technologies for efficient electric power generation from fossil fuels and for the secure geologic sequestration of $\mathrm{CO}_{2}$.

The main objective of ZEST is to demonstrate the scientific and economic viability of fossil fuel power production without environmentally detrimental atmospheric emissions. A secondary aim is to demonstrate the practicality of a multiple-objective power plant - one that produces emission-free electric power while using a combustion product to enhance oil recovery in a mature oil field.

ZEST offers tremendous potential for environmentally friendly distributed power and enhanced oil recovery applications at many combined fuel production sites around the country. The research proposed for advancing geologic sequestration science will also allow generalization of siting to areas with deep saline aquifersnot just those near active oil fields. 


\section{Why A ZEST Research Facility Needs to Be Built}

Zero Emission Steam Technology facilities offer many environmental and economic benefits. Traditional power generation from fossil fuels results in problematic air emissions that contribute to greenhouse-gas emissions and add to photochemical smog formation. In contrast, ZEST facilities offer environmentally friendly electric power generation that is also highly efficient and costeffective, especially since the process exhaust will be used to enhance oil production in mature fields. However, ZEST will not be commercialized unless the federal government takes on the task of demonstrating its scientific and economic viability. The U.S. electric power industry is a conservative community and is notably risk-averse regarding the construction of plants based on new technologies with unproven reliability and performance. The industry typically requires 50,000 hours of operational datanearly six years of continuous duty — on a new power generation technology before it is willing to invest in that technology. ${ }^{3}$ Hence, there is a strong need to provide such data for Zero Emission Steam Technology, which will accelerate commercial investment in this process.

The power industry will require answers to questions such as:

- What is the mean time to failure for the ZEST system, and in particular, for its gas generator?

- What is ZEST's maximum turn-down ratio (maximum/minimum output) with stable combustion?

- What are the technology's failure modes?

- What are its maintenance requirements?

- When will efficiency improvements be available?

- What noise issues or other "nuisance" impacts are associated with the technology?

- How effective are the high-speed controls that will be installed to insure safe operation?

Only after these questions have been answered and the technical risks well characterized will industry consider making major investments in ZEST power plants. Thus, building the ZEST research facility is on the critical path to commercialization.

\footnotetext{
${ }^{3}$ Personal communication between Clean Energy Systems and General Electric Power Systems.
} 
The ZEST facility also will provide a much-needed testbed for addressing key environmental concerns regarding safe disposal of $\mathrm{CO}_{2}$ waste streams. In the report, Carbon Sequestration: Research and Development (December 1999), DOE has outlined the fundamental scientific questions that must be answered to develop sound geologic sequestration policies and regulations:

- What is the net sequestration attainable by injecting carbon dioxide into hydrocarbon reservoirs to enhance oil recovery?

- What is the ultimate capacity and isolation security of geologic formations targeted as pure storage reservoirs for carbon dioxide waste streams?

- What "screening" criteria can be used to quantify "net sequestration," "ultimate capacity," and "isolation security" for specific geologic formation types?

- How can these screening criteria be translated into appropriate regulations for generalized geologic sequestration?

These fundamental questions can only be answered in the context of a comprehensive research program that explicitly integrates advanced computational simulation capabilities and wellcharacterized field studies. LLNL's expertise in modeling geologic $\mathrm{CO}_{2}$ sequestration, LLNL's unique geologic setting, and the $\mathrm{CO}_{2}$ waste stream captured from ZEST together present a unique opportunity to establish a U.S. geologic sequestration research facility, which is an integral part of this project. The United States needs such a facility, because of its critical importance in developing U.S. carbon sequestration policy.

The goal of the proposed project is to take advantage of the unique convergence of advanced technologies and geologic setting at LLNL to (1) demonstrate ZEST's performance, thus accelerating its emergence in the marketplace; and (2) establish a U.S. geologic sequestration research facility, which will fill DOE's existing void in this area. 


\section{What Is New and Innovative About ZEST?}

\subsection{The Gas Generator: Modular Rocket-Engine- Inspired Design and Independent Parameter Control}

Zero Emission Steam Technology borrows its gas generator design from rocket engines that have been reliably sending payloads into space for decades (see Figures 1 and 2). ${ }^{4}$ By so doing, significant environmental impacts are avoided. Conventional power plants rely heavily on emission-control devices that are expensive and only partially effective in removing nitrogen oxides and, in the case of coal- and oil-fired plants, particulates and oxides of sulfur from the waste gas stream. Many of these conventional plants have been forced to shut down because of environmental constraints.

ZEST is a pollution-prevention approach to the problem of air emissions that accompany conventional power plant operations.

Figure 1. Applying rocket engine technology to power production and $\mathrm{CO}_{2}$ sequestration.

Figure 2. The ZEST gas generator and high-pressure turbine are based on rocket

engine technology, while advanced turbine concepts contribute to the design of ZEST's intermediate pressure turbine.
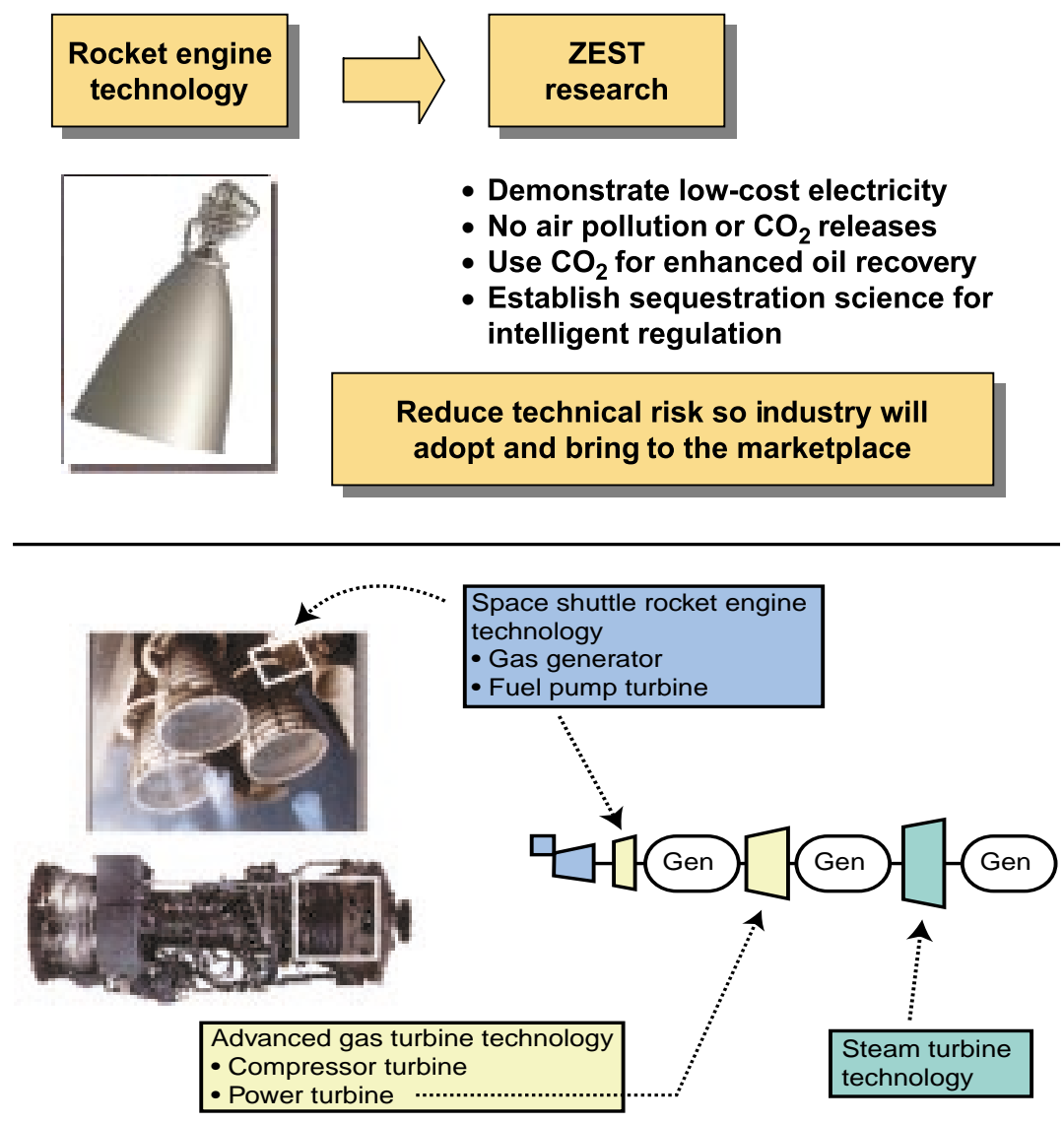

${ }^{4}$ Gas generator design will be based on the intellectual property of Clean Energy Systems (CES), a new spin-off company composed primarily of former Aerojet engineers. 
The ZEST concept does not rely on "back-end" mitigation measures but rather on a process that by its basic design does not create air pollutants. Combustion is carried out under stoichiometric conditions, burning either natural gas, synthetic gas from coal ("syngas"), or coal-bed methane, with high-purity oxygen separated from the air (see Figure 3). Because oxygen, rather than atmospheric air, is used in the combustion process, no nitrogen reactions occur, and thus no nitrogen oxides are generated. Large quantities of water are added to control temperatures, producing high-energy steam without emissions. ZEST power plants will also produce several potential revenue-generating products, including industrial gases such as carbon dioxide, argon, oxygen, and nitrogen. In addition, if the ZEST gas generator is run in the fuel-rich mode, it will generate hydrogen, which can be separated from the combustion products for use in fuel-cell-powered automobiles $^{5}$ (see Figure 4).

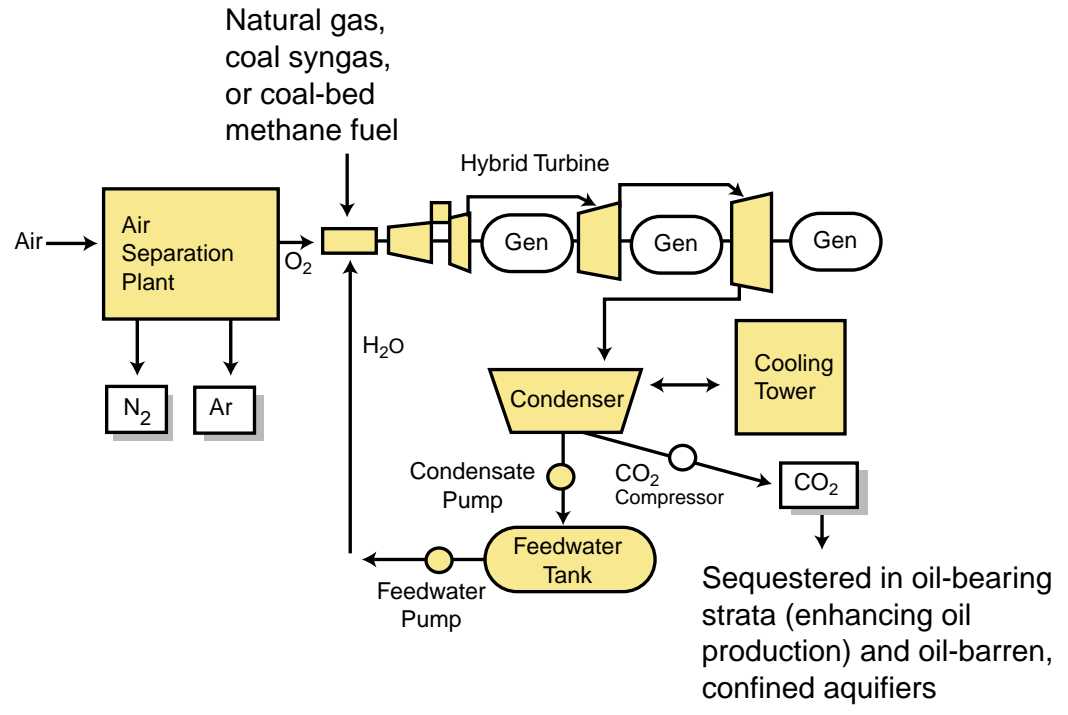

Figure 3. The Zero Emission Steam Technology power plant concept. Oxygen is burned with natural gas, coal syngas, or coal-bed methane to produce electric power devoid of $\mathrm{NO}_{\mathrm{x}}$ emissions. All $\mathrm{CO}_{2}$ generated during combustion is sequestered in oil-bearing and oil-barren geological formations.

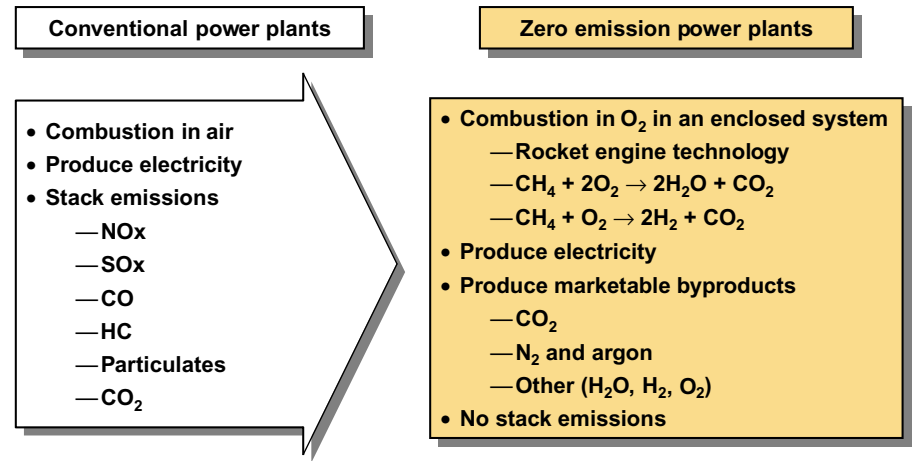

${ }^{5}$ Developing commercial hydrogen generation from a ZEST process would require a major research effort not addressed in the scope of the proposed project. The potential for hydrogen embrittlement of turbine blades and the costs of developing hydrogen separator equipment would have to be evaluated. 
The gas generator developed by Clean Energy Systems (CES) for ZEST will be able to independently control pressure and temperature of the working fluid. Pressure will be regulated by adjusting the mass flow rate of fuel and oxidizer. Temperature will be lowered as needed through the addition of water to both the primary combustion zone and the downstream cool-down sections. This independent control feature allows gas generator output to be matched to any available steam-turbine technology, enabling ZEST to be upgraded as new state-of-the-art components become available. Each turbine can either be coupled to its own generator, with power from the different generators electronically combined, or all turbines could drive a common gearbox connected to a single generator. The ZEST research facility will use the separate turbine generator configuration to allow independent upgrades of the high-pressure, intermediate-pressure, or low-pressure turbines.

Currently available commercial steam technology for power plants operates at approximately $1100^{\circ} \mathrm{F}\left(593^{\circ} \mathrm{C}\right)$ and will be used unless higher-temperature, more efficient technology becomes available by the time that construction of the ZEST research facility begins. Boeing Rocketdyne and Pratt-Whitney, for instance, build turbines for the space shuttle's main engine fuel pumps that operate at $1400^{\circ} \mathrm{F}\left(760^{\circ} \mathrm{C}\right)$. If available, a derivative of this turbine will be used as the high-pressure turbine for the initial ZEST facility. A derivative of combustion turbine design may also be available for use as ZEST's intermediate turbine. If available in the initial phase, implementing these turbines could raise the efficiency of electrical power generation to $45-50 \%$, instead of the estimated $35 \%$ attainable from current commercially available steam turbines.

Because of the success of the NETL Advanced Gas Turbine Program, state-of-the-art combustion turbines are being delivered with inlet temperatures of $2550^{\circ} \mathrm{F}\left(1400^{\circ} \mathrm{C}\right)$. A goal of ZEST is to implement steam turbines into its process that achieve similar temperature-performance. ZEST will work closely with NETL's Next Generation Turbine (NGT) Program, which is expected to meet the technical challenge of upgrading steam turbines to gas turbine temperature-performance levels.

Once ZEST is commercialized, the flexibility of its CES gas generator temperature and pressure controls will allow distributed, small-scale plants (30-100 MW) to be upgraded to higher efficiencies as commercially viable turbine improvements pen- 




etrate the marketplace. This could be accomplished without changing other major components of the plants.

Besides offering powerful operational and environmental advantages, ZEST has the potential to generate power at cost-per-kilowatt-hour rates that are competitive with or surpass all other technologies. Note from Figure 5 that the cost of geologic sequestration per ton of carbon generated by a ZEST plant ( $\$ 10$ to $\$ 17$ ) is expected to be far lower than the cost for a combined-cycle plant, which is estimated at about $\$ 72 .^{6}$ This is because of the high cost of $\mathrm{CO}_{2}$ separation required by the combined-cycle plant. A detailed discussion of Figure 5 can be found in Appendix A.

We envision that the ZEST Phase II and Phase III upgrades will use more advanced turbine technology than is currently available. As seen from Figure 6, Phase II technology plants are envisioned to operate at $45-50 \%$ efficiency and to generate electricity at approximately 7 cents per kilowatt-hour, based on a natural gas cost of $\$ 6 /$ GJ. The Phase III plants will be designed to operate at $60 \%$ efficiency and to generate power for about 6 cents per kilowatt-hour. All phases of ZEST plants will sequester $\mathrm{CO}_{2}$ in geologic formations. Note from Figure 6 that for other powergenerating technologies, costs both without sequestration (black symbols) and with geologic sequestration (green symbols) are given.

\footnotetext{
${ }^{6}$ The estimate for combined cycle plants may in fact be conservative. Dr. Chuck Schmidt, NETL Program Manager for Geologic Sequestration, noted in a private communication that the estimate in Figure 5 of about $\$ 72$ to geologically sequester one ton of carbon generated in a combined-cycle plant was more likely $\$ 110$ per ton, which would make the difference in sequestration costs even greater between ZEST and combined-cycle plants.
}

Figure 5. Comparative cost of geologic carbon sequestration for 100-MW plants. The left-hand column shows cost per ton of carbon; the right-hand axis corresponds to cost per ton of $\mathrm{CO}_{2}$. 
Figure 6. Economic comparisons of existing technologies and ZEST, with and without geologic carbon sequestration, for 200- to 300 MW plants. When sequestration is considered, the ZEST Phase III cost of electricity is lower than for competing technologies. This chart shows only fuel costs and capital costs. Maintenance and operating costs are not included.

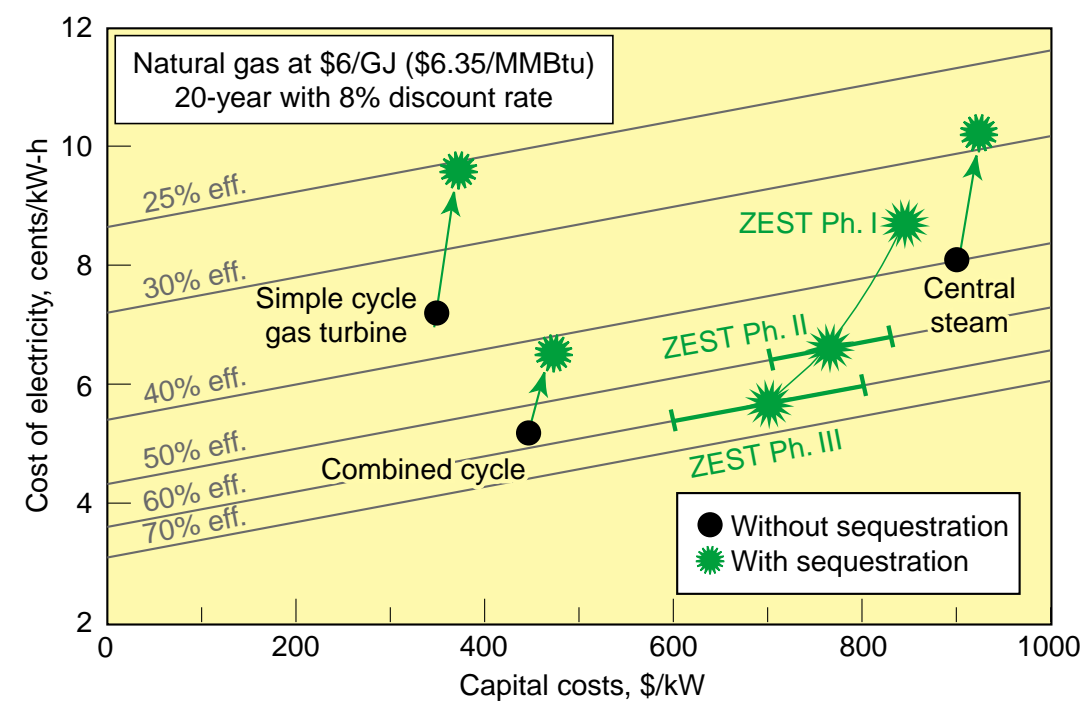

If the costs of $\mathrm{CO}_{2}$ sequestration are not considered, combinedcycle plants may appear to be the best technology choice, because they generate electricity at approximately the same cost and efficiency as the ZEST Phase III design but with half the capital cost per kilowatt. Once $\mathrm{CO}_{2}$ sequestration costs are included, however, the picture changes. The combined-cycle performance is significantly impaired; its kilowatt-hour cost rises to over 6 cents, and its efficiency slips to 43\%, because of its high cost for $\mathrm{CO}_{2}$ separation and sequestration. The ZEST Phase III technology, on the other hand, is expected to approach $60 \%$ efficiency, with cost of electricity about 6 cents per kilowatt-hour. Although a ZEST facility's capital costs are higher, these would be amortized by the lower operating costs.

\subsection{Coupling Oilfield Production Facilities with Distributed Electric Power Generation Plants}

For every barrel of crude oil produced in the United States, approximately two barrels remain in the ground. However, this historical one-third yield can often be improved through modern techniques of enhanced oil recovery (EOR). $\mathrm{CO}_{2}$ flooding has proven to be a particularly effective and economically attractive EOR methodology for suitable reservoirs located sufficiently proximate to natural $\mathrm{CO}_{2}$ sources. Implementation of this technique, however, has been severely limited - primarily to the Permian Basin of west Texas - by the sparse occurrence of adequate $\mathrm{CO}_{2}$ reserves. ZEST technology offers a win-win solution to this supply problem by providing a low-cost source of $\mathrm{CO}_{2}$ for local 
EOR while eliminating $\mathrm{CO}_{2}$ emissions from direct power generation.

The onshore oil and gas fields of the contiguous United States constitute a mature oil and gas province. Oil production in this region peaked in the early 1970 s and has declined since then. Each year, more than 15,000 marginal oil and gas wells are abandoned, and 220,000 nonproducing wells are "idled." It is important for our country to combat our currently declining oil production rate. If possible, we must reduce the rate at which our domestic oil fields are being abandoned. Once a field is "shut in," it cannot be economically restored. The ZEST project offers hope of further exploiting many of these mature fields and deriving significant additional energy from the supplementary oil recovered. LLNL estimates have shown that for every Btu of energy generated through combustion in the ZEST gas generator, sufficient oil can be recovered to produce up to five Btu of energy. ${ }^{7}$

\subsection{Establishing a Research Facility for Geologic Carbon Dioxide Sequestration}

The United States has a critical need to answer key scientific questions regarding geologic $\mathrm{CO}_{2}$ sequestration, a concept presently forecast to occupy a prominent, perhaps leading, role in the country's 21 st-century carbon management. The questions outlined in Section 2 can only be addressed following integrated development of computational modeling tools and field tests to formulate the requisite advanced simulation capabilities. Ideally, such development will be centralized at a site such as LLNL that has the capability to carry out both the modeling work and the necessary field studies. The ZEST project offers the opportunity to establish a unique U.S. geologic sequestration research laboratory at a facility such as LLNL.

\footnotetext{
${ }^{7}$ This estimate assumes that two barrels of oil can be recovered for each barrel of $\mathrm{CO}_{2}$ injected.
} 


\section{How ZEST Supports the National Energy Policy}

The National Energy Policy document ${ }^{8}$ released in May 2001 stresses the importance of advancing "new, environmentally friendly technologies to increase energy supplies and encourage cleaner, more efficient energy use." The ZEST system is intended to meet each one of these challenges. By burning pure oxygen in its gas generator, ZEST will avoid the generation of oxides of nitrogen air pollution, which the National Energy Policy report specifically mentions as needing to be controlled. By sequestering all $\mathrm{CO}_{2}$ combustion products, ZEST will eliminate contributions to global warming. And by sequestering this $\mathrm{CO}_{2}$ in oilbearing strata, ZEST will enhance oil recovery and extend the lifetimes of shallow, mature fields that otherwise might have to be closed down. Finally, through its use of cutting-edge turbine and combustion technology, ZEST will produce electricity that is competitive in price with the most advanced fossil-fuel-based power generation technologies.

The National Energy Policy recommendations recognize the importance that coal must play in our energy future. Coal is the United States' most abundant fuel source. We have a 250 -year supply of coal, and it is expected to remain the dominant fuel for meeting electricity demand through 2020. ZEST is designed to make good use of our plentiful coal reserves. The ZEST gas generator can burn synthetic gas from coal as well as coal-bed methane. The ZEST gas generator can also burn natural gas, our thirdlargest power source for electricity generation.

\footnotetext{
${ }^{8}$ This section responds to policy recommendations made in the document, National Energy Policy: Reliable, Affordable, and Environmentally Sound Energy for America's Future, a report of the National Energy Policy Development Group, ISBN 0-16-050814-2, May 2001.
} 


\section{How ZEST Supports the DOE Fossil Energy Mission}

The mission of DOE's Office of Fossil Energy includes enhancement of U.S. economic, energy, and environmental security through:

- Conducting energy-related research that promotes efficient, environmentally sound fossil fuel production and use. The goal of ZEST is to develop high-efficiency power generation from fossil fuels with minimum environmental impact. ZEST will operate with virtually no air emissions that add to either air pollution or global warming and will use $\mathrm{CO}_{2}$ gas produced in its combustion process to enhance oil production from mature petroleum reserves.

- Partnering with industry to advance fossil energy technologies toward commercialization. ZEST will involve a close partnership with Clean Energy Systems (CES) Inc. to develop rocket-engine-based gas generator technology for electric power generation. LLNL will also work with another industrial partner, such as Praxair or Air Products, to develop an economical, efficient ceramic membrane approach for oxygen separation from atmospheric air.

- Developing innovative strategies for secure nonatmospheric disposal of $\mathrm{CO}_{2}$ waste streams associated with energy production. Geologic sequestration-either in the context of injection for enhanced oil recovery or pure isolation-represents one of the most promising $\mathrm{CO}_{2}$ disposal strategies. A unique U.S. geologic sequestration research facility-one that integrates advanced modeling and field characterization of both EOR- and storage-based implementations - will be established as an essential component of the ZEST project.

DOE'S Office of Fossil Energy recognizes that coal, oil, and natural gas are all indispensable elements of our country's energy mix. Because of its abundance and low cost, coal is now used to generate more than half of the United States' electricity. ${ }^{9}$ One quarter of all the world's coal is found within the United States.

\footnotetext{
${ }^{9}$ Statement of Robert S. Kripowicz, Principal Deputy Assistant Secretary for Fossil Energy, U.S. Department of Energy, to the Subcommittee on Energy and Power, Committee on Commerce, U.S. House of Representatives, 8 June 2000.
} 
Because dependence on clean coal technologies is vital to the United States' future energy strategies, the ZEST facility will be designed to use coal syngas as an alternative to natural gas in its combustion process.

The ZEST project supports the mission of the Office of Fossil Energy's National Energy Technology Laboratory, which is to solve U.S. energy and environmental problems through conducting, partnering in, and procuring research, development, and demonstration projects to advance fossil energy technology into the commercial marketplace. NETL's aims include developing technologies that also contribute to U.S. employment and to the advancement of U.S. industries in the global market. NETL's mission leads to various strategies that will be aided by ZEST, including:

- Increase economically recoverable domestic oil supplies to reduce future import dependence. The ZEST project aims to increase petroleum production from mature fields by demonstrating the scientific and economic feasibility of multiobjective power plants that provide low-cost $\mathrm{CO}_{2}$ for enhanced oil recovery in local mature oil fields.

- Develop innovative methodologies and modeling tools for evaluating $\mathrm{CO}_{2}$-flood effectiveness in terms of oil production and $\mathrm{CO}_{2}$ sequestration. ZEST will make use of cutting-edge reservoir modeling and imaging technologies being developed at LLNL and the National Petroleum Technology Office (NPTO, now an office of NETL).

- Identify and develop new fossil energy technologies that significantly reduce greenhouse gas emissions. The main goal of ZEST is to produce emission-free power from fossil fuel, using a novel approach based on rocket engine technology. In particular, all $\mathrm{CO}_{2}$ generated from the combustion process will be sequestered geologically, by dual injection either into a relatively shallow hydrocarbon reservoir (to enhance oil recovery) or a relatively deep confined aquifer (for pure isolation). Hence, this waste stream will not contribute to atmospheric greenhouse gas concentrations or global warming.

NETL has recognized the potential benefits of ZEST and is currently funding a first-generation 10-MW gas generator demonstration. This $\$ 2.6$ million project is a critical-path experiment 
for ZEST development that also supports NETL's Vision 21 program. As part of ZEST project hardware development, NETL will initiate the design, construction, and testing of a coal syngas reheater that will increase plant efficiency by raising the temperature of the working fluid between turbine stages. 


\section{ZEST Technical Details}

\subsection{Oxygen Separation}

ZEST's combustion process requires a continuous stream of oxygen of at least $95 \%$ purity, but preferably higher. Most of the ZEST facility's oxygen requirements will be met through construction of an on-site cryogenic distillation oxygen separation plant.

Other approaches besides cryogenic distillation were examined for supplying oxygen. Vacuum pressure swing adsorption (VPSA) processes were considered for the oxygen plant, but these generally cannot furnish an oxygen stream of greater purity than 90 93\%, with nitrogen making up much of the impurities. This would result in production of unwanted oxides of nitrogen in ZEST's gas generator, and the greater gas flow required for a VPSA plant would increase equipment sizes and costs. Also considered was an option to operate ZEST without an oxygen plant, relying instead on storage tanks with oxygen delivered by truck. Although capital costs would be lower for such a system, run-out costs would be considerably higher than for a cryogenic plant operating for 10 or more years. Also, relying on stored oxygen was estimated by LLNL staff to require 12 tank trucks of oxygen per day, and the logistics of managing such a supply system would be very difficult.

The oxygen separation process will be constructed adjacent to the building housing ZEST's gas generator, turbines, and electric generators, as illustrated in Figure 7.

Figure 7. ZEST's research power plant will be built on a 1.8-acre site at LLNL.

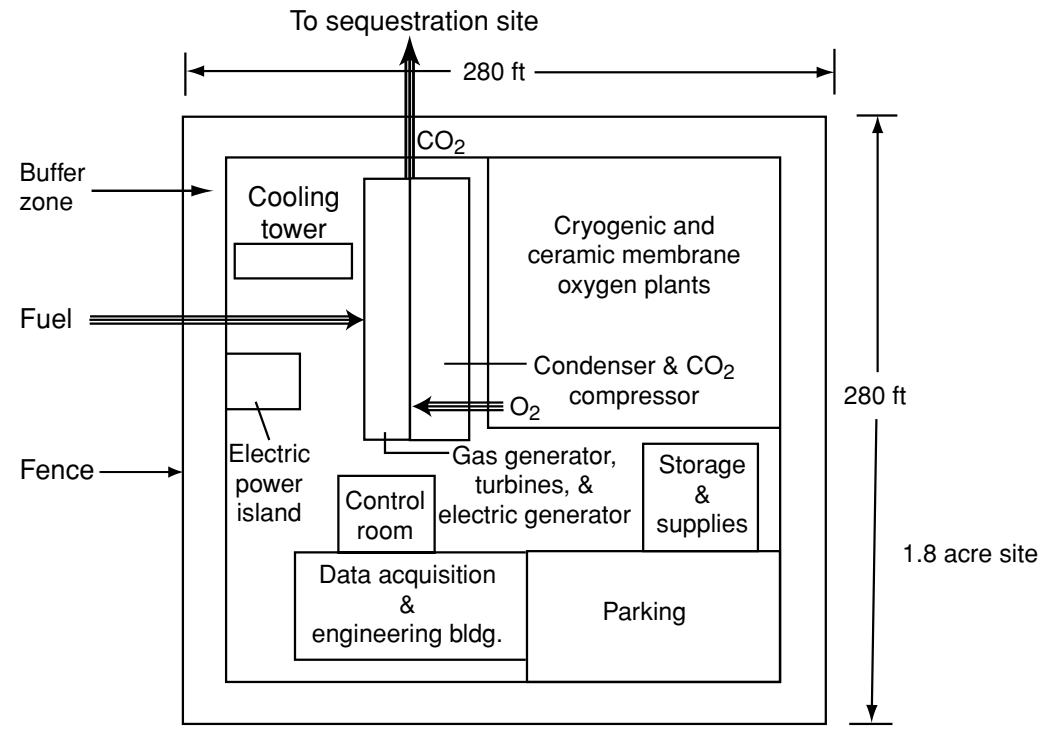


Notice from Figure 7 that two types of separation techniques will be employed. Although cryogenic techniques will provide approximately $90 \%$ of ZEST's oxygen needs, a novel membrane separation technology will also be used. An important ZEST research area will be to develop high-temperature ceramic membrane materials that can provide more energy-efficient, lessexpensive oxygen generation than is currently available. The ceramic membrane plant will include research stations for testing and monitoring the performance of membranes under development. This effort may be accomplished in partnership with a commercial manufacturer of oxygen, such as Praxair or Air Products. These companies are currently working with NETL on novel (proprietary) oxygen transport membranes.

Membrane technologies are not new to the field of gas separation. Polymeric membranes have been commercialized, but are used primarily for nitrogen production, as well as for hydrogen and $\mathrm{CO}_{2}$ separation. Polymeric membranes can also separate oxygen from air, although their selectivity is low. They typically generate an oxygen stream that is only $30 \%$ to $40 \%$ pure, with nitrogen comprising most of the remainder. Such low

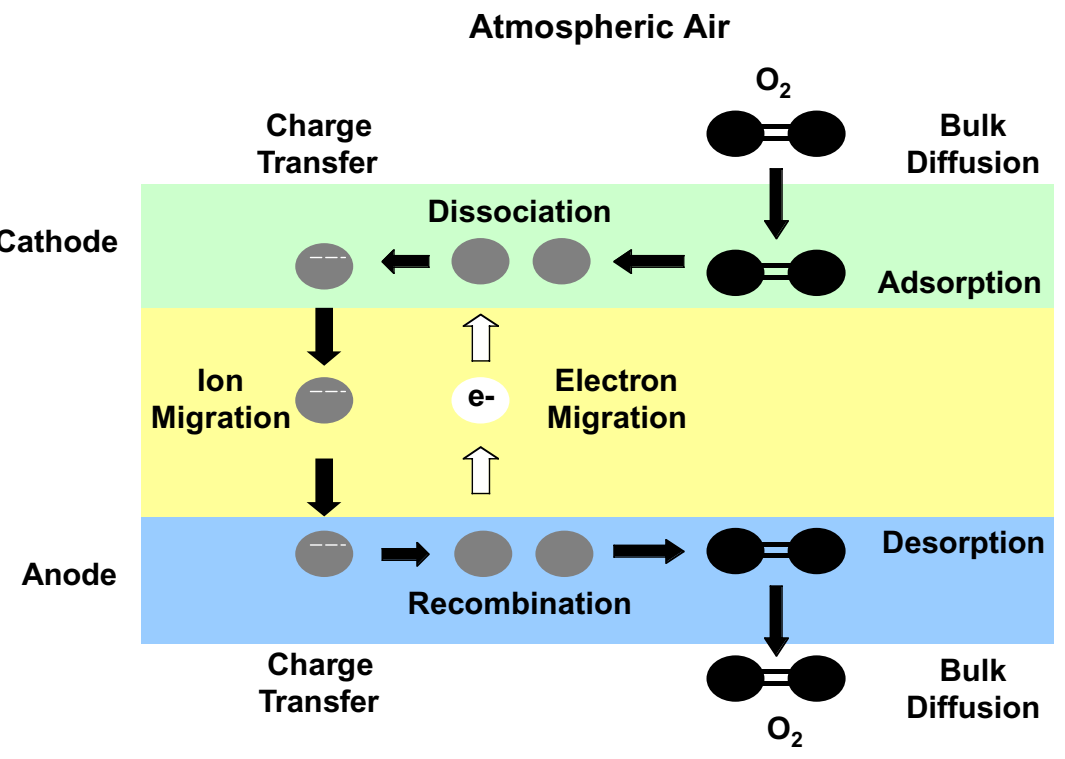

Pure Oxygen purity is not acceptable for ZEST's combustion process because of the large quantity of nitrogen oxides that would be generated. Oxygen generation from polymeric membranes is also expensive, as compared to nitrogen production.

Ceramic membranes show much more promise than polymeric membranes for high-purity oxygen separation and are the target of intense research at LLNL as well as at other locations around the country. Ceramic membranes transport oxygen by a vacancy diffusion mechanism, which is analogous to the way that semiconductors transport electric current (see Figure 8). The ceramic membrane is comprised of a doped crystal lattice with properties such that oxygen is the only gas in atmospheric air that can oc-

Figure 8. Ceramic membrane oxygen transport technology provides a means of generating pure oxygen for combustion. The membrane selectively removes oxygen from atmospheric air. (Source: Ravi Prasad, Minish Shah, Ray Drnevich, and Dave Thompson, OTM-A Novel Technology for Integrated Oxygen Production, Copyright 2000 Praxair Technology, Inc. Prepared with support of U.S. DOE under Contract No. DEFC26-99FT40437.) 
cupy holes in the lattice. As a result, ceramic membranes have a very high selectivity for oxygen and can produce it at a very high purity. The oxygen chemical potential difference across the membrane provides the driving force for oxygen permeation. As shown in Figure 8, $\mathrm{O}_{2}$ molecules adsorb on the cathode side of the membrane, dissociate into atoms, and then pick up electrons to become oxygen ions. These ions travel from the side of the membrane with high-oxygen partial pressure to the low-oxygen partial pressure (anode) side by repeatedly jumping from their lattice sites to adjacent vacancies. On the anode side, the oxygen ions give up their electrons to become atoms, then recombine into $\mathrm{O}_{2}$ molecules that desorb from the membrane into a gas phase. Electrons from the membrane's anode side move toward the cathode side to complete the circuit.

Limiting factors in oxygen transport through the membrane include (1) the ability of oxygen to cross a boundary layer; (2) the rate of surface oxygen exchange; and (3) the diffusion rate of oxygen ions and electrons through the membrane itself. The high operating temperatures of ceramic membranes, 600 to $1,100^{\circ} \mathrm{C}$, result in fast oxygen transport rates and quick separation. This characteristic of the membranes makes them potentially more costeffective than standard cryogenic separation techniques. The maturity of the ceramic membrane technology is such that it could possibly be included in an oxygen plant that begins operation in FY 2004 or later. Its cost of operation could be reduced if process heat from the ZEST facility's gas generator were used to maintain the membrane at its 600 to $1,100^{\circ} \mathrm{C}$ operating temperature.

\subsection{Control System}

For safety and reliability, the ZEST power plant's startup, operation, and shutdown must be automatically controlled. The automatic system needs to supply the gas generator with an inert purge gas during startup, then deliver precise flows of natural gas, oxygen, and water during combustion. The switching from purge gas to reactive gases and cooling water has to be fully automated. Appropriate sensors need to be installed to detect unsafe operating conditions and activate automatic shutdown if necessary. A backup control system is required to insure safe shutdown of the plant in the event of an emergency. Backup power must be available to deliver electricity to the control system to insure safe shutdown during an emergency.

Planned work in FY01 includes plant simulation, which will provide the basics for designing the automated control system. This 
effort will build on the experience of the prototype 10-MW gas generator project currently under development by CES, using NETL and in-kind funding.

\subsection{Gas Generator}

The gas generator, which will be purchased from LLNL's industrial partner, Clean Energy Systems, Inc., is the critical component in the power plant's operation. It will produce the hot gases for powering the series of turbines connected to electrical generators. The gas generator is essentially a land-based rocket engine designed to burn fossil fuel under stoichiometric conditions. Although natural gas will be used in the ZEST facility, an advantage of the CES gas generator is that it can burn virtually any gasified fossil fuel that is composed primarily of carbon, hydrogen, and oxygen, including coal-bed methane and coal syngas, with independent temperature and pressure control to match available steam turbines. The fuel will be burned with oxygen that is at least $95 \%$ pure, with argon composing the remaining 5\%. Combustion will generate gases that are predominantly steam and $\mathrm{CO}_{2}$.

A 10-MW gas generator is to be demonstrated by CES in FY01. The ZEST Research Facility will utilize the next-generation CES gas generator by building on the results of the first unit. LLNL staff expertise in thermal barrier coatings will be important for development of new internal coatings for extended-use gasgenerator surfaces. Rocket engines are typically run for short periods of time, but a gas generator used for continuous power generation must have surfaces able to withstand elevated temperatures for years of continuous operation. Successful thermal barrier coatings in the gas generator could reduce its overall cost by allowing the use of lower-cost structural materials.

The adiabatic flame temperature of the combustion products is approximately $5,600^{\circ} \mathrm{F}\left(3,100^{\circ} \mathrm{C}\right)$. Injection of demineralized water, preheated by circulation through the combustor's walls, will result in a $\mathrm{CO}_{2}$ /steam working fluid with a temperature of no more than $3,200^{\circ} \mathrm{F}\left(1,800^{\circ} \mathrm{C}\right)$ and a pressure not higher than 3,200 psi (22 MPa). Temperature will be controlled through adjustments in cooling-water flow rate. Because no fuel-rich regions exist in the gas generator, no particulate emissions or smoke will result from combustion.

Additional water will be injected into the exhaust gases from the gas generator combustion chamber because no available turbine can handle $3,200^{\circ} \mathrm{F}$ steam. The water will be added in six 
Figure 9. Working fluid turbine inlet temperature vs. water $/ \mathrm{CO}_{2}$ ratio. More advanced turbines that will be installed in the future will employ working fluids with higher temperatures and less water.

Figure 10. ZEST's gas generator can burn a variety of fuels to generate a working fluid devoid of oxides of nitrogen. cool-down modules that have been carefully designed, taking flow rates and residence times into account to permit time for the kinetically-controlled reassociation of carbon monoxide into $\mathrm{CO}_{2}$. The working-fluid temperature will be gradually lowered in the series of cool-down modules. Temperature and pressure of the working fluid will be adjusted so that it leaves the gas generator meeting the specifications of the high-pressure turbine. In the Phase I ZEST plant, the working fluid will exit the gas generator at $1,050^{\circ} \mathrm{F}$ and $1,200 \mathrm{psi}$, while in later phases that use more advanced turbines, temperature will be increased for higher efficiency. As it exits the gas generator, the working fluid will consist of roughly $90 \%$ by volume of steam and $10 \%$ by volume of $\mathrm{CO}_{2}$. As depicted in Figure 9, the exact $\mathrm{H}_{2} \mathrm{O} / \mathrm{CO}_{2}$ ratio will depend on the required turbine inlet temperature. Lower temperatures will require fractionally more water added. Because of the range of possible water $/ \mathrm{CO}_{2}$ temperatures, some fundamental research and optimization needs to be performed early in the project. The data from this effort will influence not only working fluid temperatures but also final turbine nozzle and blade designs.

The components of ZEST's gas generator are depicted in Figure10. The injector body consists of an Inconel-625 forging that premixes the fuel and oxygen reactants prior to injection into the combustion chamber. Impinging reactant jets create a mixing
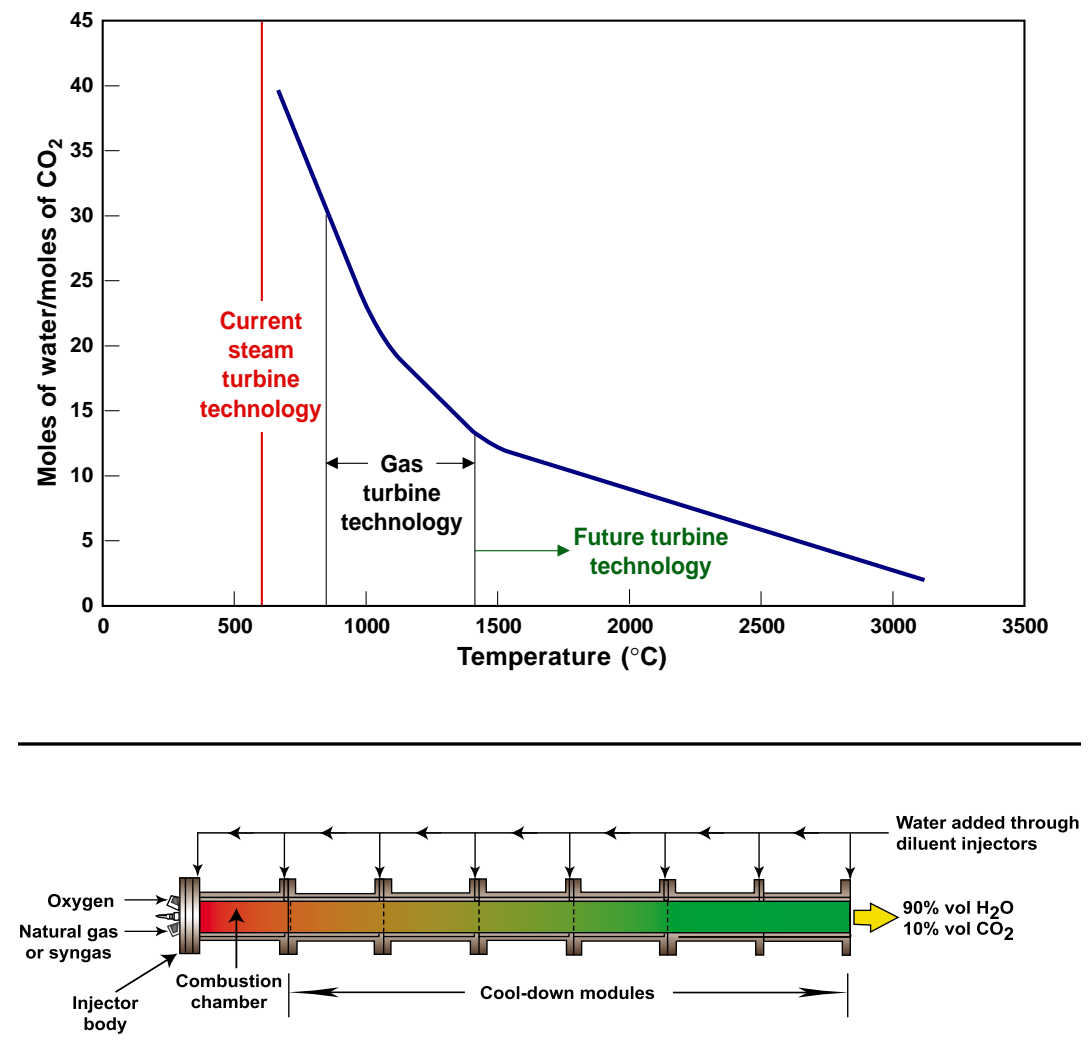
environment within the injector body, while check valves prevent accidental fuel and oxygen backflows. Injector elements within the injector body receive the precisely mixed fuel. These injector elements consist of a stack of diffusion-bonded Inconel-600 platelets with chemically-etched passageways. (Figure11 contains an enlarged drawing of a platelet section for a 10-MW combustor.) Note that cooling water is also introduced into the platelet passageways to control temperatures. The igniter, mounted inside the injector body, contains a spark ignition system to initiate combustion.

The gas generator's combustion chamber, constructed of a Monel K-400 water-cooled liner and a high-strength steel structural housing, is relatively small for a 10-MW generator-only 12 inches in length, with a 4-inch inner diameter. Coolant water enters the chamber liner at the output end of the chamber and exits at the fuel/oxygen injection end into the injector body.

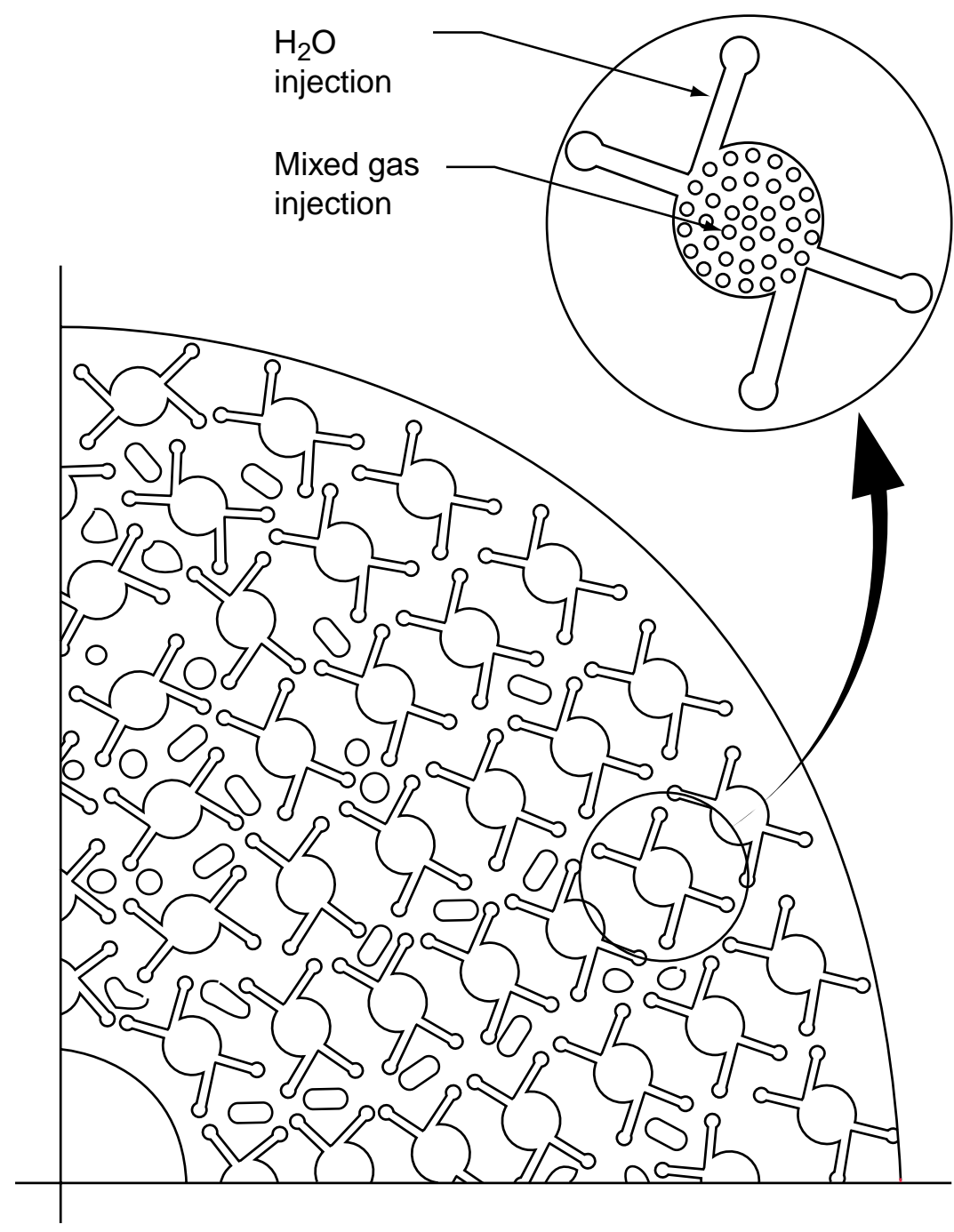

Figure 11. Quarter section of an injector element. 
Six cool-down modules follow the combustion chamber, each of which is nearly identical to the chamber, to minimize manufacturing costs. The combustion chamber and cool-down module liners consist of slotted walls containing 100 coolant slots. Diluent injectors located at the upstream end of each cool-down module add controlled amounts of highly atomized water, in order to optimize working fluid parameters. The coolant flows "upstream" through the chamber liners-i.e., counter-current to the flow direction of exhaust gases, so that the coolant flows into successively higher-temperature modules. Coolant flow rate, pressure, and temperature are all adjusted to keep the coolant in liquid phase for maximum cooling efficiency and to precisely maintain gas/side wall temperatures at levels that will achieve long gas-generator and turbine operating lives, while maintaining high plant efficiency.

The ZEST gas generator is considered to be the highest risk item in the power train. Before construction of the ZEST facility begins, an important activity will be to reduce the technical risk of gasgenerator failure. Using characterization-science techniques developed for LLNL's Yucca Mountain and Stockpile Stewardship programs, methods will be devised for employing short period ( 0.5 hour to 10 hour) gas generator testing to detect submicronlevel erosion, corrosion, dimensional changes, and thermally induced stresses that promote cyclic fatigue. These data will be extrapolated to longer use times to estimate lifetimes of the gas generator components. Methods will also be developed for preventing particulate plugging of the small platelet holes, which can affect complete mixing of fuel and oxygen inputs and lead to temperature gradients and hot spots in the combustion chamber. In addition, the testing capabilities of the High Temperature Materials Laboratory at Oak Ridge National Laboratory will be employed to analyze the gas generator's thermal barrier coating corrosion rates at elevated temperatures.

\subsection{Turbines}

Three turbine stages (high, intermediate, and low pressure) will be employed, with commercially available turbine technology installed in the Phase I system. For maximum research flexibility, individual turbines will be removable and replaceable with upgraded designs, as they become available. To facilitate future turbine replacement, each of the three turbines will drive a separate generator (see Figure12). Thermal power input to the turbines will be approximately $25 \mathrm{MW}$ with an initial overall plant 


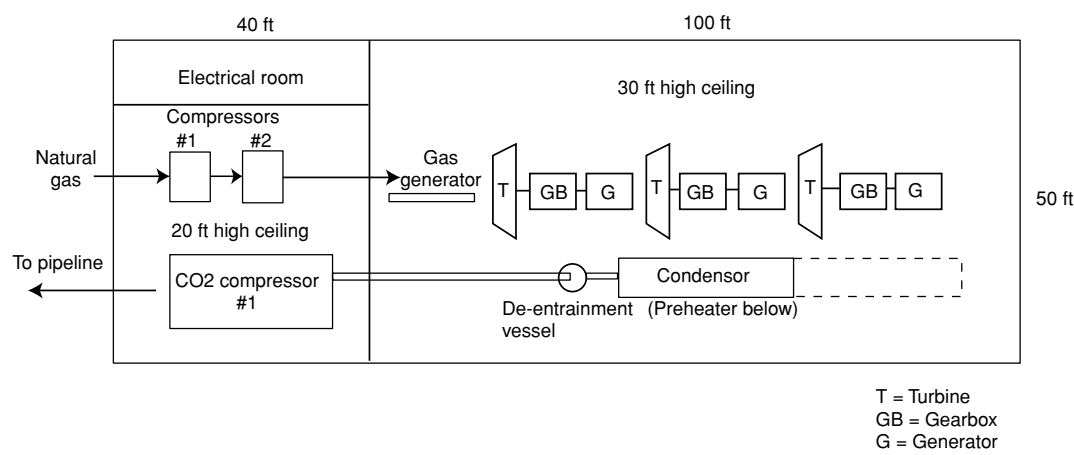

efficiency estimated at $35 \% .{ }^{10}$ This assumes the use of a derated Solar gas turbine as an intermediate turbine stage. Using LLNL's multipole Halbach array generators, which were developed for advanced flywheel applications, it may be possible to eliminate the gearboxes between turbines and generators. This has the potential for raising plant efficiency by $2 \%$.

As illustrated in Figure13, a reheater following the high-pressure turbine will raise the working fluid temperature to $2,200^{\circ} \mathrm{F}$. Heat exchangers following the intermediate- and low-pressure turbines will preheat gas generator feedwater to approximately $600^{\circ} \mathrm{F}$.

Near-term improvements in turbine technology are expected to raise inlet temperatures of the high-pressure turbine from $1,050^{\circ} \mathrm{F}$ to over $1,500^{\circ} \mathrm{F}$ using Rocketdyne adaptations of space shuttle turbines and to boost plant efficiency as high as 50\%. Longerterm turbine improvements from the Next Generation Turbine Program may be able to attain $2,500^{\circ} \mathrm{F}$ inlet temperatures and $60 \%$ efficiencies.

Initial operating conditions envisioned for turbine stages in the Phase I plant are:

\section{-High-pressure turbine}

Inlet pressure $1,200 \mathrm{psi}(8.3 \mathrm{MPa})$

Inlet temperature $1,050^{\circ} \mathrm{F}\left(57^{\circ} \mathrm{C}\right)$

\section{-Intermediate-pressure turbine}

Inlet pressure $140 \mathrm{psi}(0.97 \mathrm{MPa})$

Inlet temperature $2,200^{\circ} \mathrm{F}\left(1,200^{\circ} \mathrm{C}\right)$

\section{- Low-pressure turbine}

Inlet pressure $14.7 \mathrm{psi}(0.10 \mathrm{MPa})$ Inlet temperature $1,200^{\circ} \mathrm{F}\left(650^{\circ} \mathrm{C}\right)$

${ }^{10}$ This efficiency estimate includes the power expenditure necessary for $\mathrm{CO}_{2}$ sequestration. Without sequestration, the estimated efficiency is $38 \%$.
Figure 12. ZEST turbines (T), generators (G), and condenser. 


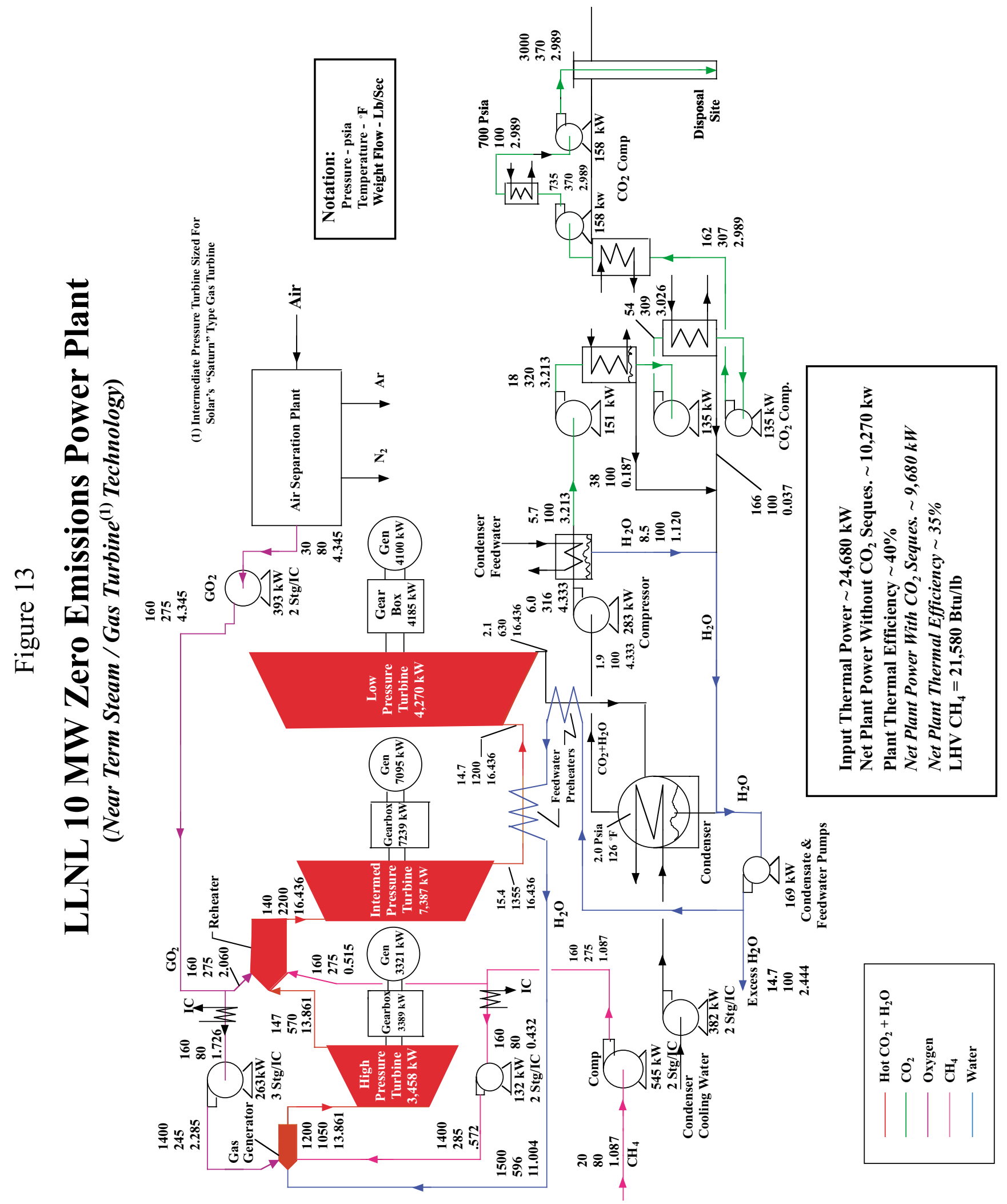


Exhaust from the turbines will consist mainly of steam (approximately $90 \%$ by volume) and $\mathrm{CO}_{2}$ (10\% by volume). Trace amounts of nitrogen and argon will also be present in quantities, depending on the purity of the input gases.

\subsection{Condenser}

Because of the presence of a high percentage of $\mathrm{CO}_{2}$ in the exhaust, the condenser needs to be designed differently than for a conventional steam power plant. A larger heat transfer surface area will be required. The condenser will operate at a pressure of $2.0 \mathrm{psi}$ and a temperature of $126^{\circ} \mathrm{F}$. The small amount of dissolved $\mathrm{CO}_{2}$ and $\mathrm{SO}_{2}$ (generated from natural gas odorants) in the condensate will render it mildly acidic. Condenser materials, as well as all downstream materials used for condensate service, must be resistant to the expected acidity. This part of the power plant will thus need to be constructed of materials that are more corrosion-resistant than for conventional steam power plants. Suitable materials include aluminum alloys, titanium, many stainless steels, and other corrosion-resistant alloys such as Chloromet 2 and 3, Durco, Durichlor, Durcomet 100, Durimet 20, Duriron, Hastelloy, and Stellite. Besides being more resistant to the acidic concentrate, such materials will also limit the quantity of corrosion products entering the condensate.

\subsection{Water Treatment}

Potable industrial service-water will be used for startup, after purification through a 10-micron filter, an anion resin bed, a cation/anion mixed bed, and a 5-micron filter to assure a resistivity of one megohm or better. (Alternatively, the ZEST facility could utilize LLNL's sitewide low-conductivity water system to reduce capital cost.)

Because combustion of natural gas and oxygen generates water as one of the reaction products, the power plant will be a producer of water. A bleed stream will continuously remove excess water from the process and by so doing will provide a control on impurities buildup. This excess water will be used to reduce the amount of cooling water needed by the cooling tower.

Water impurities are expected to include approximately $400 \mathrm{ppm}$ $\mathrm{CO}_{2}, 27 \mathrm{ppm} \mathrm{SO} \mathrm{S}_{2}$, less than $1 \mathrm{ppm}$ of other dissolved combustion products, and an unknown amount of dissolved corrosion products such as iron, nickel, and copper. While the bleed stream may be sufficient to maintain a level of water quality that still has to be determined, it may instead be necessary to treat the recycled 
water stream. Excess water leaving the plant may also have to treated. Its acidity could be neutralized, if needed, through various standard methods. One approach that might be particularly suited to the power plant would be to strip the dissolved $\mathrm{CO}_{2}$ and $\mathrm{SO}_{2}$ out of solution by sparging the bleed stream with nitrogen gas exiting the oxygen plant, or by passing the stream countercurrent to the nitrogen in a packed column. The stream could then be used as makeup water for the plant's cooling tower. 


\section{Carbon Dioxide Sequestration}

Carbon dioxide from the ZEST facility will be transported by pipeline approximately one-half mile northeast of the plant, then injected — at the rate of 15,000 tons per year ${ }^{11}$ - into two distinct geologic units. The first of these will be oil-bearing, either the Greenville sand (Cierbo for-

Figure 14. Project location map. mation) or a deeper marine facies (Tesla formation), which represent the primary and secondary pay zones of the Livermore Oil Field. The second unit will be an oil-barren saline aquifier that underlies the oil field (see Figures 14 and 15). Although the injection site lies east of LLNL, the Cierbo/Tesla formations and the underlying saline aquifier extend beneath the laboratory; monitoring wells can therefore be located either

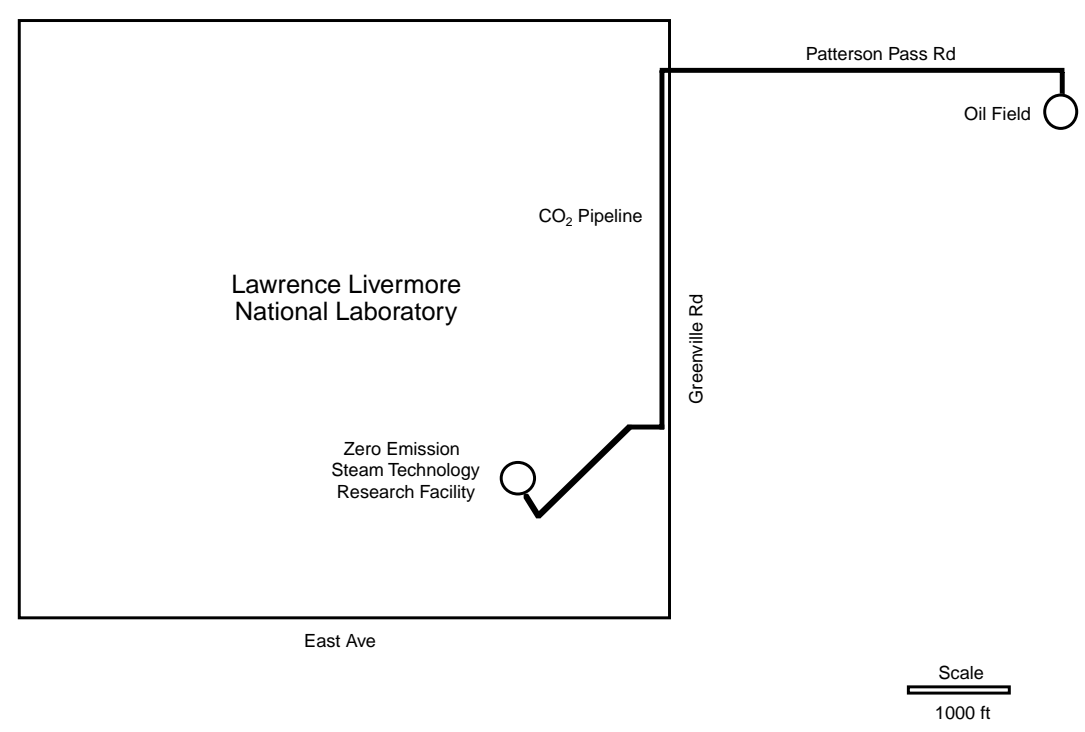

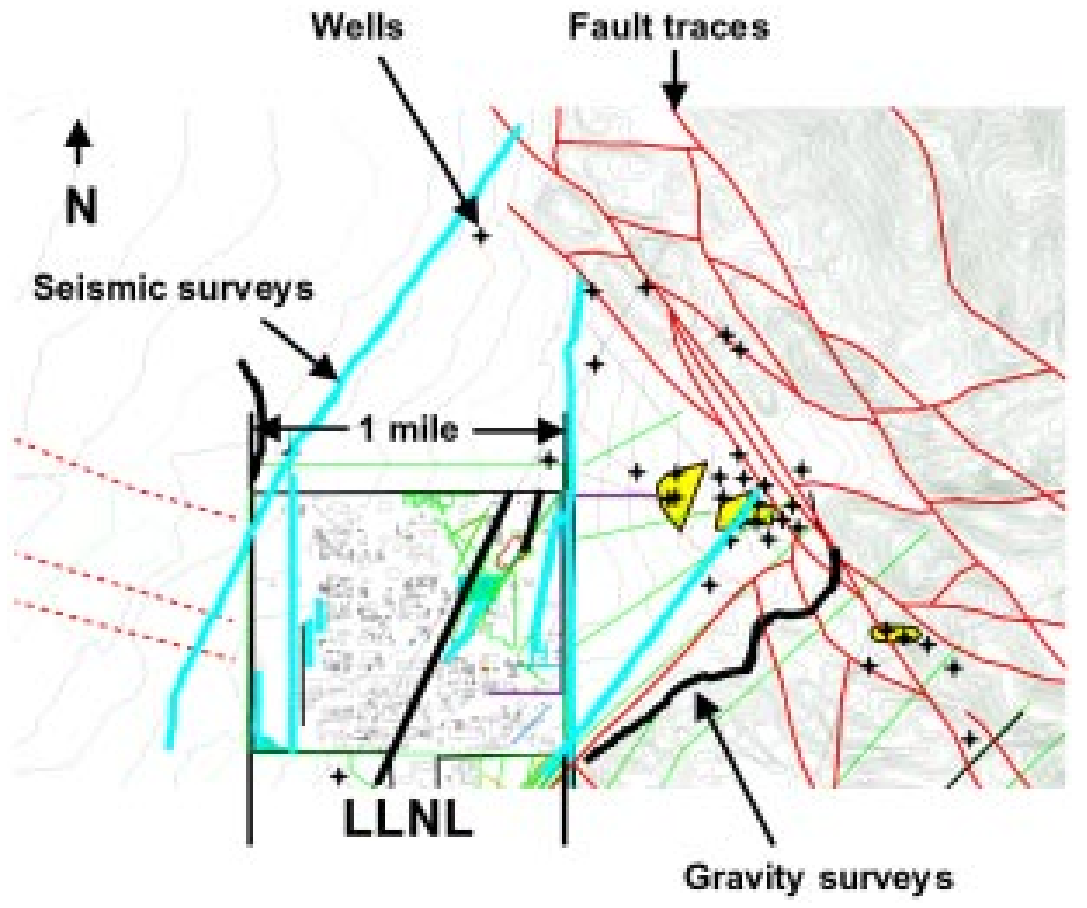

${ }^{11}$ Based on a plant size of $10 \mathrm{MW}$ and a duty cycle of $50 \%$.
Figure 15. Field geophysical surveys provide extensive data on possible sequestration zones around LLNL. Wells that have been drilled are denoted by +'s. Oil-bearing zones are marked in yellow. Red lines indicate surface traces of faults. Blue and black lines denote locations of seismic and gravity surveys, respectively. Magnetic and resistivity studies have also been conducted in the area. 
within or beyond LLNL boundaries. The precise locations and sampling capabilities of such wells will be optimized for obtaining key geochemical and geophysical data.

Injection into the Livermore Oil Field exemplifies an often-used technique for enhanced oil recovery, where partial sequestration of $\mathrm{CO}_{2}$ within the target formation represents an environmental benefit ancillary to economic gain. Injection into the deeper saline aquifer implements an often-proposed technique for isolating $\mathrm{CO}_{2}$ waste streams from the atmosphere, where the direct benefit is environmental. This unique dual-injection approach permits simultaneous field assessment of $\mathrm{CO}_{2}$ sequestration in both hydrocarbon reservoirs and oil-barren saline aquifers-the two primary formation types currently proposed for geologic sequestration.

\subsection{Injection for Enhanced Oil Recovery}

$\mathrm{CO}_{2}$ floods for EOR are termed either "miscible" or "immiscible," depending on hydrocarbon density and pressure-temperature conditions within the target reservoir. Most common are miscible floods, which refer to implementations of the technique within reservoirs that contain light crude oil (API gravity of 28-45) at sufficient depth to define supercritical conditions for $\mathrm{CO}_{2}$ (typically, greater than $2500 \mathrm{ft}$.). In these settings, the oil and $\mathrm{CO}_{2}$ are highly miscible, which decreases viscosity (flow resistance) and increases specific volume (pressure) of the oil, thereby permitting additional production from otherwise inaccessible reserves. Immiscible floods refer to implementation of the technique within reservoirs that either contain heavy-crude oils (API gravity <20) or occur at insufficient depths to obtain supercritical conditions for $\mathrm{CO}_{2}$ (typically, less than $2500 \mathrm{ft}$.). In such cases, extreme density contrast between the oil and $\mathrm{CO}_{2}$ precludes significant miscibility of the two phases, which reduces effectiveness of the technique. However, improved production is still achieved, primarily by repressurizing the reservoir but also by limited viscosity reduction and swelling of the oil.

Of the $64 \mathrm{CO}_{2}$-flood projects ongoing in the United States as of March 2000, 63 are miscible floods, and 45 of these are in the Permian Basin of west Texas, owing to their relative proximity to large-scale natural $\mathrm{CO}_{2}$ reserves in Colorado (McElmo Dome) and New Mexico (Bravo Dome). ${ }^{12}$ The true cost of $\mathrm{CO}_{2}$ extracted

\footnotetext{
12"'2000 Worldwide EOR Survey." Oil \& Gas Journal, March 20, 2000, p.45.
} 
from such reserves is difficult to assess, although estimates of $\$ 20 /$ ton are common, with $\$ 10 /$ ton desirable. CES projections of the cost to sequester $\mathrm{CO}_{2}$ generated by the ZEST facility, using commercially available steam-turbine technology in Phase I, is about \$17/ton of carbon (Figure 5). Assuming successful development of high-temperature turbine systems, this cost should drop to DOE's goal of \$10/ton.

Although EOR-related $\mathrm{CO}_{2}$ injection has been used successfully by the petroleum industry since the 1970 s, the net $\mathrm{CO}_{2}$ sequestration obtained as a byproduct of this technique - that fraction of the injected fluid that remains in the target formation-has not been quantified precisely. DOE must evaluate this net sequestration to assess the potential role of EOR techniques in future U.S. carbon management. A fundamental goal of the integrated modeling work and field measurements associated with LLNL's proposed $\mathrm{CO}_{2}$ flooding of the Livermore Oil Field is accurate characterization of the net sequestration achieved and the ultimate fate of this sequestered $\mathrm{CO}_{2}$.

The Livermore Oil Field is located a half-mile east of LLNL within a seismically active, structurally complex region that marks the intersection of the Greenville and Las Positas fault zones. This small 50-acre field consists primarily of several distinct, structurally- and fault-trapped hydrocarbon accumulations at depths of 900-2000 feet within the 40-250-foot-thick Greenville sand of the Cierbo Formation. A minor secondary pay zone occurs at a depth of 5300 feet in the 35-foot-thick marine facies of the Tesla formation. The field was discovered and brought into production in 1967 and produced 1.42 million bbl of low-sulfur, 21-29 API gravity (light to intermediate crude) oil from 1967 to 1982; total expected production is 1.75-2.00 million bbl. Tertiary recovery via water flooding has now been carried out for some time. Current production, which is exclusively from the Greenville sand, is approximately $1000 \mathrm{bbl} /$ month and has remained fairly constant since $1995 .{ }^{13}$ Hence, this is a classic mature "stripper" field.

$\mathrm{CO}_{2}$-flooding EOR in the Livermore Oil Field holds the potential to increase significantly this current stripper production rate. In addition, $\mathrm{CO}_{2}$ flooding of oil accumulations in the Greenville sand offers an opportunity to investigate both the recovery effectiveness and the sequestration performance of an immiscible

\footnotetext{
${ }^{13}$ Personal communication with Rick Jeeter, owner of oil leases for the Livermore Oil Field, 1 June 2001.
} 
flood, while potential $\mathrm{CO}_{2}$ injection into the deeper Tesla accumulation would permit such investigations of the more common miscible implementation. Although both possibilities will be pursued, the immiscible-flood scenario is especially intriguing because so little is known about this currently uncommon method. It is also particularly relevant to California, whose preponderance of shallow oil reserves - all of which represent potential immiscible- $\mathrm{CO}_{2}$-flood targets-is well documented. ${ }^{14}$ In this regard, it is worth noting that although uncommon and less efficient than their miscible counterparts, all seven of the ongoing immiscible floods worldwide have been rated "successful" or "promising." 15

For either immiscible- or miscible-flood EOR, the $\mathrm{CO}_{2}$ injection well will be equipped to facilitate tight control of well-head pressure, temperature, and injection rate. A strategically located series of monitoring wells will permit sampling of formation mineralogy and fluids; these wells will also be equipped with sensors to facilitate geophysical imaging of the $\mathrm{CO}_{2}$ front as it migrates through the formation. These geochemical and geophysical data represent an invaluable means of benchmarking and improving computational modeling capabilities.

\subsection{Injection for Environmental Isolation}

Carbon dioxide injection into deep saline aquifers for the sole purpose of environmental isolation represents arguably the most attractive geologic alternative for large-scale sequestration. Statoil (Norway's state oil company) estimates that storage capacity within European saline aquifiers, primarily those beneath the North Sea, exceeds 800 billion metric tons-a quantity greater than the total amount of $\mathrm{CO}_{2}$ emitted to the atmosphere since preindustrial times. At the present rate of $\mathrm{CO}_{2}$ generation by all the power stations in Europe, approximately one billion metric tons per year, the continent's saline-aquifier storage capacity would be sufficient to sequester all $\mathrm{CO}_{2}$ generated for the next 800 years. $^{16}$

\footnotetext{
${ }^{14}$ Sally M. Benson, "Comparison of Three Options for Geologic Sequestration of $\mathrm{CO}_{2}$ : A Case Study for California," Proceedings of $5^{\text {th }}$ International Energy Agency's International Conference on Greenhouse Gas Control Technologies, Cairns, Austrailia, August 2000. 15“2000 Worldwide EOR Survey." Oil \& Gas Journal, March 20, 2000, p.45.

${ }^{16}$ Tore A. Torp, "Capture and Reinjection of $\mathrm{CO}_{2}$ in a Saline Aquifer at Sleipner Field and the Future Potential of this Technology," Dinner-debate with the fondation Europeenne de l'Energie in Brussels, Statoil Research Centre, Trondheim, Norway, 2 June 1998.
} 
U.S. sequestration options in terms of saline aquifiers are currently being quantified. The thick sedimentary basins of California's Central and Imperial Valleys, which range up to 8000 meters in depth, offer extensive storage possibilities. Estimated $\mathrm{CO}_{2}$ sequestration capacity of Central Valley sediments alone exceeds 300 years of current California annual $\mathrm{CO}_{2}$ emissions. Imperial Valley sediments add another 60 years of $\mathrm{CO}_{2}$ emissions to this storage capacity. ${ }^{17}$

The key attributes of saline aquifers include their broad geographic distribution, their immense sequestration potential, and the demonstrated integrity of their confining cap-rock formations. However, because this pure-isolation approach yields - at presentno direct economic benefits to industrial concerns in most countries, there is only one field project in the world that has implemented the concept. This is the unique North-Sea Sleipner facility, owned and operated by Statoil, in which one million metric tons of $\mathrm{CO}_{2}$ have been injected annually into a confined sandstone aquifer since 1996. Although certain Sleipner field data are obtainable from Statoil and their collaborators, the most critical samples and measurements either have not been taken or are-at present- proprietary and therefore unavailable. Hence, U.S. scientists currently lack access to the most important field data associated with $\mathrm{CO}_{2}$ injection into saline aquifers, even though $\mathrm{DOE}$ recognizes this as one of its most promising long-term sequestration options.

In contrast to the situation for $\mathrm{EOR}, \mathrm{CO}_{2}$ is largely immiscible with the saline formation waters it typically encounters within deep confined aquifers. Because it is also considerably less dense than these ambient saline fluids, most of the injected $\mathrm{CO}_{2}$ will rise toward the aquifer cap rock as an immiscible plume, which then migrates laterally beneath this permeability barrier. The plume/formation-water interface is typically irregular, owing to the lower viscosity of $\mathrm{CO}_{2}$, which leads to "viscous fingering" of the plume within regions of heterogeneous permeability.

As the injected $\mathrm{CO}_{2}$ migrates via these processes of immiscible displacement, gravity segregation, and viscous fingering, fractions of it will be "trapped" by each of three fundamental sequestration processes:

\footnotetext{
${ }^{17}$ Sally M. Benson, "Comparison of Three Options for Geologic Sequestration of $\mathrm{CO}_{2}$ : A Case Study for California," Proceedings of $5^{\text {th }}$ International Energy Agency's International Conference on Greenhouse Gas Control Technologies, Cairns, Austrailia, August 2000.
} 
- Mineral trapping, or reaction with formation minerals to precipitate carbonates.

- Solubility trapping, or dissolution into formation waters.

- Hydrodynamic trapping, or isolation beneath the cap rock within localized structural highs of the aquifer.

Scientific viability of geologic sequestration within saline aquifers hinges on the relative effectiveness of these migration and sequestration processes, while its successful implementation relies on our ability to predict sensitivity of this migration/sequestration balance to key physical and chemical characteristics of potential target reservoirs. Quantification of this sensitivity reveals geochemical, hydrologic, and structural constraints on maximizing sequestration performance that can be used to identify those formations most likely to provide optimal storage capacity and isolation security. At LLNL, we have integrated a state-ofthe-art reactive-transport simulator (NUFT), comprehensive supporting geochemical software and thermodynamic/kinetic databases (SUPCRT92, GEMBOCHS), and recent equation-of-state and viscosity formulations for $\mathrm{CO}_{2}$ to develop a unique modeling capability for identifying optimal target formations for $\mathrm{CO}_{2}$ sequestration.

Confidence in this modeling approach necessarily follows from success in simulating the observed behavior of field systems. Hence, our initial studies have focused on simulating $\mathrm{CO}_{2}$ injection at Sleipner and quantifying the relative effectiveness of structural, solubility, and mineral trapping in Sleipner-like settings. ${ }^{18}$ Although this work provides first-of-its-kind quantitative insight into these interrelated sequestration processes, the skeletal nature of Sleipner field observations-which are needed to evaluate and constrain model predictions - spotlights the importance of obtaining a complete set of such observations from a wellcharacterized field project in the United States. Hence, the saline-aquifer disposal component of ZEST will fill a critically important need.

\footnotetext{
${ }^{18}$ Johnson, J.W.; Nitao, J.J.; Steefel, C.I.; and Knauss, K.G., 2001, "Reactive transport modeling of geologic $\mathrm{CO}_{2}$ sequestration in saline aquifers: the influence of intra-aquifer shales and the relative effectiveness of structural, solubility, and mineral trapping during prograde and retrograde sequestration." Proceedings of the First National Conference on Carbon Sequestration, May 14-17, 2001. <http://www.netl.doe.gov/ publications/proceedings/01/carbon seq/P28.pdf>
} 
The same injection and monitoring wells described above for the EOR project will be employed in this deeper saline-aquifier project, although wellhead pressure at the injection well will be increased appropriately. This cost-saving dual usage is made possible by outfitting each of the wells with a down-hole string of packing devices that permit collection of geochemical and geophysical data from isolated vertical sections. These data will be used to quantify the relative contributions of mineral and solubility trapping and to delineate the magnitude, migration path, and time-dependent location of the immiscible $\mathrm{CO}_{2}$ plume. Each of these parameters represents a critical constraint on our computational simulation capabilities.

Figure16 depicts a dual-injection approach to $\mathrm{CO}_{2}$ storage in the formations adjacent to LLNL.

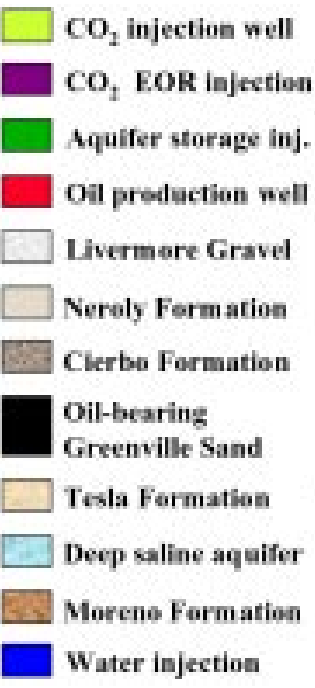

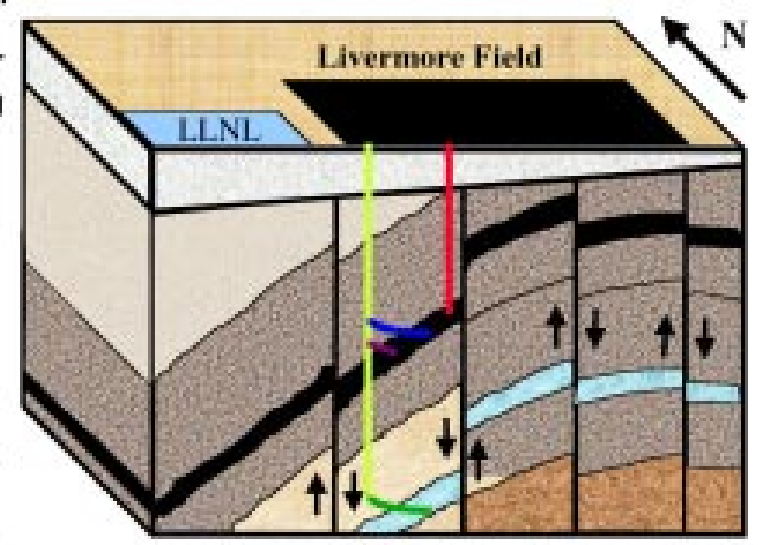

tetal depth; appros. $5000 \mathrm{ft}$.
At present, regulations covering $\mathrm{CO}_{2}$ sequestration in saline aquifiers do not exist. Injecting $\mathrm{CO}_{2}$ into an oil-barren underground formation is a new concept, and the regulatory process has not yet addressed this issue. Although pure $\mathrm{CO}_{2}$ is not a hazardous substance, impurities within a $\mathrm{CO}_{2}$ waste stream may be hazardous. The large quantities of high-pressure $\mathrm{CO}_{2}$ being injected into saline aquifers may also have unforeseen consequences that create the need for regulation. During the ZEST project, LLNL will seek to generate critical data that regulators can use to formulate appropriate sequestration regulations. In particular, ZEST sequestration studies will attempt to identify the environmental
Figure 16. Dual-injection approach to $\mathrm{CO}_{2}$ sequestration: Enhanced oil recovery and saline aquifer storage. 
and human health risks associated with $\mathrm{CO}_{2}$ injection into saline aquifers and to determine threshold impurity concentrations in the stream that can lead to harmful impacts. 


\section{Why LLNL Is the Best Site for This Project}

A combination of factors points to LLNL as the logical host for ZEST. LLNL has unique site attributes that include proximity to petroleum and groundwater basins of the right depth, size, and maturity to serve as ideal field laboratories for geologic sequestration. In addition, LLNL staff have expertise in several areas that are key for successful development of ZEST, including:

- Ceramic membrane oxygen separation.

- Thermal barrier coating technology for high-temperature turbines and gas generator.

- Computational capabilities: turbulent combustion simulation.

- Computational modeling capabilities: Geologic $\mathrm{CO}_{2}$ sequestration.

- Geophysical imaging and geochemical sampling and analytic capabilities.

- Carbon dioxide injection and enhanced oil recovery in seismically active oil basins.

It is well known that local opposition to power-plant sitings on the basis of perceived health and quality-of-life issues can be very difficult to overcome, especially in California. This holds true even for small facilities such as ZEST. Stakeholder opposition to new plants, however, generally focuses on the risks from toxic air emissions, and the zero-emissions aspect of this proposed plant is expected to help greatly in winning local support. ZEST will be presented to the local community as an environmentally friendly alternative to traditional electric power plant technologies, which present severe air quality and global warming issues.

\subsection{Ceramic Membrane Oxygen Separation}

LLNL has successfully fabricated high-performance oxygen gas separation membranes. Our supported thin-film membranes are processed using a proprietary low-cost manufacturing technique that employs only inexpensive materials and no precious metals. We have measured oxygen fluxes through our membranes of up to $15 \mathrm{sccm}$ (standard cubic centimeters per minute) at $1650^{\circ} \mathrm{F}$ $\left(900^{\circ} \mathrm{C}\right)$ in air/methane gas mixtures, an improvement of $30 \%$ over state-of-the-art competitive technologies under the same conditions. In addition, we have developed a precisely controlled, low-cost colloidal spray technology for dense ceramic layer manu- 
facture for our solid oxide fuel cell program that is also suitable for oxygen separation membrane production (see Figures 17 and $18)$.

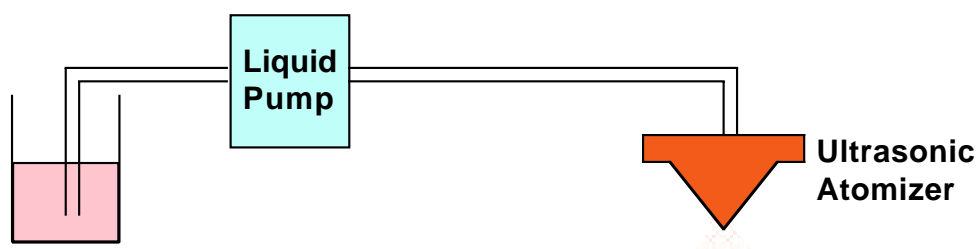

Colloidal

Solution

Figure 17. LLNL's colloidal spray deposition techniques can produce dense ceramic layers suitable for oxygen separation applications.

Figure 18. Scanning electron microscope image of a fully dense ceramic layer deposited on substrate using LLNL's colloidal spray deposition technology.

\section{Deposition characteristics:}

- colloidal suspension of sub-micron size powder in a solvent

- spraying of the solution using ultrasonic nozzle for fine dispersion

- sintering at high temperatures

\section{Heater}

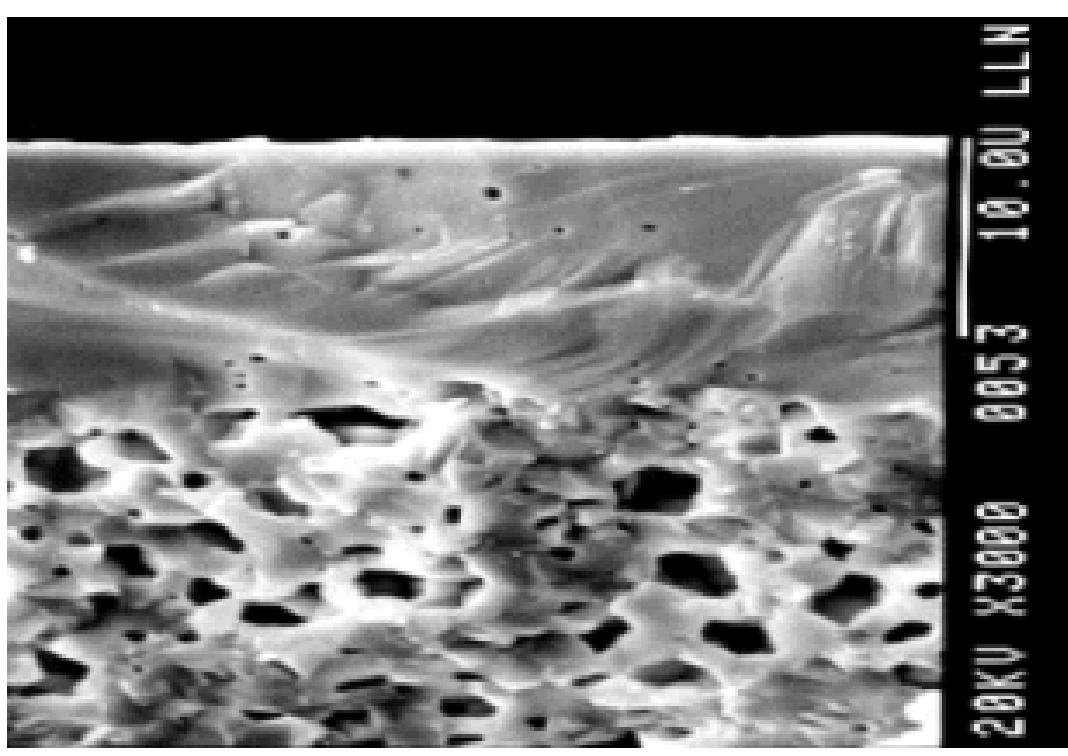

\subsection{Thermal Barrier Coating Technology for High- Temperature Turbines and Gas Generator}

LLNL has a history of developing proprietary thermal barrier coatings for industrial turbine companies, under CRADA agreements. We have successfully fabricated microstructure layers of yttrium/ zirconium alloys alternating with alumina for use as turbine airfoil thermal barrier coatings, with deposition control at near-atomic lev- 
els (Figure19). A scanning electron microscope image of a 50- $\mu \mathrm{m}$ thick yttria-stabilized zirconia electron-beam deposit applicable to turbine-blade coatings is depicted in Figure 20. Many of our deposition techniques were developed during our design and fabrication of $\mathrm{x}$-ray mirrors for defense-related lasers technology. Our specialty coatings have also been used in developing compatible materials for uranium separation processes and solid-oxide fuel cell manufacture. In addition, LLNL has a wider range of characterization tools for analyzing the coatings than can be found at most other research facilities.

\section{Turbine airfoil thermal barrier coatings}

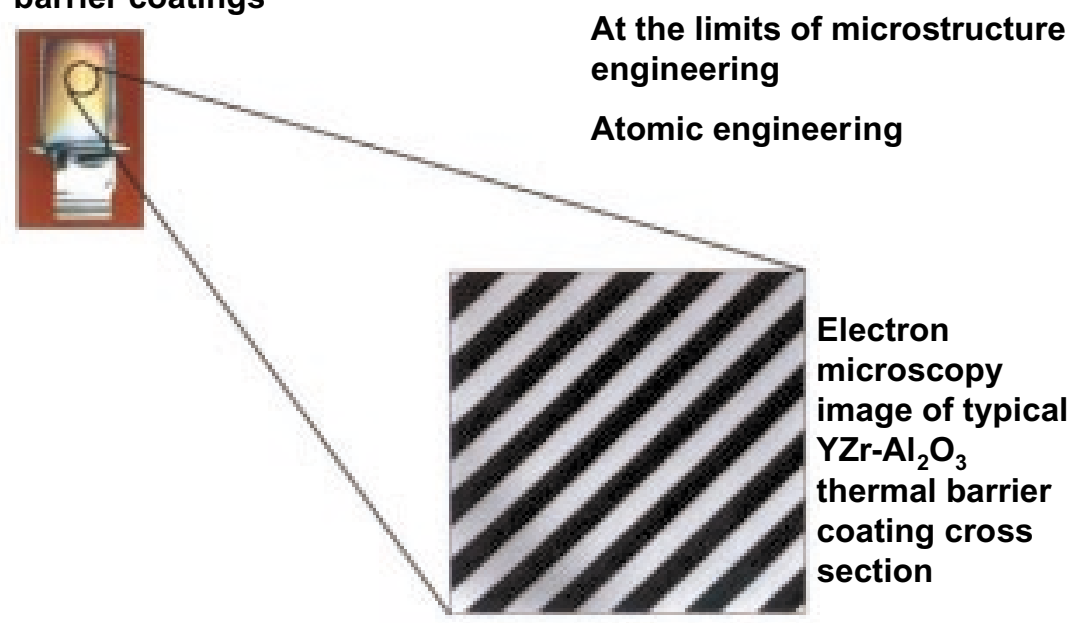

\subsection{Computational Capabilities: Gas Generator Combustion Region}

LLNL has developed a sophisticated multiphysics code entitled the Arbitrary Lagrangian and Eulerian Three Dimensional (ALE3D) code that combines computational fluid dynamics, structural mechanics, heat transfer, and reaction chemistry. It is capable of modeling both the reaction chemistry and the acoustic wave environment of the gas generator's combustion region, including shock wave formation and propagation. Understanding these parameters is critical for combustion stability analysis.

Detailed chemical kinetics simulation methods have also been developed at LLNL and are used by research teams around the world. These codes will be especially important in tracking minor species through ZEST's combustion process. An important area of research and development in the ZEST project is to combine LLNL's chemical kinetics simulation capabilities with its
Figure 19. Thermal barrier coatings are achievable with control at near-atomic levels.

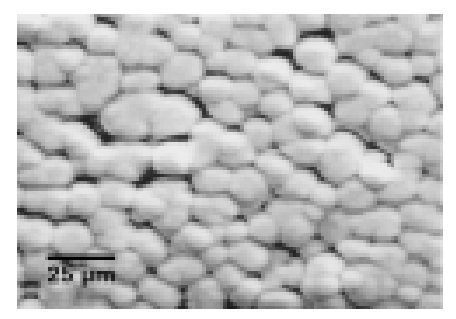

Figure 20. Electron microscopy image of electronbeam-deposited yttriastabilized zirconia suitable for turbine-blade coatings. 




Figure 21. Reactive transport modeling: an advanced simulation capability for geologic systems. Coupled processes can be represented that redistribute mass and energy within geologic systems to resolve disequilibrium temperature, pressure, and fluid-density gradients imposed by natural or engineered perturbations. (Modified from D. Norton, 1984, "Theory of Hydrothermal Systems," Annual Review of Earth and Planetary Sciences, v. 12, pp. 155-177.) for the combustor.
ALE3D fluid dynamics software, to develop an extremely powerful multiphysics code capable of modeling many different combustion environments. This combined code will be utilized by NETL with the Pittsburgh Computing Center's teraflop parallel-processor computer. Eventually this code is expected to become a tool used by the gas turbine industry.

An accurate simulation of the entire combustion and power generation process, and of the effect of feedback flows on combustion, is essential to optimize ZEST's performance and to understand how to build in a fail-safe control system that will allow reliable, safe operation of the system. The process simulations will be the basis for developing a control strategy for plant operations and, in particular, for designing high-speed controls

Another application for our simulation tools is to understand the load-following capabilities of ZEST. An area of research will be to maximize the turn-down ratio of the ZEST plant, with a goal of attaining a 2-to-1 difference between peak and minimum electrical output. Our computational capability will allow us to precisely model the system to maximize turn-down ratio, implementing the design into ZEST's actual combustion operations.

\subsection{Computational Modeling Capabilities: Geologic Carbon Dioxide Sequestration}

Carbon sequestration science represents an emerging core capability of LLNL's Energy and Environment Directorate, with more than $\$ 3 \mathrm{M}$ in FY01 internal and external support across nearly 20 projects. In particular, scientists in this directorate have developed an internationally recognized suite of kinetically-controlled reactive-transport and multiphase-flow simulators (GIMRT, 
NUFT), supporting geochemical software (SUPCRT92, JEWEL), and thermodynamic/kinetic databases (GEMBOCHS). This integrated computational toolbox provides a unique modeling capability for representing coupled thermal, hydrologic, geochemical, and mechanical processes in complex subsurface environments (see Figure 21).

An ongoing (FY00-FY01), internally funded project has focused on customization of this capability to identify and address key technical issues associated with geologic sequestration of $\mathrm{CO}_{2}$ waste streams. Beyond implementing the requisite model modifications and additions, the project team has established a collaboration with Statoil, which resulted in access to sufficient field data from their Sleipner project to permit reactive-transport simulations of this unique geologic sequestration site as an initial test case. ${ }^{19}$ In addition, LLNL scientists are presently carrying out modeling work in the DOE/NETL-sponsored geologic sequestration program, which aspires to "deliver the technology and information needed to enable application of safe and costeffective methods for geologic sequestration of carbon dioxide by the year 2015."

In view of our recent model advances, application experience, and international collaborations directly focused on geologic $\mathrm{CO}_{2}$ sequestration, LLNL is ideally poised-from a computational simulation perspective - to fully exploit the wealth of field data that will be collected at the ZEST field-sequestration facilities.

\subsection{Geophysical Imaging and Geochemical Sampling and Analytic Capabilities}

LLNL's leading-edge computational modeling tools for addressing geologic sequestration issues are complemented by a wide range of advanced geophysical imaging/interpretation and geochemical sampling/analytic capabilities. Geophysical capabilities include both seismic and electrical methods. Seismic reflection and transmission imaging (SRI and STI) techniques permit subsurface 3-D mapping of lithologic boundaries; electrical resistance tomography (ERT) imaging provides critical informa-

\footnotetext{
${ }^{19}$ Johnson, J.W.; Nitao, J.J.; Steefel, C.I.; and Knauss, K.G.; 2001.

"Reactive transport modeling of geologic $\mathrm{CO}_{2}$ sequestration in saline aquifers: the influence of intra-aquifer shales and the relative effectiveness of structural, solubility, and mineral trapping during prograde and retrograde sequestration." Proceedings of the First National Conference on Carbon Sequestration, May 14-17, 2001. <http://www.netl.doe.gov/ publications/proceedings/01/carbon seq/P28.pdf $>$
} 
tion regarding the properties of subsurface fluids. These imaging techniques, together with associated interpretive methodologies, will be used to define the precise geometry of target formations for both EOR and pure-isolation targets, as well as the migration paths of injected $\mathrm{CO}_{2}$.

Geochemical sampling and analytic techniques will be used to determine pre- and post-injection mineralogy, as well as aqueousfluid and hydrocarbon compositions. Cores and fluid samples from the monitoring wells (including post-injection side-wall cores) will be collected and analyzed using a variety of techniques. Detailed mineralogy will be determined using techniques that include:

- Standard petrographic analyses.

- Electron microprobe techniques.

- Scanning electron microscopy (SEM).

- Transition electron microscopy (TEM).

- X-ray diffraction (XRD).

Fluid inclusion analysis of secondary carbonates will be used to determine the precise composition and temperature of precipitating fluids. Several techniques will be employed to determine bulk composition of sampled formation waters:

- Light cation concentrations will be derived from inductivelycoupled plasma atomic emission spectroscopy (ICP-AES).

- Heavy cation concentrations will be obtained from inductively-coupled plasma mass spectroscopy (ICP-MS).

- Anion concentrations will be obtained from liquid chromatography (LC).

These determinations may be supplemented by in-situ fiber-optic analysis of data collected remotely from down-hole optrodes. Hydrocarbon compositions will be determined using gas chromatography (GC), mass spectroscopy (MS), and total carbon analysis.

\subsection{Carbon Dioxide Injection and Enhanced Oil Recovery in Seismically Active Oil Basins}

LLNL has a strong capability in the design of enhanced oil recovery systems, as well as in the modeling of seismic effects. We are currently imaging $\mathrm{CO}_{2}$ and water injection for the Chevron Lost Hills oil field in California's Central Valley, employing 2$\mathrm{kHz}$ electromagnetic transmission imaging as well as electrical 
resistivity imaging that is able to resolve geological features as small as 10 feet. These data are being collected down-hole, largely in the 1600-to-1700-footdepth region, approximately the same depth as the oil deposits in Livermore's Greenville formation, where the $\mathrm{CO}_{2}$ from ZEST will be sequestered (see Figures 22 and 23).

In our partnerships with the DeepLook Consortium and NETL, we have developed petroleum basin simulation codes with state-of-the-art transport and kinetics features. In projects with the Gas Research Institute

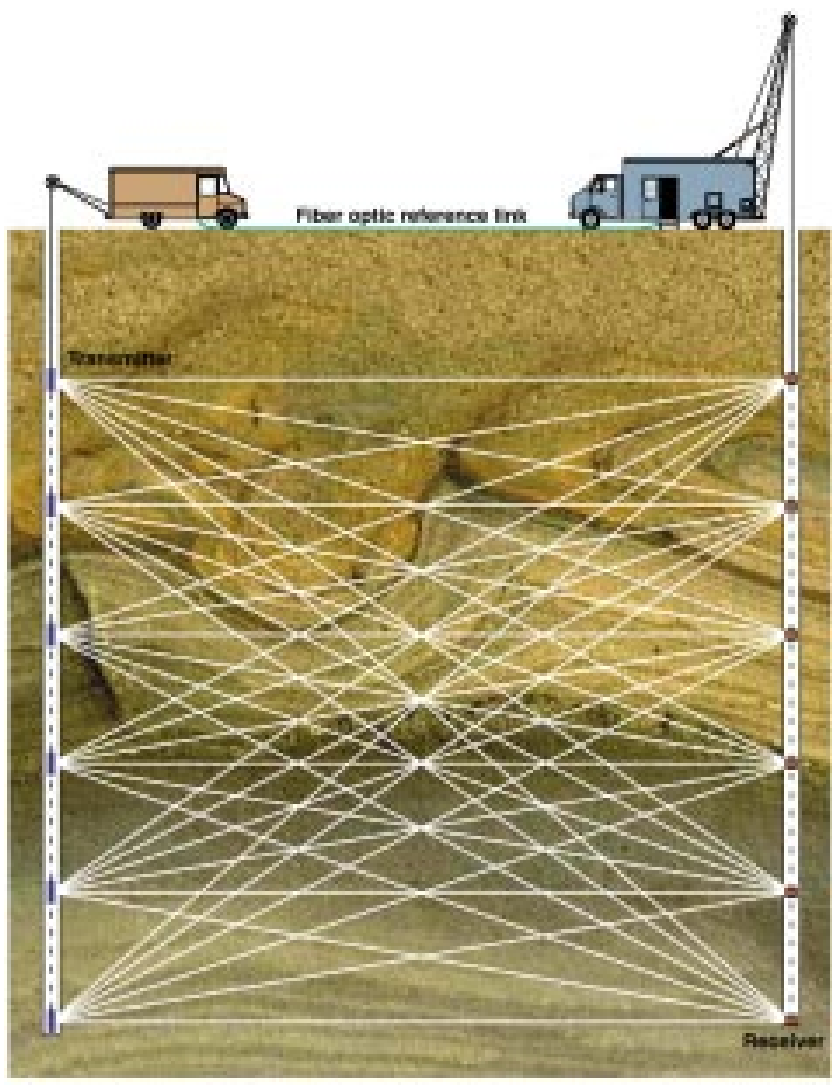
(GRI), NETL, and its National Petroleum Technology Office (NPTO), we have fabricated tiltmeter instrumentation with nanoradian sensitivity that can fit within a 2.5-inch-diameter well bore, in order to map reservoir

Figure 22. Cross-well electromagnetic imaging of $\mathrm{CO}_{2}$ and water injection.
OB-7

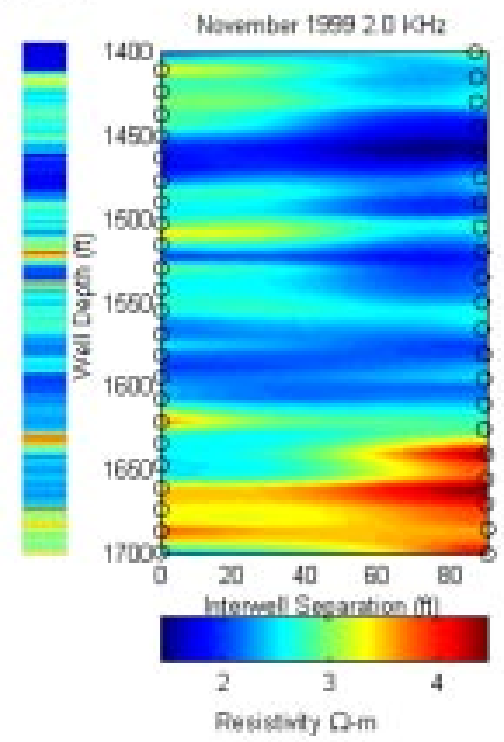

OB-8

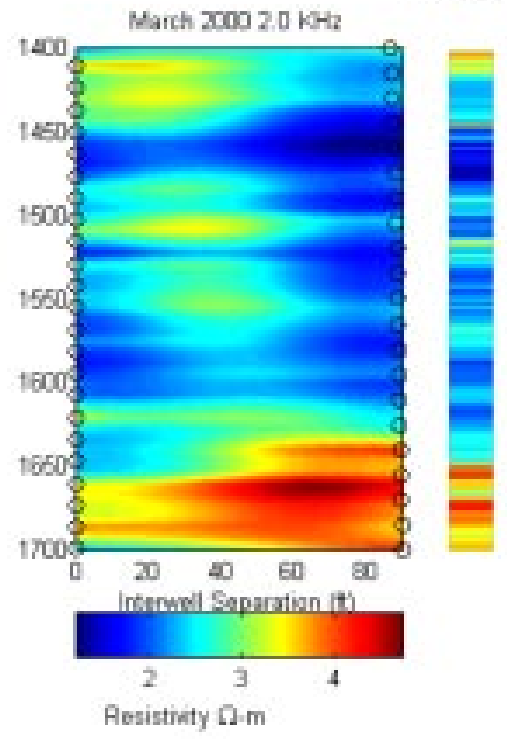

Figure 23. Two-kilohertz cross-well electromagnetic imaging for use in secondary enhanced oil recovery operations. 


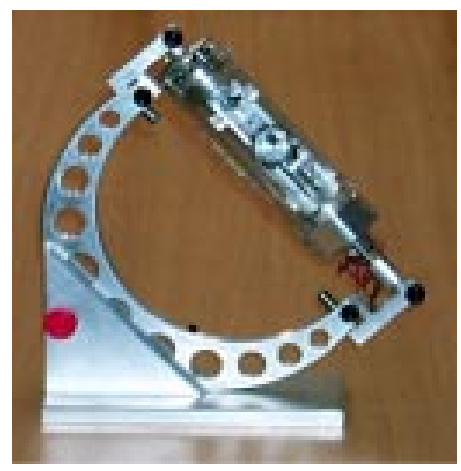

Figure 24. LLNL tiltmeters with nanoradian sensitivity can fit within a 2.5 -inchdiameter well bore and can map reservoir pressure and basin reinflation. The tiltmeter has a $110^{\circ}$ autogimbled range.

pressure and basin reinflation (Figure 24). We also have performed advanced perforation technology studies in partnership with NETL, using sequential shaped-charge penetration methods.

Novel noble gas tracers (such as krypton isotope formulations) have been developed at LLNL that can be used to spike injected carbon dioxide. Other areas of specialty include the chemical kinetics of water/rock/ $/ \mathrm{CO}_{2}$ interactions; gas-phase vadose zone transport; and geochemical modeling. 


\section{Competitive Technologies}

Technologies that have some of the same advantages as ZEST, and that may in the future compete for the same market niche, include:

- Combined-cycle turbines.

- Solid-oxide fuel cells.

- Coal syngas generation combined with fuel cells.

\subsection{Combined-Cycle Gas and Steam Turbines}

A combined Brayton-cycle gas turbine and Rankine-cycle steam turbine is typified by high efficiencies but includes inherent energy losses of approximately $15 \%$ in the heat exchanger energy coupling between combustion gas and steam units. AZEST plant, which will rely on an internal Rankine cycle, is not limited by coupling losses and may be able to attain efficiencies of $>60 \%$ for the same turbine inlet temperatures.

Combined-cycle plants generate oxides of nitrogen and $\mathrm{CO}_{2}$ emissions. Although the $\mathrm{CO}_{2}$ can be separated and sequestered, estimated costs run $\$ 72$ to $\$ 110$ per ton of carbon. ZEST plants, which will burn pure oxygen instead of air, will generate no oxides of nitrogen. All $\mathrm{CO}_{2}$ emissions will be sequestered at an estimated cost of only $\$ 10$ to $\$ 17$ per ton of carbon. (See Figure 5.)

\subsection{Solid-Oxide Fuel Cells}

Siemens-Westinghouse is developing a zero-emission plant design that employs solid-oxide fuel cells and ceramic oxygen transport membranes. At present, the capital costs for this technology are very high — perhaps $\$ 10,000$ per kilowatt. To date, the biggest demonstration plant is smaller than $1 \mathrm{MW}$. Although there is much promise for this technology in the future, the potential to scale the design to higher powers has not yet been demonstrated.

\subsection{Los Alamos National Laboratory (LANL) Zero Emission Coal Power Plant}

LANL's zero emission coal (ZEC) concept involves hydrogen generation from coal, use of the hydrogen in a high-temperature solid oxide fuel cell, and binding the $\mathrm{CO}_{2}$ as a mineral through carbonation of magnesium silicates. LANL states that there will be no $\mathrm{CO}_{2}$, $\mathrm{SOx}, \mathrm{NOx}$, particulates, or mercury produced. LANL 
has put together a team composed of major utilities, coal and energy companies, and government entities and hopes to build a pilot process plant. It is anticipated that this technology will mature after the ZEST technology has matured. Very large quantities of solid material must be transported to sequester the $\mathrm{CO}_{2}$ as carbonates, and these transportation costs may limit the economic viability of the ZEC concept. 


\section{Facility Design, Engineering Services, and Construction Plan}

ZEST facility design, engineering services, and other related project functions will be performed by a combination of architectural and engineering (AE) firms and LLNL's Plant Engineering organization. Construction and procurement will be accomplished through the use of fixed, competitively-bid contracts and subcontracts. Activation of the research facility will be accomplished by LLNL staff.

\subsection{Project Participants}

\section{LLNL Design and Engineering Services}

LLNL will develop project-specific design criteria, perform value engineering, and carry out selection of the AE firm. LLNL will also provide engineering services during Title III and will support and monitor the selected AE firm during Title I, II, and III services.

\section{LLNL Construction Services}

LLNL will contract for construction and provide construction services for the project as agreed by the Federal Project Manager and the LLNL Project Manager.

\section{Long-Lead Components}

- Components for cryogenic oxygen separation plant.

- Gas generator.

- High-, intermediate-, and low-pressure turbines.

- Electrical generators.

- Reheater(s).

- Condenser.

- Carbon dioxide compressors.

\subsection{Facility Construction Budget Estimate}

The facility budget estimate is detailed in Appendix B, which consists of a Preliminary Design Study and Cost Estimate for Zero Emission Steam Technology Research Facility, prepared by Bechtel National Inc. and submitted to LLNL on June 30, 2000. This study includes cost estimates for all components of the ZEST plant except for a demonstration ceramic membrane oxygen separation plant. The estimate for the demonstration plant was prepared by Praxair. 
Note: Bechtel calculated all capital cost estimates, except for the ceramic membrane oxygen plant, which was calculated by Praxair. Operating costs include personnel, fuel, and water treatment expenses. The approximate 10-MW size of the ZEST research facility was chosen as a compromise between a larger facility (for greater credibility in scaling to 50-MW to 100-MW sizes) and a smaller facility (to minimize operating costs).

The major ZEST construction budget items and estimated costs are listed in Table 1.

\section{Table 1. ZEST Facility Construction Budget Summary} (3Q FY01 \$ Million)

\begin{tabular}{lccc}
\hline & Cost & Contingency & Total \\
\hline Engineering & 5.6 & 2.0 & 7.6 \\
\hline Plant facility & & & 37.3 \\
Process equipment and cryogenic oxygen plant & 27.6 & 9.7 & 1.9 \\
Ceramic membrane oxygen plant & 1.4 & 0.5 & 3.6 \\
Process facilities & 2.7 & 0.9 & 1.8 \\
Support facilities & 1.3 & 0.5 & 6.5 \\
LLNL site preparation and tie-in & 4.8 & 1.7 & 51.1 \\
\hline Plant facilities total & 37.9 & 13.2 & 2.8 \\
\hline Pipeline and well systems & & & 2.9 \\
Carbon dioxide pipline & 2.0 & 0.7 & 1.1 \\
$\quad$ Injection well system & 2.1 & 0.8 & 6.8 \\
$\quad$ Oil field facilities & 0.8 & 0.3 & 65.5 \\
\hline Pipeline and well total & 5.0 & 1.8 & 1.5 \\
\hline Total capital cost & 48.5 & 17.0 & \\
\hline Annual operating cost & 1.5 & & \\
\hline
\end{tabular}

Note: Based on preliminary Bechtel study of Spring 2000. Costs include project engineering, management, and integration. Costs do not include DOE management.

\subsection{Proposed Funding Schedule and Milestones}

Funding to design and construct the ZEST research facility will span six years. Based on the preliminary Bechtel costing study, a breakdown of the funding proposed during each of these yearsand the milestones to be met-is included in Table 2. Note that the Table 2 estimate differs slightly from Table 1 because this cost estimate includes escalation to mid-construction and realistic project management costs.

All ZEST design and construction activities will be carried out according to DOE's critical design process, as required under DOE Order 413.3. This process will ensure that the required mile- 


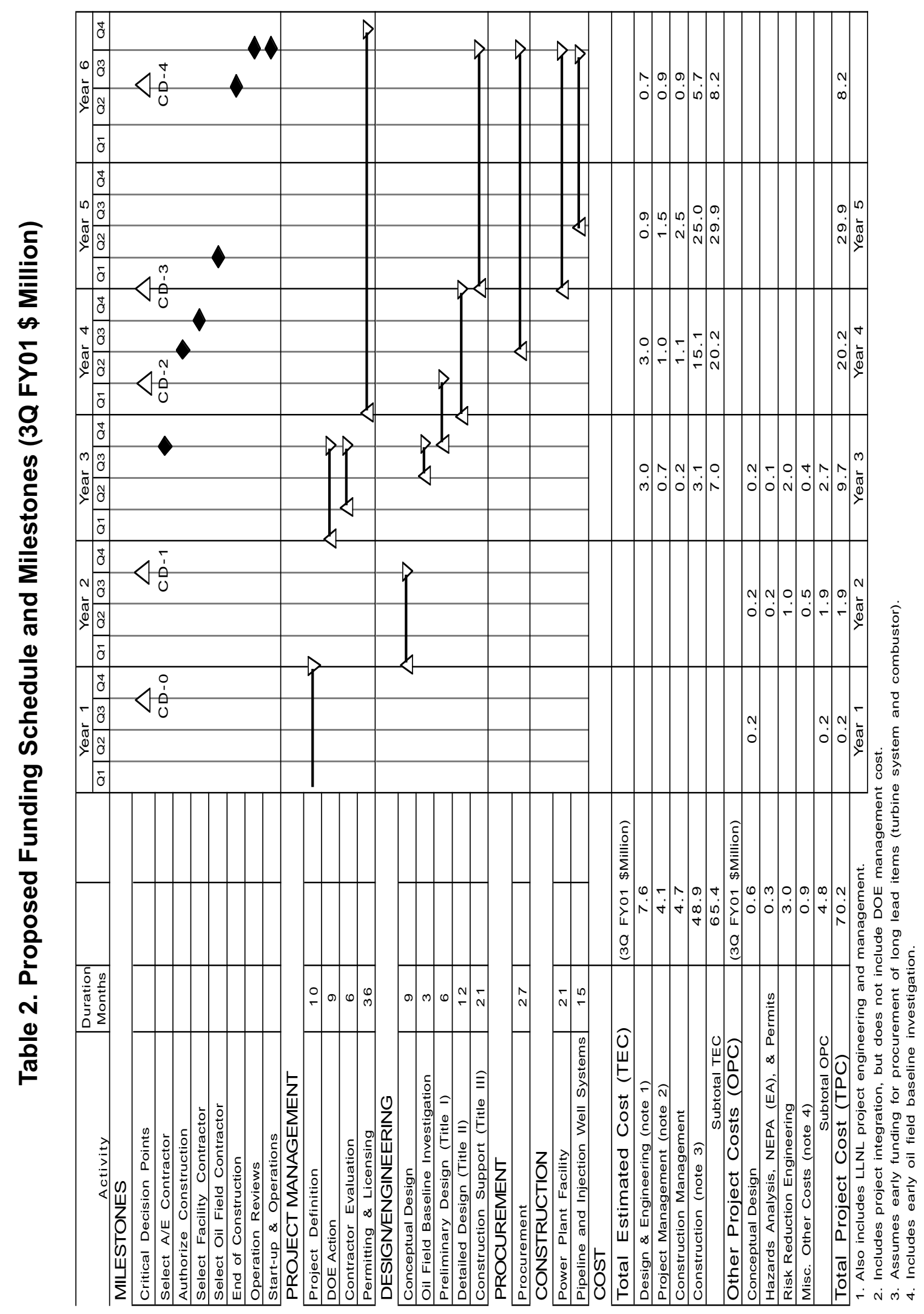


stones for construction are met. The appropriate timing of critical decision processes is included in Table 2 .

\subsection{Industrial Partner Share-of-Cost}

LLNL is placing a high priority on obtaining an industry shareof-cost for the ZEST project of at least $20 \%$, to be acquired as early in the project as possible. An industrial stakeholders workshop in August 2001 is a forum for seeking industrial comment on facility design and operation and exploring options for the management and operation of the research facility. 


\section{ZEST Research and Operations Management Plan}

\subsection{Organizational Structure}

LLNL's ZEST Research Facility Manager will report to the associate director of LLNL's Energy and Environment Directorate, who in turn reports to the Director of LLNL. (See the organization chart in Figure 25). The ZEST Manager will oversee both research and development activities and engineering and maintenance functions of the facility. The ZEST Manager will receive guidance from key DOE personnel, who include the Deputy Assistant Secretary for Coal and Power Systems, and the NETL Associate Director of the Strategic Center for Natural Gas. In addition, to make ZEST's research agenda responsive to the needs of U.S. industry, an Industrial Advisory Panel will be formed that will be composed of technical experts from the U.S. electric power generation and oil and gas industries. Each year, the ZEST Manager, working closely with the Industrial Advisory Board and DOE oversight personnel, will draft a research plan for the ZEST facility that sets research priorities for the coming year and includes a proposed facility budget for R\&D activities and engineering and maintenance operations.

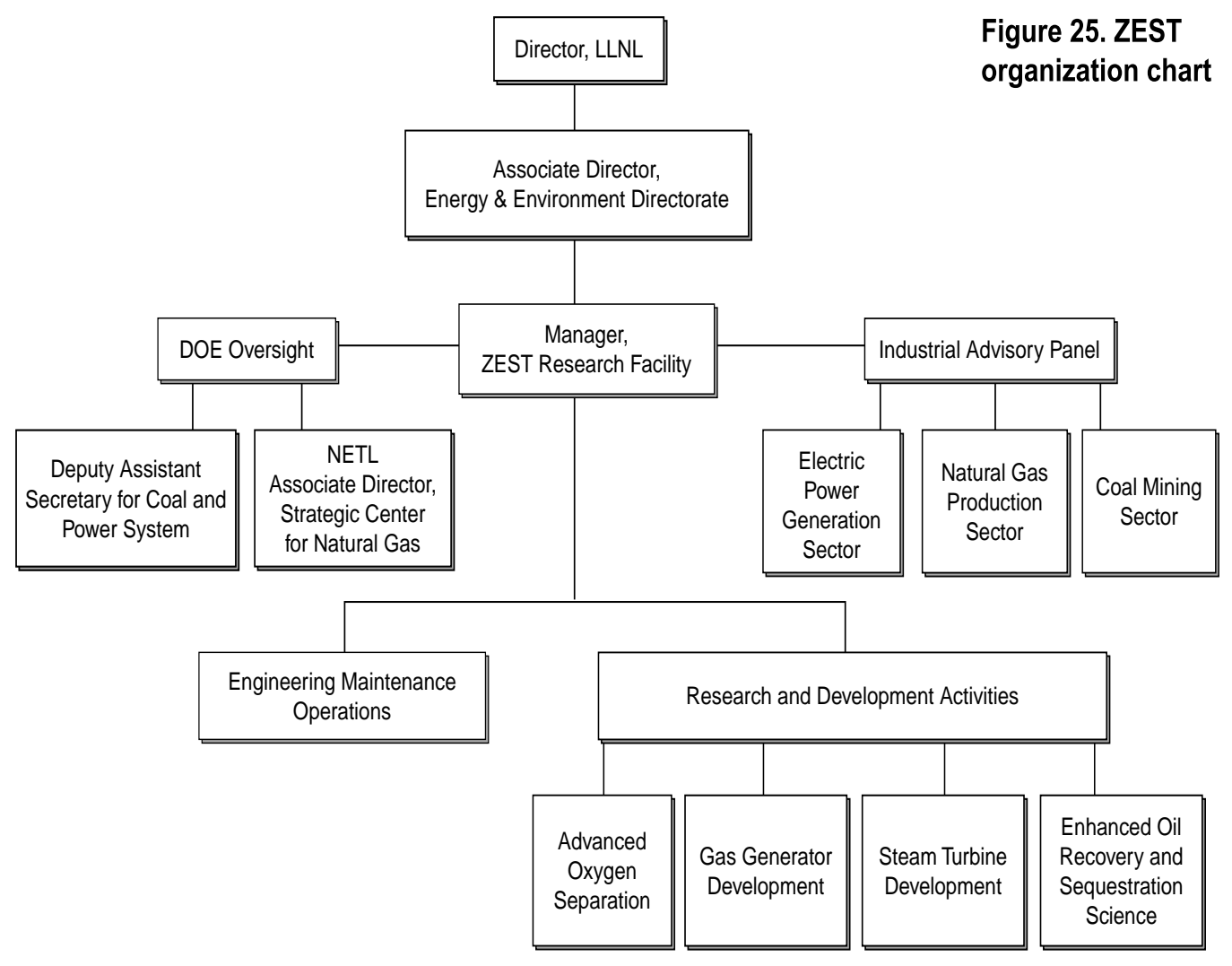




\subsection{Annual Research Activities}

Critical research activities will include development of novel technologies and improvement of existing technologies key to the success of ZEST. Each year, the ZEST Manager will detail and develop the research projects and budgets that can best meet ZEST's research goals and answer the specific questions necessary to speed ZEST's adoption by industry. One of the most important research goals will be to minimize the risks of critical equipment failure. LLNL envisions, for instance, that many research activities will focus on reducing the technical risk of gas generator failure. Other critical research will target development of ceramic oxygen separation membranes for the oxygen plant; thermal barrier coating and combustion modeling for the gas generator; using $\mathrm{CO}_{2}$ to enhance oil recovery from shallow, mature fields; and $\mathrm{CO}_{2}$ sequestration science for both oil-bearing and confined aquifer formations. An estimated FY05 budget for ZEST research and operations, including project management expenses, is included in Table 3.

\section{Table 3. FY05 ZEST Research and Operations Budget Estimate}

\begin{tabular}{lr} 
Activity & Budget $(\mathbf{\$ M})$ \\
\hline Gas generator development & 1.00 \\
Ceramic membrane oxygen separation development & 0.75 \\
Thermal barrier coating development & 0.75 \\
Combustion modeling & 0.75 \\
Enhanced oil recovery & 0.35 \\
CO2 sequestration analysis, tracking, and monitoring & 0.75 \\
Program management and administration costs & 0.40 \\
Research Budget Total & $\mathbf{4 . 7 5}$ \\
Operating Cost & $\mathbf{1 . 7 2}$ \\
TOTAL & $\mathbf{6 . 4 7}$ \\
\hline
\end{tabular}




\section{Appendices}

Preliminary ZEST research facility designs and cost estimates were prepared in FY00 by LLNL's Plant Engineering Department, Bechtel National Inc., and Praxair, Inc. LLNL's and Bechtel's designs and estimates were based on the use of commercially available turbines and other equipment. More accurate cost estimates based on our most up-to-date designs will be provided by our Conceptual Design Review report, to be completed during FY01.

A. Discussion of Factors Affecting the Cost of Carbon
Dioxide Sequestration (Prepared by Clean Energy Sys-
tems.)

B. Bechtel Preliminary Design Study and Cost Estimate 


\section{Appendix A}

\section{Discussion of Factors Affecting the Cost of Carbon Dioxide Sequestration}

\section{Background}

The cost of carbon dioxide sequestration was presented in a recent paper [1] ${ }^{1}$ for a combined cycle and a cycle based on the Clean Energy Systems, Inc. ${ }^{2}$ (CES) technology. The sequestration costs were given in a figure of the paper, which is reproduced below. This review presents the assumptions that were made to determine the sequestration costs.

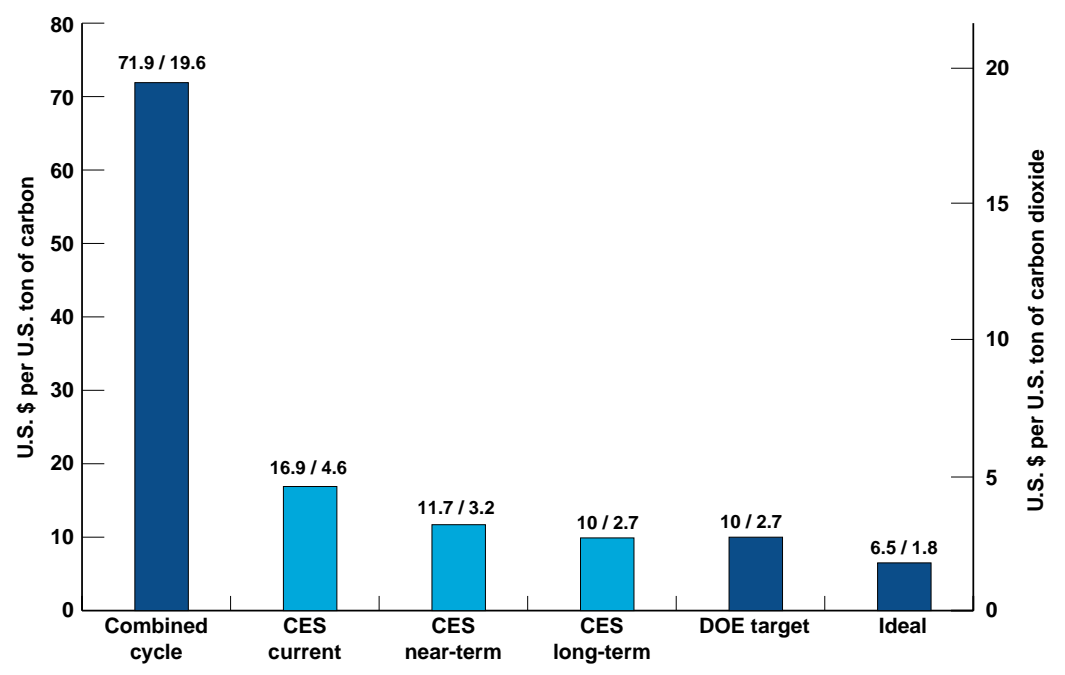

Sequestration cost includes separating, liquefying and pumping $\mathrm{CO}_{2}$ to $5000 \mathrm{psi}$ (34.5 $\mathrm{MPa}$ ). Compressor efficiency $80 \%$, electric generator efficiency $98 \%$, liquefaction coefficient of performance 3.0. Ideal cost assumes compressor, pump, liquefying and plant thermal efficiencies of $100 \%$; Turbine technology for three turbine stages, I, II, III (pressure, temperature). Current: I (1200 psi $\left.(8.3 \mathrm{MPa}), 1050^{\circ} \mathrm{F}\left(566^{\circ} \mathrm{C}\right)\right)$, II $(141 \mathrm{psi}(0.97$ $\mathrm{MPa}), 1050^{\circ} \mathrm{F}\left(566^{\circ} \mathrm{C}\right)$, III $\left(17.4 \mathrm{psi}(0.12 \mathrm{MPa}), 1050^{\circ} \mathrm{F}\left(566^{\circ} \mathrm{C}\right)\right.$; Near-term: $\mathrm{I}(1500 \mathrm{psi}$ $\left.(10.3 \mathrm{MPa}), 1500^{\circ} \mathrm{F}\left(816^{\circ} \mathrm{C}\right)\right)$, II $\left(165 \mathrm{psi}(1.14 \mathrm{MPa}), 2597^{\circ} \mathrm{F}\left(1425^{\circ} \mathrm{C}\right)\right)$, III $(17.4 \mathrm{psi}(0.12$ $\mathrm{MPa}), 1050^{\circ} \mathrm{F}\left(566^{\circ} \mathrm{C}\right)$; Long term: I $\left(3200 \mathrm{psi}(22.1 \mathrm{MPa}), 1796^{\circ} \mathrm{F}\left(980^{\circ} \mathrm{C}\right)\right)$, II $(270 \mathrm{psi}$

$(1.86 \mathrm{MPa}), 3200^{\circ} \mathrm{F}\left(1760^{\circ} \mathrm{C}\right)$, III $\left(25 \mathrm{psi}(0.17 \mathrm{MPa}), 1796^{\circ} \mathrm{F}\left(980^{\circ} \mathrm{C}\right)\right.$

Figure 1: Comparative Cost of Carbon Sequestration for $100 \mathrm{MW}$ Plants.

1 Numbers in square brackets refer to references at the end of the report.

${ }^{2}$ Clean Energy Systems, Inc. (CES) 1812 Silica Avenue Sacramento, California 95815-3431, Phone: (916)

925-8206, Facsimile (916) 925-2135. Web address: http://www.cleanenergysystems.com 
Several factors such as plant installation cost, amortization cost, fuel cost, maintenance cost, and plant efficiency enter into an economic analysis of an electric power plant. Although, in this review, we are interested only in the sequestration cost of the plant, nevertheless a number of the assumptions that enter into the economic analysis of the whole plant need to be considered in the sequestration part.

\section{Sequestration Energy Requirements}

The cost of exhaust gas sequestration includes the cost of separating the $\mathrm{CO}_{2}$ from the turbine working fluid and pumping the $\mathrm{CO}_{2}$ to a pressure of 5,000 psi. This pressure was chosen because it is sufficient to pump the $\mathrm{CO}_{2}$ trough a pipeline of several miles and to pump the $\mathrm{CO}_{2}$ into a subterranean formation at a depth of 5,000 ft.

Two sequestration cases will be analyzed. One case is for several CES plants and the second case is for a combined cycle plant.

In the CES plant, the working fluid leaving the turbines consists of a mixture of $\mathrm{H}_{2} \mathrm{O}$ and $\mathrm{CO}_{2}$. The mixture then is delivered to a condenser where the $\mathrm{CO}_{2}$ separates from the $\mathrm{H}_{2} \mathrm{O}$. The pressure in the condenser is assumed to be $1.5 \mathrm{psi}$.

If the $\mathrm{CO}_{2}$ were to be discharged to the environment, as would be done in a conventional plant, the pressure of the $\mathrm{CO}_{2}$ would have to be raised from $1.5 \mathrm{psi}$ in the condenser to atmospheric pressure. The energy required to raise the pressure of the $\mathrm{CO}_{2}$ to atmospheric pressure is independent of sequestration options and therefore is charged to the cycle.

The energy required for $\mathrm{CO}_{2}$ sequestration then is reduced to the energy required to increase the pressure of the $\mathrm{CO}_{2}$ from atmospheric pressure to a pressure of 5,000 psi. All calculations are made for a methane flow rate of $1.0 \mathrm{lb} / \mathrm{sec}$. The power of $\mathrm{CO}_{2}$ compression will be expressed both in terms of $\mathrm{kW}$ per $\mathrm{lb} / \mathrm{sec}$ of $\mathrm{CO}_{2}$ and as $\mathrm{kW}$ per $\mathrm{lb} / \mathrm{sec}$ of fuel.

We could increase the $\mathrm{CO}_{2}$ pressure by compressing the $\mathrm{CO}_{2}$ as a gas, or we could liquefy the $\mathrm{CO}_{2}$ and then pump the liquid $\mathrm{CO}_{2}$ to a pressure of 5,000 psi. We will consider first the option of compressing gaseous $\mathrm{CO}_{2}$.

Table 1. Compression Power for CES Technology Based Plants

\begin{tabular}{|c|c|c|}
\hline \multicolumn{3}{|c|}{ Power Required for Different Compression Stages } \\
\hline $\begin{array}{c}\text { Pressure ranges, } \\
\text { Psi }\end{array}$ & $\begin{array}{c}\text { Power, } \\
\mathrm{kW} \mathrm{per} \mathrm{lb/sec} \mathrm{CO}_{2}\end{array}$ & $\begin{array}{c}\text { Power, } \\
\mathrm{kW} \mathrm{per} \mathrm{lb/sec} \mathrm{fuel}\end{array}$ \\
\hline 15 to 60 & 47 & 129 \\
\hline 60 to 240 & 51 & 140 \\
\hline 240 to 960 & 44 & 121 \\
\hline 960 to 3840 & 34 & 94 \\
\hline 3840 to 5000 & 6 & 17 \\
\hline Summary 15 to 5000 & 182 & 501 \\
\hline
\end{tabular}


To raise the $\mathrm{CO}_{2}$ pressure, we use five compression stages as shown in Table 1. The efficiencies of the compressors are assumed to be 80 per cent. As shown in Table 1, the power required for the gaseous compression of $\mathrm{CO}_{2}$ is $501 \mathrm{~kW}$ per $\mathrm{lb} / \mathrm{sec}$ of fuel.

To use a liquefying process, we first increase the pressure of the $\mathrm{CO}_{2}$ from 15 psi to 145 psi using a gaseous compression process. The power required for this process is $240 \mathrm{~kW}$ per lb/ $\mathrm{sec}$ of fuel. We then use a liquefaction process and assume a coefficient of performance of 3.0 for the liquefaction process. The power required to liquefy the $\mathrm{CO}_{2}$ is $193 \mathrm{~kW}$ per lb/sec of fuel. Finally, we compress the liquid $\mathrm{CO}_{2}$ to a pressure of 5,000 psi using $48 \mathrm{~kW}$ per lb/sec of fuel. The total energy required to increase the pressure of the $\mathrm{CO}_{2}$ from 15 to 5,000 psi is 481 $\mathrm{kW}$ per $\mathrm{lb} / \mathrm{sec}$ of fuel.

When we compare the power required to increase the pressure of the $\mathrm{CO}_{2}$ from 15 to 5,000 psi, we note that the liquefaction approach requires $481 \mathrm{~kW}$ per $\mathrm{lb} / \mathrm{sec}$ of fuel and the gaseous compression method $500 \mathrm{~kW}$ per $\mathrm{lb} / \mathrm{sec}$ of fuel. The difference between these two methods is approximately 4 per cent, and either method could be used.

\section{Combined Cycle $\mathrm{CO}_{2}$ Sequestration Power}

In the case of a combined cycle, the $\mathrm{CO}_{2}$ first needs to be separated from the exhaust gases. We assume that the separation is 85 per cent effective. Thus, 15 per cent of the $\mathrm{CO}_{2}$ generated by the plant would be emitted to the atmosphere. It is believed that increasing the separation effectiveness to a value greater than 85 per cent would make the process too expensive.

The separation of $\mathrm{CO}_{2}$ from the turbine exhaust was studied by Falk-Pederson and Dannström [2] and C.A. Hendricks et al. [3]. Using the data from these references, we conclude, that the energy to separate the $\mathrm{CO}_{2}$ at a pressure of $15 \mathrm{psi}$ is $1,848 \mathrm{~kW}$ per $1 \mathrm{~b} / \mathrm{sec}$ of fuel. To increase the pressure of the $\mathrm{CO}_{2}$ from 15 psi to $5,000 \mathrm{psi}$ was found above to be $481 \mathrm{~kW}$ per $1 \mathrm{~b} / \mathrm{sec}$ of fuel. However, in the case of the combined cycle, the compression work is reduced because only 85 per cent of the $\mathrm{CO}_{2}$ is sequestered. Hence, the compression work required is $409 \mathrm{~kW}$ per $\mathrm{lb} / \mathrm{sec}$ of fuel. If we add this latter amount to the $\mathrm{CO}_{2}$ separation energy of $1,848 \mathrm{~kW}$ per $\mathrm{lb} /$ sec of fuel, we obtain a total sequestration energy for a combined cycle of $2,257 \mathrm{~kW}$ per lb/sec of fuel.

In summary, for a CES plant, the power to sequester $\mathrm{CO}_{2}$ of $481 \mathrm{~kW}$ per $\mathrm{lb} / \mathrm{sec}$ of fuel corresponds to $97.2 \mathrm{~kW}$-hr per ton of $\mathrm{CO}_{2}$ and the power to sequester the $\mathrm{CO}_{2}$ of a combined cycle is $456.0 \mathrm{~kW}$-hr per ton of $\mathrm{CO}_{2}$. In the next part of this report, these sequestration energy requirements will be translated into dollars and cents.

\section{Sequestration Cost Evaluation}

In a cost evaluation, we will consider 1) the capital cost of the plant, 2) the fuel cost and 3) the maintenance cost. These three costs form a basis from which the cost to generate electricity can be calculated. 
Table 2. Capital Costs

\begin{tabular}{|l|c|c|}
\hline \multicolumn{2}{|c|}{ Capital Cost for 100 MW plant, million\$ } \\
\hline & $\begin{array}{c}\text { CES plant } \\
100 \% \text { Sequestration }\end{array}$ & $\begin{array}{c}\text { Combined Cycle plant } \\
85 \% \text { Sequestration }\end{array}$ \\
\hline Steam turbine / generator & 9.5 & 3.9 \\
\hline Gas turbine generator / generator & --- & 23.8 \\
\hline Condenser & 0.7 & 0.3 \\
\hline Heat recovery steam generator & --- & 9.9 \\
\hline Cooling tower & 1.8 & 0.8 \\
\hline Steam generator / reheater & 2.6 & --- \\
\hline Oxygen compressor & 1.0 & --- \\
\hline Natural gas Compressor & 0.5 & --- \\
\hline Transformer / switch gear & 7.9 & 7.9 \\
\hline Balance of plant & 7.4 & 7.4 \\
\hline Subtotal Equipment Cost, (EC) & & 20.0 \\
\hline Mech. \& Electr. Construction (0.37 EC) & 11.6 & 4.3 \\
\hline Engineering (0.08 EC) & 2.5 & \\
\hline Plant Construction Cost, no sequestration & & 31.4 \\
\hline Oxygen plant & 25.9 & 14.9 \\
\hline CO $_{2}$ Sequestration Equipment & --- & 0.9 \\
\hline CO $_{2}$ Compressor & 1.0 & 3.0 \\
\hline Pipeline, drilling and completion of well & 3.0 & 971 \\
\hline Total plant cost, including sequestration & & 75.5 \\
\hline Unit Cost, \$ kW including sequestration & 754 & 97.1 \\
\hline
\end{tabular}

The capital costs of $100 \mathrm{MW}$ plants based on CES and combined cycle technologies are presented in Table 2. In Table 2, the cost of the sequestration equipment is included. The capital costs of the combined cycle plant were based on a scaled version of the actual costs of a 107 MW plant built at John F. Kennedy International Airport in Brooklyn New York [4]. The plant has two LM 6000 gas turbines at $40 \mathrm{MW}$ and a steam turbine. The heat recovery steam generator is assumed to include $\mathrm{NO}_{\mathrm{x}}$ scrubbers and $\mathrm{CO}$ fuel duct burners.

The turnkey 100 to $110 \mathrm{MW}$ combined cycle plant prices range from $\$ 658 / \mathrm{kWhr}$ to $\$ 1,200 /$ $\mathrm{kWhr}$ without sequestration. [4] The figures in Table 2 are within this range.

The cost figures of the combined cycle plant were compared also with data presented by Chiesa and Consonni for a $373 \mathrm{MW}$ plant. [5] When these costs are scaled to a $100 \mathrm{MW}$ plant the cost figures are respectively $\$ 823 / \mathrm{kWhr}$ and $\$ 1,225 / \mathrm{kWhr}$ for a combined cycle plant without and with sequestration.

Using cost figures by Simbeck [6] the scaled cost figures for a $100 \mathrm{MW}$ plant without and with sequestration are found to be $\$ 635 / \mathrm{kwhr}$ and $\$ 1424$ respectively. 
In the cost figures of Table 2, the injection well is assumed to be located at, or near, the power plant site. Drilling and completion costs of the injection well with its surface equipment are estimated to be $\$ 0.8$ million. In Table 2 , a cost of $\$ 2.2$ million is allocated for a $\mathrm{CO}_{2}$ pipeline from the plant to the injection well.

Table 3 presents the efficiencies of the plants. In Table 3, the efficiency of the CES long-term data are based on a future oxygen separation technology, such as ion transfer membranes, that are assumed to produce a reduction in oxygen plant capital cost of $25 \%$ and a reduction in oxygen separation cost of $50 \%$.

Table 3. Efficiencies of Plants, Including Sequestration

\begin{tabular}{|c|c|c|c|}
\hline \multicolumn{4}{|c|}{ Efficiencies based on lower heating value and including sequestration } \\
\hline CES Current & CES Near-term & CES Long-term & Combined Cycle \\
\hline $31 \%$ & $51 \%$ & $66 \%$ & $43 \%$ \\
\hline
\end{tabular}

If we assume that the plant life is 20 years, the interest rate is $11 \%$, the utilization factor is $85 \%$ and the efficiencies of the plants are as indicated in Table 3, then we can determine the unit cost contribution of the electricity due to the capital investment. These unit capital costs are presented in Table 4 below.

The fuel unit costs are based on a lower heating value of $21,580 \mathrm{Btu} / \mathrm{lb}$, a fuel cost of $\$ 2.50$ per million Btu of fuel, and plant efficiencies as given in Table 3. The resulting fuel unit costs are given in Table 4.

Table 4. Unit Costs

\begin{tabular}{|l|c|c|c|c|}
\hline \multicolumn{5}{|c|}{ Unit Costs of 100 MW plant, \$ $/ \mathrm{kWh}$} \\
\hline & CES current & CES Near term & CES Long-term & Combined cycle \\
\hline Capital cost & 0.013 & 0.012 & 0.012 & 0.017 \\
\hline Fuel cost & 0.028 & 0.017 & 0.012 & 0.020 \\
\hline Maintenance cost & 0.006 & 0.004 & 0.004 & 0.006 \\
\hline $\begin{array}{l}\text { Total cost with } \\
\text { sequestration }\end{array}$ & 0.047 & 0.033 & 0.028 & 0.043 \\
\hline
\end{tabular}

Unit maintenance costs are based on $15 \%$ of the sum of the capital and fuel costs. These unit maintenance costs are given in Table 4.

Using the cost figures of Table 4, we can determine the cost of sequestration either per ton of $\mathrm{CO}_{2}$, or per ton of carbon. These costs are given in Table 5 . 
In Table 5, the CES plants emit no $\mathrm{CO}_{2}$ to the environment and the combined cycle plant emits $15 \%$ of the plant's $\mathrm{CO}_{2}$ to the environment.

Table 5 Sequestration Unit Costs

\begin{tabular}{|l|c|c|c|c|}
\hline \multicolumn{5}{|c|}{ Sequestration Unit Costs per ton of $\mathrm{CO}_{2}$ and per ton of carbon. } \\
\hline Cost & CES Current & CES Near-term & CES Long-term & Combined Cycle \\
\hline \$/ton $\mathrm{CO}_{2}$ & 4.6 & 3.2 & 2.7 & 19.6 \\
\hline \$/ton carbon & 16.9 & 11.7 & 9.9 & 71.9 \\
\hline
\end{tabular}

Turbine efficiencies typically are based on the lower heating value of the fuel. The ratios of the sequestration costs of the CES and combined cycle technologies are independent of the use of either the lower or higher heating value of the fuel. However, in determining the overall cost of plant operation, the higher heating values should be used. Because fuel cost is only part of the overall plant operation cost, the actual costs are approximately $6 \%$ higher than the costs presented in Table 5.

Finally, the capital cost of a $100 \mathrm{MW}$ combined cycle plant with sequestration as shown in Table 2 is approximately 20 to $30 \%$ lower than the data presented in References 5 and 6.

\section{References}

1. J. Ray Smith and Terry Surles, Lawrence Livermore National Laboratory; Brian Marais, Bechtel National, Inc.; Harry Brandt, and F (Vic) Viteri, Clean Energy Systems, Inc. "Power Production with Zero Atmospheric Emissions for the $21{ }^{\text {st }}$ Century. Fifth International Conference on Greenhouse Gas Control Technologies, Cairns, Australia, August 14-16, 2000.

2. O. Falk-Pederson and H. Dannström, "Separation of Carbon Dioxide from Offshore Gas Turbine Exhaust.” Energy Conversion Management. Vol. 38, Suppl., pp. S81S86, 1997.

3. C.A. Hendricks, K. Blok and W.C. Turkenburg, "Technology and Cost of Recovering and Storing Carbon Dioxide from Integrated-Gasifier, Combined-Cycle Plant." Energy, Vol.16, No11/12, pp.12277-1293, 1991.

4 Gas Turbine World 1997 Handbook. Vol. 18, Pequot Publishing, Inc. 654 Hillside Rd. Fairfield, CT.

5. Chiesa, P and Consonni, S. "Natural Gas Fired Combined Cycles with Low $\mathrm{CO}_{2}$ Emissions." Journ. Engineering for Gas Turbines and Power. Vol.122, pp.429-436, July 2000.

6. Simbeck, D., "A Portfolio Selection Approach for Power Plant $\mathrm{CO}_{2}$ Capture, Separation and R\&D Options." Fourth International Conference on Greenhouse Gas Control Technologies, Interlaken, Switzerland, Sept. 1998 
Appendix B

\title{
Preliminary \\ Design Study and Cost Estimate for \\ Zero Emission Steam Technology \\ Research Facility
}

\section{Letter Report Study}

\author{
June 30,2000
}

Lawrence Livermore National Laboratory

Prepared by

Bechtel National Inc. 


\subsection{Introduction}

Lawrence Livermore National Laboratory (LLNL) has initiated a research and development project on a technology for production of electric power with no emission of exhaust gases to the atmosphere. Bechtel was asked by LLNL to conduct a design study of a Zero Emission Steam Technology (ZEST) Research Facility to be built at the LLNL. The objectives of this report are to identify plant equipment and facilities at a preconceptual level and to provide a rough cost estimate for project planning purposes. The results of this report will be used to support a more detailed conceptual design report.

This report presents preliminary design information and cost data that were developed based on design criteria and information provided by LLNL and Clean Energy Systems, Inc (CES). Technical and cost issues are also examined in the report for future consideration. This study was completed in 6 weeks.

Major design bases and assumptions include:

- The facility will be located on the LLNL site and Greenville oil field site.

- The process design is based on the flowsheet and mass balance by CES (see Appendix A).

- The fuel source will be natural gas. Oxygen for combustion will be supplied from an on site oxygen separation plant.

- Natural gas, oxygen and water will be injected in a gas generator for combustion

- The combustion gaseous mixture will be fed through a three-stage turbine connected to an electrical generator to produce electricity.

- Nominal electrical power output will be $5 \mathrm{MW}$ net. Subject to DOE approval, the electricity produced will be retured to LLNL's power grid and used at the lab.

- Carbon dioxide from combustion will be compressed, pumped through a pipeline to an oil field northeast of LLNL, and injected underground into the Greenville formation.

- The facility will be operated on a 3-month on and 3-month off basis, equivalent to 4,380 hours per year.

- Only two full-time employees are included in the operations cost estimate. A research program budget will cover the cost of other required employees.

- The LLNL site will have sufficient electrical power capacity for plant start-up and shutdown.

- The design will consider future expansion with a turbine generator system of higher temperature and pressure. 


\subsection{Summary of Results}

The Zero Emission Steam Technology Research Facility has a gas generator-turbine system with $15.7 \mathrm{MW}$ thermal input and generating 7.9 MW of electricity. After accounting for plant equipment power usage, the nominal net power output of the plant is $5 \mathrm{MW}$. About 15,000 tons / yr of carbon dioxide (CO2) exhaust will be injected into the oil field formation at 1000 psia. The facility, which includes an oxygen separation plant, occupies about 1.5 acres at the LLNL. Rough sizes of major equipment, the process building and support facilities were calculated from the preliminary conceptual design information.

The preliminary estimated total construction capital cost is $\$ 62$ million. This includes $\$ 48.1$ million for plant facilities; $\$ 6.5$ million for the pipeline, injection well system, and oil field facilities; and $\$ 7.4$ million for design and engineering. These costs are in current (June 2000) dollars. The capital cost escalated to midpoint of construction (March 2004) is $\$ 68$ million.

The annual operating cost is about $\$ 550,000$. This cost includes 2 full time employees and revenue from sales of electricity which offsets some operating cost. But does not include other program personnel (scientists, technicians, maintenance, etc.) or oil field leasing or royalties.

The preliminary schedule assumes selection of an architect/engineer (A/E) contractor in mid 2002. The schedule shows engineering design starting in October 2002, construction beginning in October 2003, and operations beginning in September 2005. The schedule assumes that no funding restraints will curtail project activities.

The Zero Emission Steam Technology is more complex than a conventional combined cycle turbine technology. The gas generator, steam turbine system, and condenser are critical plant systems. These plant systems must be fully integrated and may require a complex control system. Further review of these systems is necessary to facilitate a more detailed facility design.

It is suggested that a simulation program be used to fully analyze gas / fluid flow. Among considerations are the stoichiometry of oxygen and natural gas combustion, $\mathrm{CO} 2$, N2 and steam content.

Fuel feed systems must be clean and therefore natural gas, oxygen and water system cleanliness requirements need to be verified.

The cost of oxygen separation is an important element to be reviewed. Also, the possible use of steam injection into the oil wells, efficient use of water and the sale of CO2 or N2 will also have an effect on cost. Materials of construction for the various systems and equipment need to be established. 
Geological sequestration of $\mathrm{CO} 2$ and enhanced oil recovery are both active research topics supported by US DOE Fossil Energy programs. The Livermore Oil Field is located near the proposed site for the ZEST Plant. The Livermore Oil Field consists of about a dozen oil wells and has been producing oil from a sandstone formation that is about 1600 feet below the surface. This oil field began producing in the late 1960 's. This oil field lies in the active seismic fault zone of the Greenville Fault System.

The plan for ZEST includes tertiary CO2 injection (or flood) into the producing formation or oil reservoir. This $\mathrm{CO} 2$ will be injected with well-head pressure of 500 psi to 700psi to help repressurize the oil reservoir and enhance oil production by sweeping more of the remaining oil out of the reservoir. It is important to monitor the $\mathrm{CO} 2$ flooding front and to control the pressure and volume of $\mathrm{CO} 2$ into the tertiary injection well. Various sensors and controls will be installed into the injection well and in the monitoring wells to provide this information and control. Geological, geochemical, and geophysical modeling and analysis will help provide input to basin or reservoir simulators to help optimize the tertiary oil recovery research as well as the $\mathrm{CO} 2$ sequestration.

The zero emission technology is in developmental stage and there is little existing data available to evaluate the economics of this kind of plant. Therefore, cost data generated from detailed design, construction and operations of this facility, would be very valuable, in assessing the economic viability of a scaled-up industrial plant based on zero emission power generation technology.

\subsection{Facility Description}

\subsection{Process Description}

Natural gas and oxygen are burned and mixed with water to produce steam and carbon dioxide. This mixture drives a three-stage turbine connected to an electrical generator to produce electricity. The turbine exhaust is cooled in a condenser. The condensate is recycled back to the gas generator. Excess condensate is bled off and discharged to sewer. The carbon dioxide is compressed and pumped via a pipeline to an oil field for injection into the ground.

The major systems are the oxygen plant, gas generator (i.e., combustor/ steam generator), steam turbine and electrical generator, condenser and condensate system, carbon dioxide compressors, pipeline, and injection well. Process flow diagrams are shown in Figures 1 to 4 . A list of major equipment is shown in Appendix B.

Oxygen is produced on site using a cryogenic distillation process that separates oxygen from air. The oxygen gas is supplied to the number 2 turbine reheater at 30 psia and compressed and fed to the number 1 turbine reheater at 160 psia. 


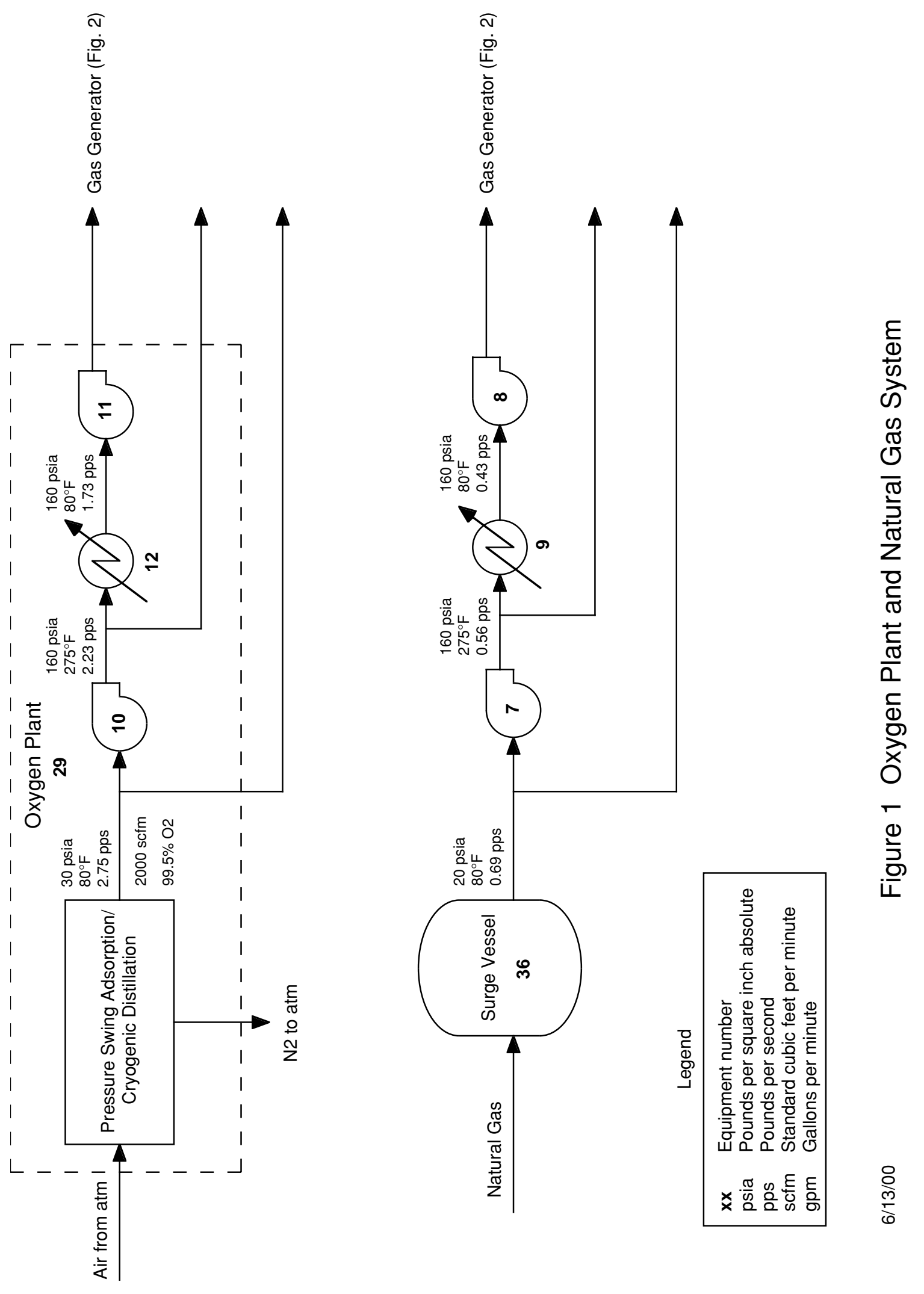




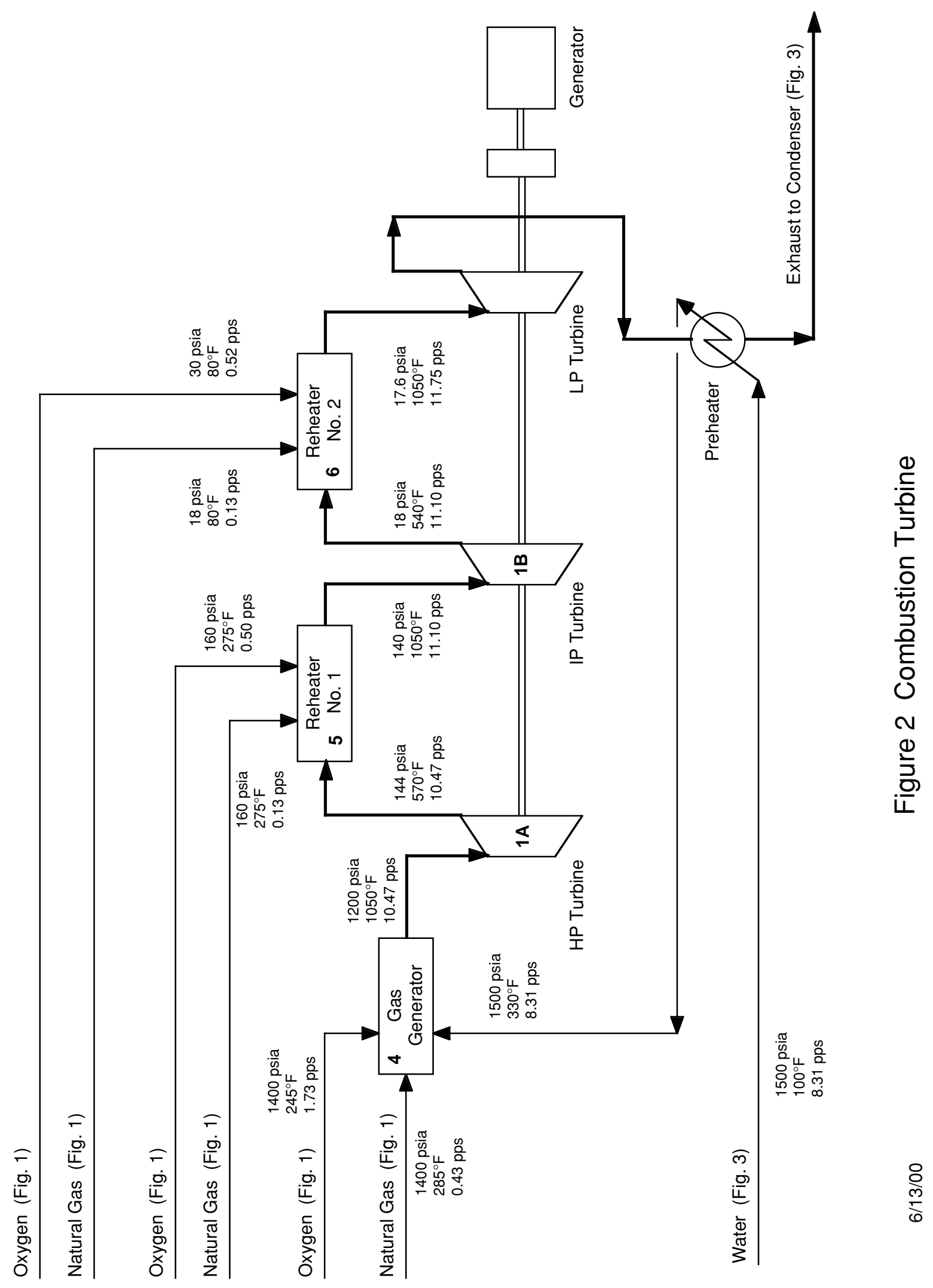




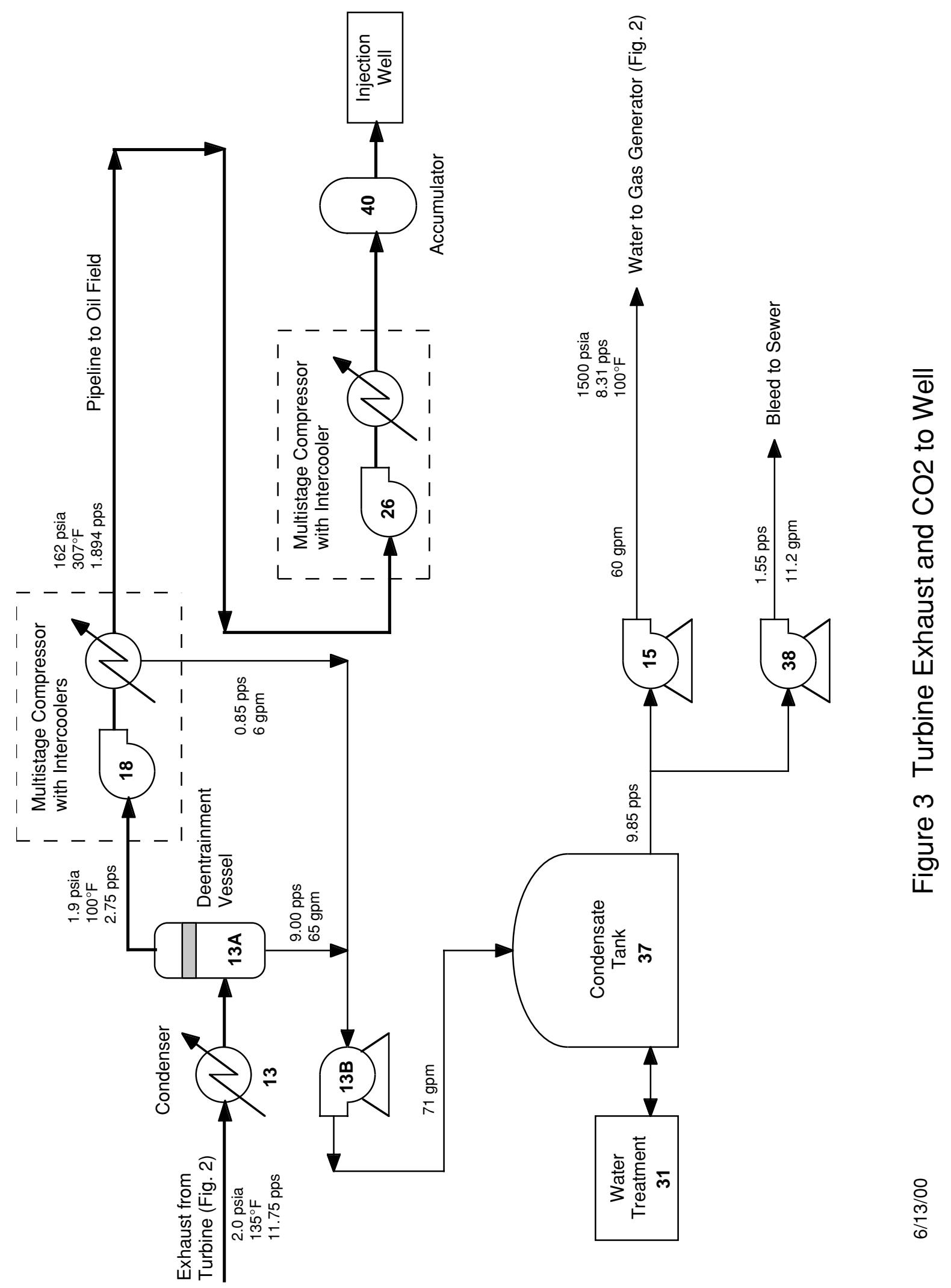




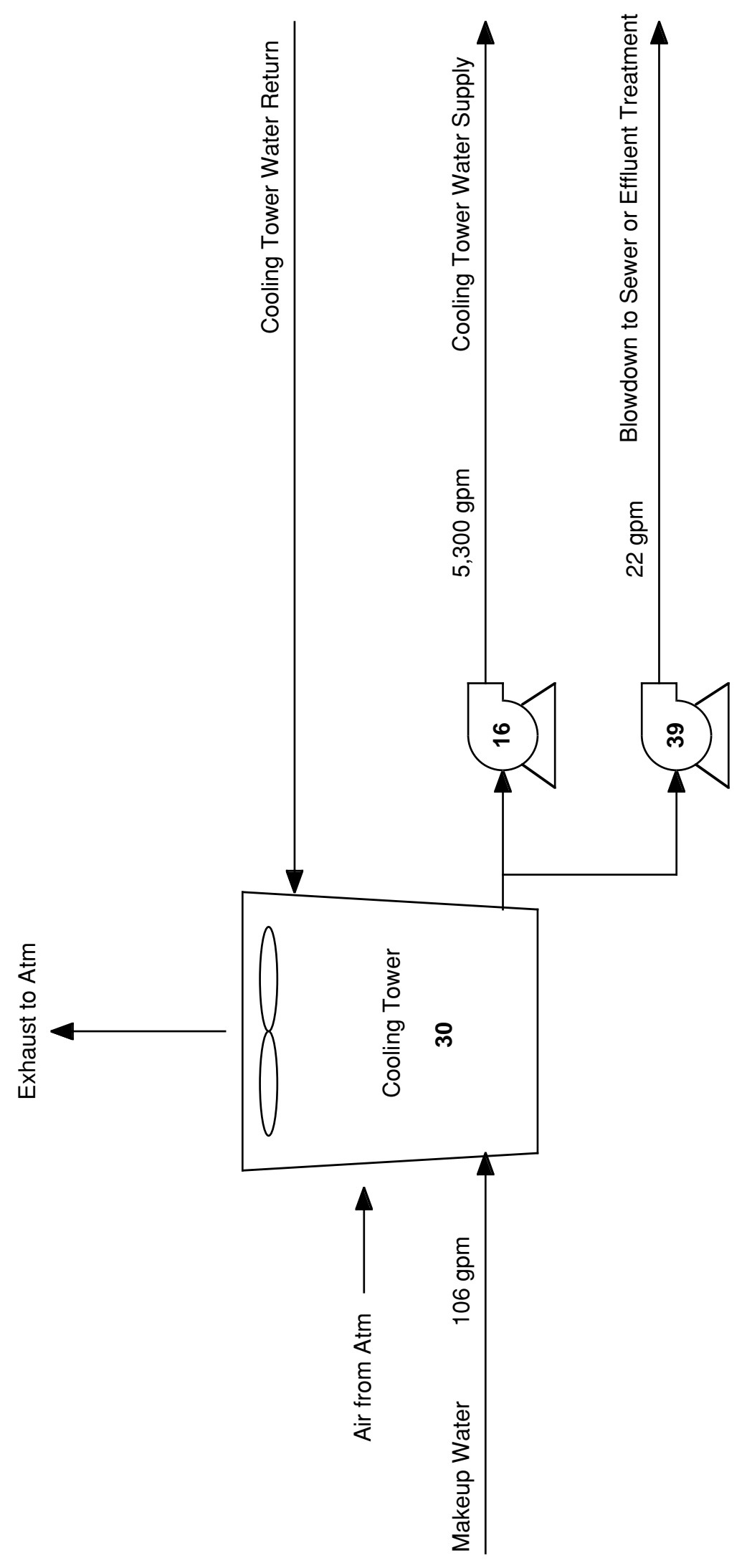

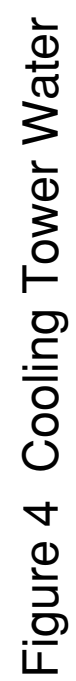

$\frac{8}{\frac{8}{6}}$ 
Oxygen gas is compressed to 1,400 psia for feed to the gas generator. The nitrogen gas byproduct from the oxygen plant operation is vented to atmosphere.

Natural gas from the local utility company is supplied to the number 2 turbine reheater at 20 psia and compressed and fed to the number 1 turbine reheater at 160 psia. Natural gas is compressed to 1,400 psia for feed to the gas generator.

A high pressure water pump supplies feed water to the gas generator at a pressure of 1500 psia.

The natural gas and oxygen are injected and mixed in the gas generator, where they burn to produce heat, carbon dioxide and water vapor. Water is injected into the gas generator to cool the mixture and to produce steam. The resulting steam and carbon dioxide mixture (nominally 1200 psia 1050F) passes through a three-stage turbine which is connected to an electrical generator. Reheaters burning natural gas and oxygen are provided between the turbine stages.

After the third stage turbine, the exhaust passes through a preheater that heats the feed water to the gas generator. The exhaust then flows to the condenser and deentrainment vessel, where most of the steam is condensed and separated from the carbon dioxide gas. Remaining water vapor is condensed out in subsequent compressor intercoolers. The condensate is collected and supplied to the high pressure water pump for recycle to the gas generator. Because the combustion reaction produces water, excess condensate is bled off and discharged to the LLNL sewer. This bleed stream also limits the buildup of impurities in the recycle condensate. A sidestream of condensate can be treated to further maintain water quality.

The carbon dioxide gas is compressed to about 160 psia using a multistage compressor. Intercoolers between the stages cool the gas and remove additional moisture. The carbon dioxide gas is fed to a 1.9 mile long, 3 inch diameter stainless steel underground pipeline to the oil field. At the oil field, the carbon dioxide is compressed to 1000 psia and injected into the oil formation.

Materials of construction are stainless steel for wet carbon dioxide, stainless steel or high nickel alloys for oxygen, and carbon steel for natural gas. It is assumed the condensate system will require corrosion-resistant materials such as stainless steel or plastics to maintain water quality.

An evaporative cooling tower supplies cooling water to the turbine condenser. Small amounts of cooling water are also supplied to compressor intercoolers, aftercoolers, and miscellaneous equipment. Makeup water is supplied from the LLNL water system and cooling water blowdown water is discharged to the LLNL sewer system. 
Major plant input and output quantities are summarized in Table 1.

Table 1 Major Plant Input and Output Streams

\begin{tabular}{|c|c|}
\hline Major Input Streams & Major Output Streams \\
\hline $\begin{array}{l}\text { Natural Gas } \\
223 \text { million std. cubic feet/yr } \\
(2.34 \text { million therms/yr) }\end{array}$ & $\begin{array}{r}\text { Carbon Dioxide } \\
15,000 \text { tons/yr }\end{array}$ \\
\hline $\begin{array}{l}\text { Oxygen (from oxygen plant) } \\
21,681 \text { tons / yr }\end{array}$ & $\begin{array}{l}\text { Nitrogen (to atmosphere from oxygen plant) } \\
71,367 \text { tons / yr }\end{array}$ \\
\hline \multirow[t]{2}{*}{$\begin{array}{l}\text { Makeup Water to Cooling Tower } \\
28 \text { million gallons/yr }\end{array}$} & $\begin{array}{l}\text { Excess Condensate Water (from condenser) } \\
2.9 \text { million gallon } / \mathrm{yr}\end{array}$ \\
\hline & $\begin{array}{l}\text { Cooling Tower Blowdown Water } \\
5.8 \text { million gallons/yr }\end{array}$ \\
\hline
\end{tabular}

Initially, the electrical generator will produce about 7.9 MW electric power with a 15.7 MW thermal power input to the turbine system. The ZEST facility will consume about 3.5 MW of electricity, resulting in a net energy production of 4.4 MW. The major consumers of electrical power are $1500 \mathrm{~kW}$ for oxygen separation, $400 \mathrm{~kW}$ for oxygen compression, and $900 \mathrm{~kW}$ for the CO2 compressors. The plant operation is monitored by a computer based control system located in the plant facility.

\subsection{Plant Facilities}

The major facilities to be constructed will be located at the LLNL site. A site location in the MFE Capacitor DC Power Area adjacent to Building 531 has been tentatively identified for the plant construction. Additional construction will occur at the oil field and along the pipeline from the LLNL site to the oil field. An injection well system for CO2 will be built at the oil field northeast of the LLNL. A project location map and site aerial photograph are shown in Figures 5 and 5A, respectively.

The ZEST facility at LLNL occupies about 1.5 acres and includes a Process Building, oxygen plant, and support facilities. The site plan considers future expansion of the Process Building to accommodate a turbine generator system of higher temperature and pressure. A conceptual site layout is shown in Figure 6.

The Process Building is a steel frame, metal structure with a $2 \mathrm{ft}$ thick concrete mat foundation. The $50 \mathrm{ft} \times 140 \mathrm{ft}$ building is $30 \mathrm{ft}$ high in the turbine/ generator area and $20 \mathrm{ft}$ high in the compressor area. The building is ventilated and lighted, but no 


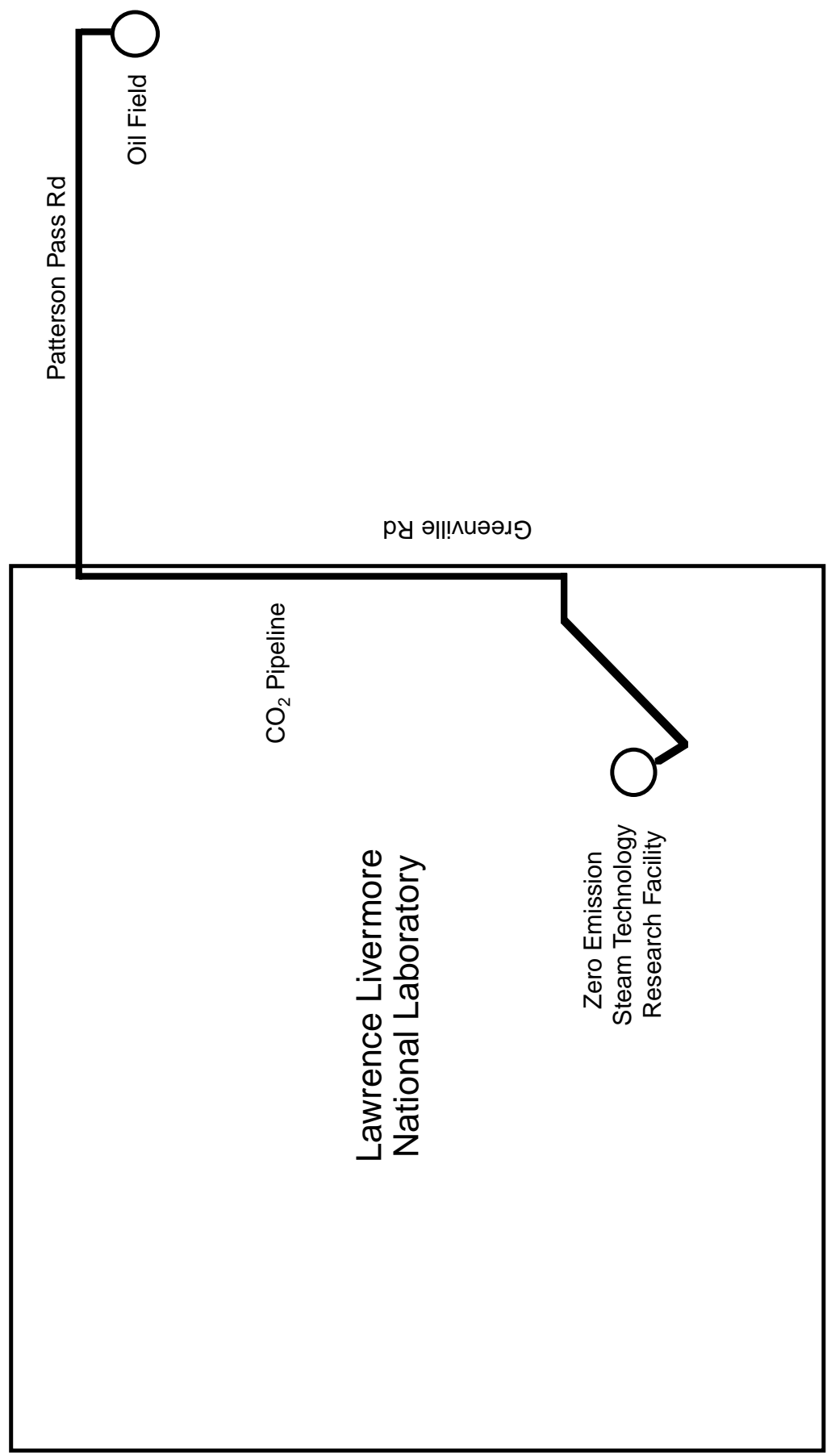

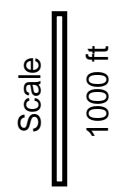

$\frac{0}{2}$

등

O

$+$

(1)

음

10

논

$\frac{8}{\frac{8}{6}}$ 





$190 \mathrm{ft}$

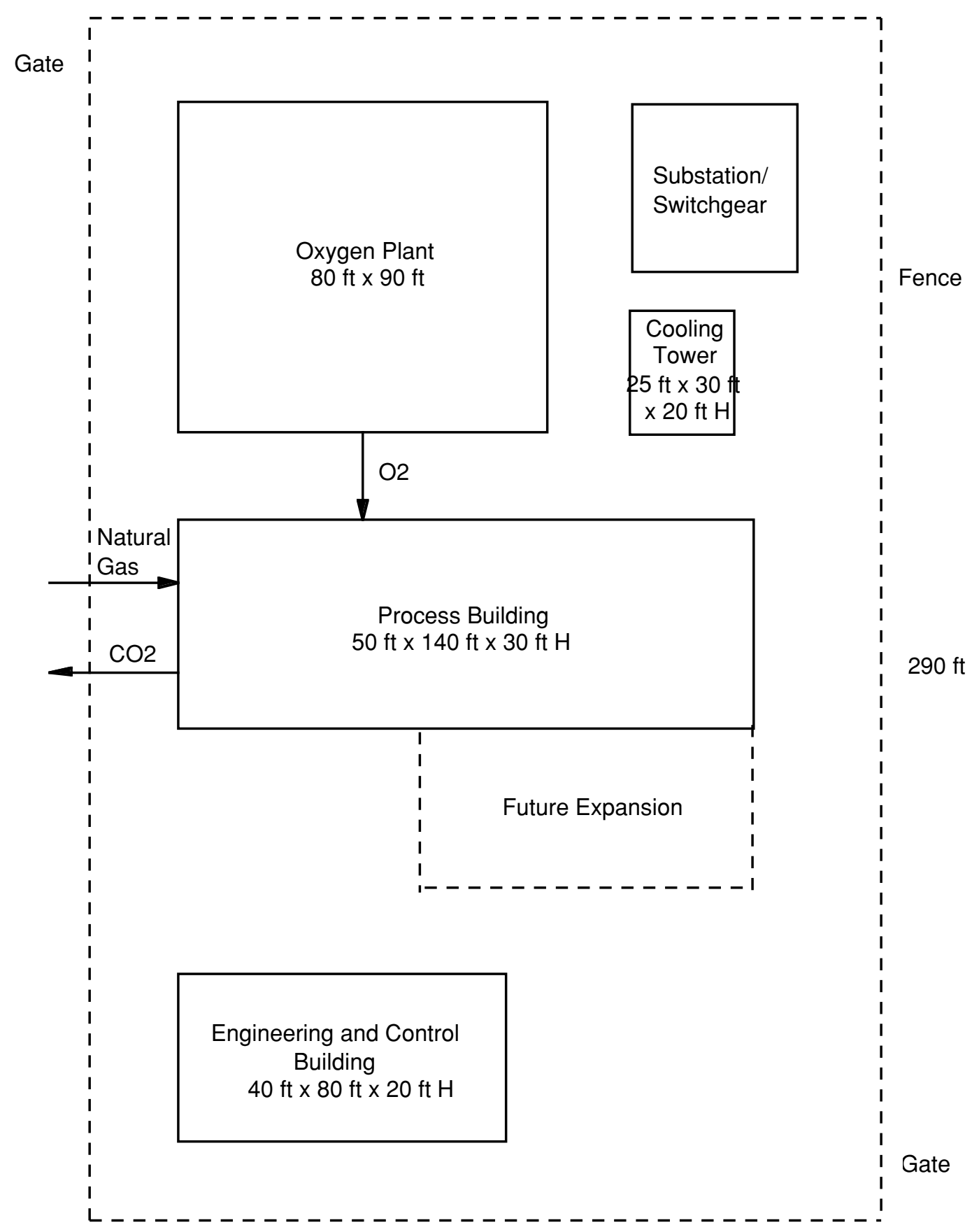

Scale

$20 \mathrm{ft}$

$6 / 13 / 00$

Figure 6 Site Layout at LLNL 
heating or cooling is provided. A $40 \mathrm{ft}$ high vent stack is provided to discharge exhaust gases to atmosphere during startup, shutdown and upsets. The facility will be designed and constructed in compliance with DOE Orders and applicable regulations and codes. In the absence of a hazard analysis, it is assumed that the Process Building is performance category PC-1. A conceptual Process Building general arrangement is shown in Figure 7.

Support facilities at the LLNL site includes an Engineering and Control Building and cooling tower pad, electrical switchgear, substation, and a security fence.

The Engineering and Control Building is $40 \mathrm{ft} \times 80 \mathrm{ft}$ and houses the control room, offices, storage and maintenance areas. The building is a prefabricated modular building with conventional HVAC for personnel comfort.

The injection well system includes one $\mathrm{CO} 2$ injection well and four monitoring wells to be drilled at the Greenville oil field site. The injection well is $2000 \mathrm{ft}$ deep with a casing size of $51 / 2$ inch. Each monitoring well is $3200 \mathrm{ft}$ deep with a casing size of $85 / 8$ inch.

Oil field facilities include a $\mathrm{CO} 2$ injection pump station and four monitoring stations near the well heads. The injection pump station has a $20 \mathrm{ft} \times 20 \mathrm{ft}$ metal building with final-stage compressor and equipment. Each monitoring station is provided with a small ( $15 \mathrm{ft} \times 15 \mathrm{ft}$ ) metal building to house monitoring equipment.

The plant will be operated on a cycle of 24 hours/ day and 7 days / week for a duration of three months for testing and demonstration runs, followed by a three month shutdown. 


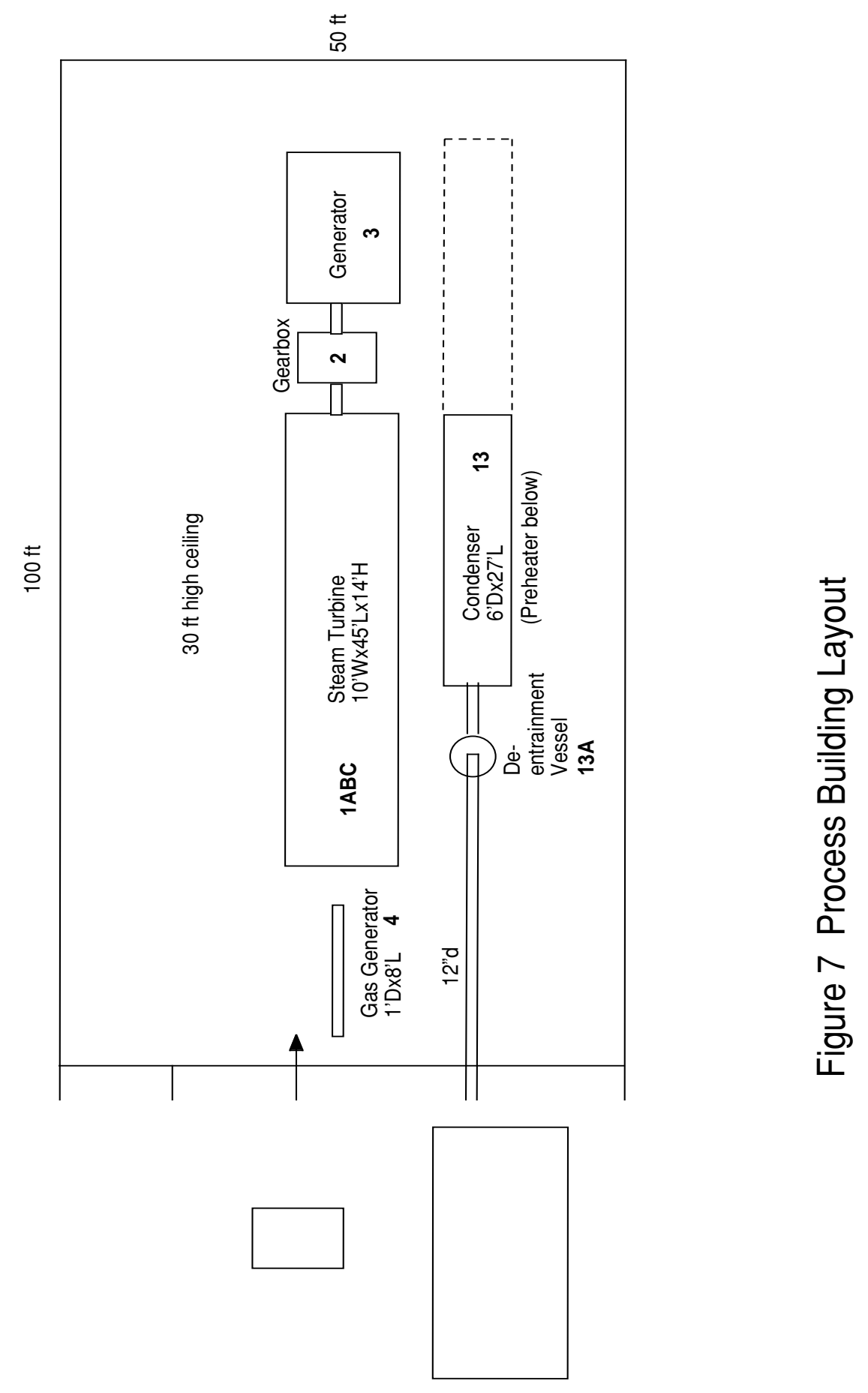




\subsection{Cost Estimates and Schedule}

The cost estimates are rough order of magnitude estimates based on preconceptual design information. Results of the capital cost and of operating cost estimates are summarized in Table 2.

Table 2 Cost Estimate Summary

(June 2000 dollars)

\section{Engineering}

\section{Plant Facility}

Process Equipment \&

Oxygen Plant

Process Facilities

Support Facilities

LLNL Site Prep \& Tie-in

Plant Facility Total

Pipeline and Well Systems

$\mathrm{CO} 2$ Pipeline

Injection Well System

Oil Field Facilities

Pipeline and Wells Total

Total Capital Cost

Annual Operating Cost

Cost
$(\$$ million $)$

5.5

27.0

2.6

1.3

4.73

35.6

1.97

0.69

0.73

0.26

1.7

16.1

45.9

0.55

1.9

9.5

0.9

0.4

1.66

12.5

0.75

4.8

--
Contingency

6.4

36.5

3.5

1.7

\section{1}

2.66

2.81

1.02

6.5

62.0

0.55
Total Cost

(\$million)

The preliminary estimated total construction capital cost is $\$ 62.0$ million. This cost is based on current (June 2000) dollars. The capital cost escalated to midpoint of construction (March 2004) is \$68.2 million, based on DOE's cost index.

The estimates are based on the labor cost in the San Francisco Bay area and include indirect cost factors for a LLNL project. The cost estimates for the LLNL site preparation and utility tie-in and the $\mathrm{CO} 2$ pipeline were furnished by LLNL. The costs for the gas generator and oil well system subcontract were furnished by CES. The oxygen plant cost is based on a subcontract that includes materials, installation and startup by an oxygen vendor. Cost estimate basis and details of the cost estimate results are shown in Appendix C. 
The construction capital costs are based on an engineering, procurement and construction management (EPCM) approach. The capital cost estimate utilized budgetary quotations, estimating manuals, allowances, and historical cost data. A 35\% contingency was applied to the capital cost. This contingency level is based on previous risk analysis on projects of similar scope and level of design details. Costs excluded from the estimate are technical design data development, oil field land lease, royalties, $R \& D$ cost, DOE oversight, and facility removal and site restoration after project completion.

The operating cost includes costs for natural gas, consumable materials, utilities, and operating labor, and revenue from sales of electricity. Two full-time employees are costed for plant operations. Due to the research nature of plant operations, research staff and other required employees are not included in the operating cost. The research program budget will cover the cost of other required employees. Subject to DOE approval, revenue from sales of electricity is estimated to be $\$ 1.0$ million annum based on $3 \notin$ per $\mathrm{kWh}$. The revenue is credited to offset the operating cost. Potential revenue from $\mathrm{CO} 2$ sales is excluded.

The preliminary project schedule is shown in Figure 8. The schedule assumes selection of an A/E contractor in mid 2002. The schedule allows 15 months for engineering design starting in October 2002 and 21 months for construction beginning in October 2003. Plant operations would begin in September 2005. The schedule assumes that no funding restraints will curtail construction activities throughout the project duration.

\subsection{Discussion and Issues}

Several technical issues have been identified during the course of this study which will require further investigation in the next CDR design phase.

\subsection{Process Equipment}

The facility will utilize newly developed equipment and demonstrate a new technology. The most important equipment issues include:

- The process utilizes a gas generator for combustion and steam generation. The gas generator is currently under development by CES and is critical to the design.

- The plant system is more complex than a conventional combined cycle turbine system. Any gas fluctuation will have impact on stability of downstream equipment operations. Startup and control of the process should be simulated before plant operation. 


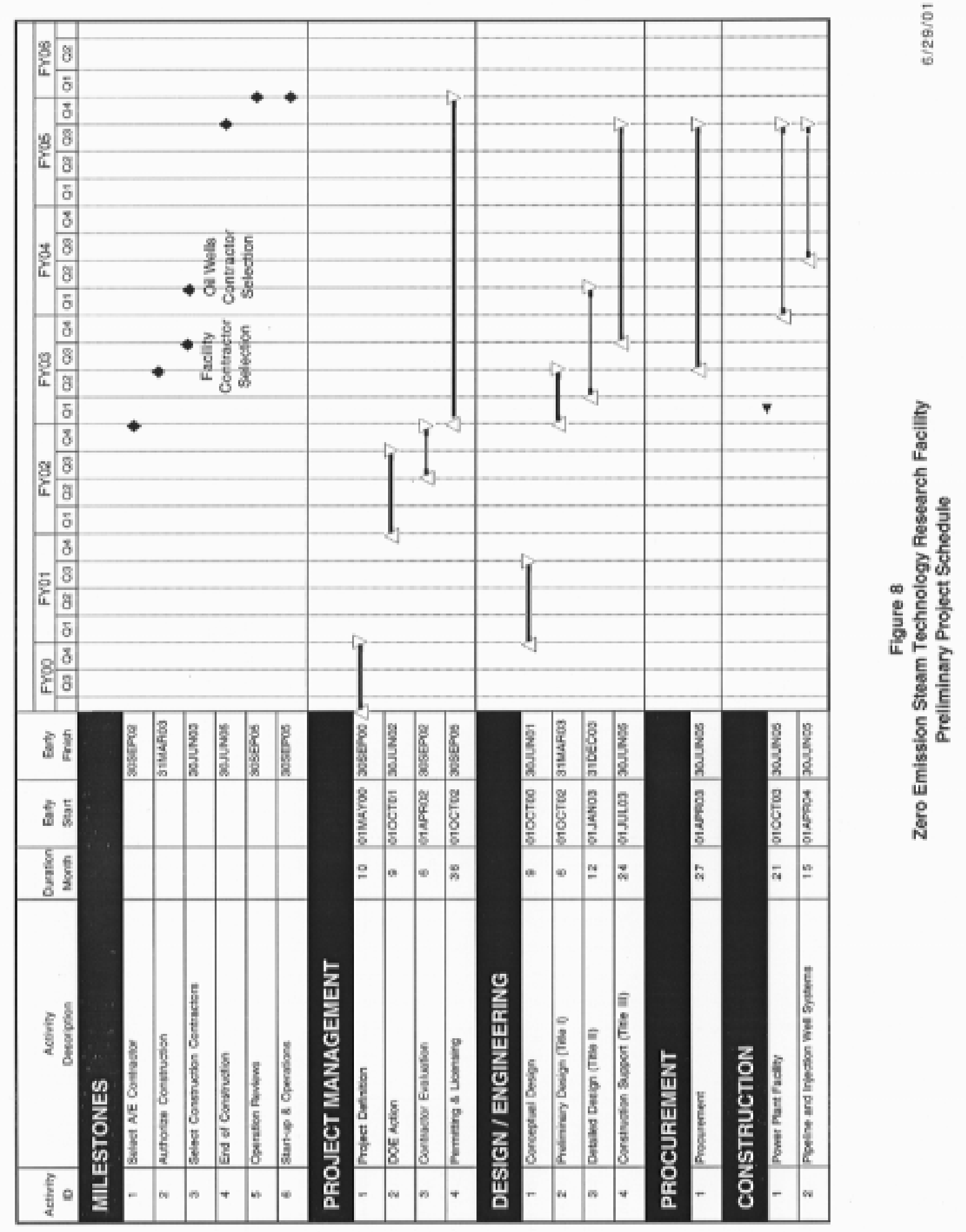


Potential areas of study concerning the oxygen plant include:

- The reliability of the oxygen plant and stability of the oxygen pressure is a concern. A surge and backup source of oxygen should be considered.

- The oxygen plant could be deleted and replaced by storage tanks for liquid oxygen delivered by truck.

(The cost would be about $\$ .35 / 100 \mathrm{cf}$ and a $\$ 5000 /$ month equipment rental fee. At an oxygen consumption rate of 25,000 gallons/day, or $2.75 \mathrm{lb} / \mathrm{sec}$ for $4380 \mathrm{hrs} / \mathrm{yr}$, the cost is $\$ 1.85$ million/yr. For comparison, the cryogenic plant cost is about $\$ 7.5$ million plus $\$ 380,000$ per year for electricity, based on $1900 \mathrm{~kW}$ for $4380 \mathrm{hrs}$ at $4.6 \notin / \mathrm{kWh}$.)

- Oxygen separation is based on cryogenic distillation process in this study. The use of 90-94\% purity oxygen produced by a vacuum pressure swing adsorption system could be studied. This system has a lower capital cost ( $\$ 5.8$ million vs. $\$ 7.5$ million for cryogenic plant), but potentially some nitrogen will be converted to undesirable nitrogen oxides in the gas generator, and the greater gas flow will increase some equipment sizes.

- The effect of excess oxygen needed to assure complete combustion must be considered in future process design and detailed equipment sizing.

Other potential areas of study include:

- The cleanliness of gases and water feed is critical to the gas generator operation because particle impurities in the feed may cause system plugging. Adding a second parallel gas generator should be considered in the design.

- Water purity requirements for the gas generator, turbine and condenser systems need to be defined to determine what if any treatment is necessary to enable condensate to be recycled as feed water to the gas generator.

- The design of turbine exhaust condenser will need particular effort because the presence of non-condensable $\mathrm{CO} 2$ gas will significantly decrease the overall heat transfer coefficient and increase the exchanger area required.

- In this study, an evaporative cooling tower was selected in the cooling water system. An alternative is a dry cooling tower that has zero discharge of blowdown water and requires no makeup water. The cooling water supplied from a dry cooling tower can be as warm as $120^{\circ} \mathrm{F}$ or higher. This would require a change in the condenser operating temperature and its impacts on plant energy efficiency and cost need to be reevaluated.

- Additional study is needed to determine the suitability of the chosen materials for corrosion resistance. 
- Surge and storage vessels in the plant system design need further evaluation.

\subsection{Site and Facility}

The Process Building, which houses the turbine, generator and compressors, was assumed to be performance category PC-1 (UBC industrial type). A safety and accident analysis is required to determine the hazard classification and performance category.

Further study is needed to establish the Process Building size and appropriate structure for weather protection and noise abatement. The possibility of eliminating the building and installing the turbine and compressors outdoors under a rain cover needs study.

This study assumed a site location adjacent to Building 531. Exact location of the facility must be determined with consideration of pipeline connection and noise issues.

Further study is needed to confirm the feasibility of transmitting excess power produced at the plant back into LLNL's power grid without impacting its stability and reliability.

Geotechnical and other issues concerning oil well drilling and $\mathrm{CO} 2$ injection into underground formation are not covered in this study, and may need examination.

\subsection{Cost Estimate and Schedule}

Major equipment costs are based on rough equipment sizing with engineering judgment and budgetary quotations from vendors with incomplete engineering data. Additional design is needed to allow a more accurate pricing.

The major contributors to the capital cost are the oxygen plant and steam turbine. A survey from several turbine manufacturers has been conducted. A turbine with the actual two-reheater design is found not available and the information collected is inadequate for estimate purpose. The steam turbine in the estimate is based on MW rating of the turbine. Further cost confirmation and validation is required.

Cost for the oxygen plant is based on a vendor supplied and installed plant. Capital cost can be reduced if the oxygen plant is leased from the supplier. The oxygen plant could even be operated by the vendor, who would then sell the oxygen on a dollars per cubic foot basis. These alternatives were not addressed in this study.

The schedule shows a construction start in October 2003. This appears to be attainable if early approval for construction dates are met. The steam turbine and 
compressors are on critical path of the construction and their procurement generally requires 12-24 month lead time. Early procurement of long-lead equipment items is required to meet the schedule.

\subsection{Economics}

The plant produces a fairly pure nitrogen gas byproduct from the oxygen plant. The nitrogen is vented to atmosphere. If the economics are favorable, the nitrogen could be compressed and distributed to users at the laboratory.

The plant also produces a fair amount of steam (35,000 lbs per hour) from the combustion process, the economics of steam injection to oil field formation to enhance oil and gas recovery need to be examined.

The ZEST facility has been sized on a nominal $5 \mathrm{MW}$ capacity for technology demonstration, and therefore, the economic viability of a zero emission power plant has not been assessed in this study. An economic analysis to be based on a design study of a scaled-up industrial plant is necessary to address this issue. 


\section{Appendix B.1}

\section{Zero Emission Steam Technology Research Facility}

\section{Flowsheet and Mass Balance}

by

Clean Energy Systems, Inc. 


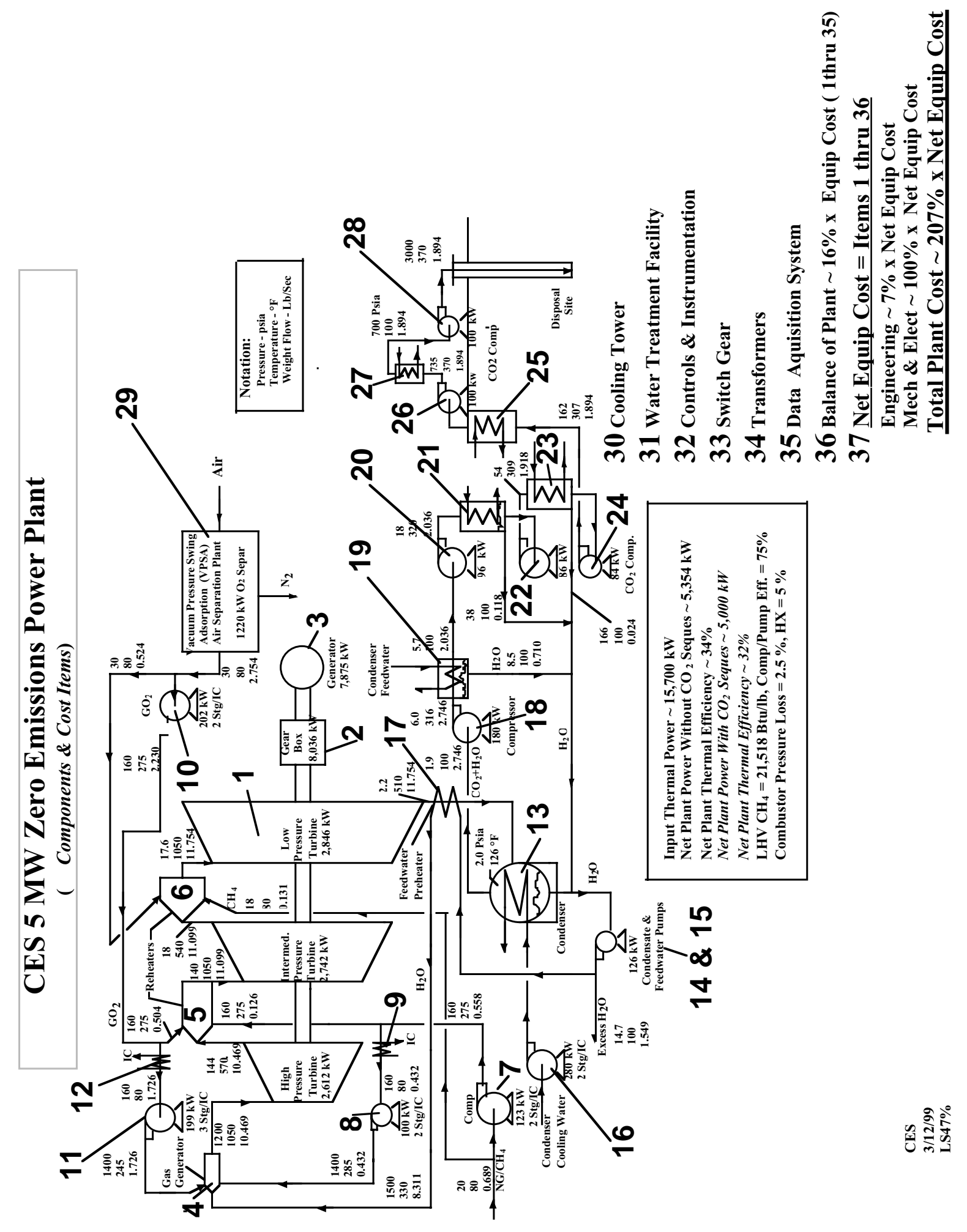




\section{Appendix B.2}

\section{Major Equipment List}

for

\section{Zero Emission Steam Technology Research Facility}




\section{MAJOR EQUIPMENT LIST ZEST Research Facility}

\begin{tabular}{|c|c|c|c|c|}
\hline $\begin{array}{l}\text { Equip ment } \\
\text { No. }\end{array}$ & EQQUIPMENT DESCRIPTION & Qृuantity & $\begin{array}{l}\text { Equipment Size or } \\
\text { Power }\end{array}$ & Design Parameters \\
\hline $1 \mathrm{~A}$ & High Pressure Turbine & 1 & & $\begin{array}{l}\mathrm{Pi}=1,000-1,200 \text { psia, Ti=900-1,050 } \\
\text { Flow }=45,000 \text { la } / \text { hir }\end{array}$ \\
\hline $1 \mathrm{~B}$ & Intermediate Pressure Turbine & 1 & & $\begin{array}{l}\mathrm{Pi}=130-160 \mathrm{psia}, \mathrm{Ti}=900-1,050^{\circ} \mathrm{F}, \mathrm{Flow}=45,000 \\
\mathrm{l} \mathrm{b} / \mathrm{hr}\end{array}$ \\
\hline $1 \mathrm{C}$ & Low Pressure Turbi ne & 1 & & $\mathrm{Pi}=15-16 \mathrm{psia}, \mathrm{Ti}=900-1050^{\circ} \mathrm{F}, \mathrm{Flow}=45,000 \mathrm{lb} / \mathrm{hr}$ \\
\hline 2 & Geartiox & 1 & & $\begin{array}{l}\text { Input speed } 6,000 \mathrm{rpm} \text {, Dutput speed } 3,600 \mathrm{rpm} \text {, } \\
\text { power } 8 \mathrm{MW}\end{array}$ \\
\hline 3 & Electrical Generator & 1 & $7.9 \mathrm{MW}$ & \\
\hline 4 & Gas Generator & 1 & $1^{\prime}-0 " D \times 8^{\prime}-0 " L$ & \\
\hline 5 & Rehegter No.1 & 1 & Diameter $6 "$ & $\mathrm{Pi}=146 \mathrm{psia}, \mathrm{Po}=142 \mathrm{psia}, \mathrm{Ti}=570^{\circ} \mathrm{F}, \mathrm{To}=1,050^{\circ} \mathrm{F}$ \\
\hline 6 & Rehegter No.2 & 1 & Diameter $18 "$ & $\mathrm{Pi}=16.5 \mathrm{psia}, \mathrm{Po}=16.0 \mathrm{psia}, \mathrm{Ti}=570^{\circ} \mathrm{F}, \mathrm{To}=1,050^{\circ} \mathrm{F}$ \\
\hline 7 & CH4 Compresor \# 1 & 1 & $148 \mathrm{BHF}$ & $\begin{array}{l}\mathrm{Pi}=20 \text { psia, Po=160 psia, } 0.56 \mathrm{l} \text { b/sec, } 2 \text { stage } \\
\text { reciprocating, includes intercooler }\end{array}$ \\
\hline 8 & CH4 Compressor $\# 2$ & 1 & $122 \mathrm{BHF}$ & $\begin{array}{l}\mathrm{Pi}=160 \mathrm{psia}, \mathrm{Po}=1400 \mathrm{psia}, 0.43 \mathrm{lt} / \mathrm{sec}, 2 \text { stage } \\
\text { reciprocating, incl udes intercooler }\end{array}$ \\
\hline 29 & Oxygen Plant & 1 & $1500 \mathrm{~km}$ & $\begin{array}{l}\text { 2.75 Ib 02/sec, Cryogenic separation from air, } 1900 \\
\text { kW incl } 02 \text { compressors } 182\end{array}$ \\
\hline 10 & 02 Compresor \#1 (incl in 0xygen Plant) & 1 & $264 \mathrm{BHF}$ & $\begin{array}{l}\mathrm{Pi}=30 \text { psia, Po=160 psia, } 2.23 \mathrm{l} \mathrm{b} / \mathrm{sec}, 2 \text { stage } \\
\text { reciprocating, includes intercooler }\end{array}$ \\
\hline 11 & 02 Compressor \#2 (incl in 0xygen Plant) & 1 & $250 \mathrm{BHF}$ & $\begin{array}{l}\mathrm{Pi}=160 \mathrm{psia}, \mathrm{Po}=1400 \mathrm{psia}, 1.73 \mathrm{lb} / \mathrm{sec}, 2 \text { stage } \\
\text { reciprocating, includes intercooler }\end{array}$ \\
\hline 15 & Turbine Exhaust Condenser & 1 & $6 \cdot 0 \times 27 \mathrm{~L}$ & $\begin{array}{l}\text { Hegt Duty }=34,472,630 \text { BTU/hr, Surface Area }=14,934 \\
\text { ft 2, ACFM i }=167,598 \text {, ACFM out = } 16,321, \text { CW }=4596 \\
\text { gpm, Carbon steel shell, Stainless steel tubes }\end{array}$ \\
\hline $1 \Xi A$ & De-entrainment vessel & 1 & $4 \cdot 0 \times 8^{\prime} H$ & $A C F S=272, T=100^{\circ} \mathrm{F}$ \\
\hline $13 \mathrm{~B}$ & Condensate Pump & 1 & $2 \mathrm{BHF}$ & $71 \mathrm{gpm}, \mathrm{P}=1.9 \mathrm{psia}, \mathrm{T}=100^{\circ} \mathrm{F}$ \\
\hline 15 & Feedwater Pump & 1 & $75 \mathrm{BHF}$ & $60 \mathrm{pm}, \mathrm{Pi}=30 \mathrm{psia}, \mathrm{Ti}=100^{\circ} \mathrm{F}, \mathrm{Po}=1500 \mathrm{psia}$ \\
\hline 17 & Preheater Exchanger & 1 & $5.0 \times 24^{\prime} L$ & $\begin{array}{l}\text { Surface area }=9,796 \text { ft } 2 \text {, ACFS out }=1,713 \text {, carbon steel } \\
\text { shell, stainless steel tubes, Heat Duty }=6,940,512\end{array}$ \\
\hline 18 & C02 Compressor \#1 & 1 & $951 \mathrm{BHF}$ & $\begin{array}{l}\mathrm{Pi}=1.9 \text { psia, Fo=162 psia, } 2 \text { lb/sec, } 6 \text { stage centrifugal , } \\
\text { stl steel, includes i nterooglers }\end{array}$ \\
\hline 26 & C02 Compressor \#2 (at oil field) & 1 & $185 \mathrm{BHF}$ & $\begin{array}{l}\mathrm{Pi}=162 \text { psia, Po=1,000 psia, } 1.9 \mathrm{lb} / \mathrm{sec}, \text { stainless } \\
\text { steel, includes intercooler }\end{array}$ \\
\hline 40 & C02 Acoumulator (at oil field) & 1 & $3 '-6 " 0 \times 7 \cdot-0 " H$ & Stainless Steel, 1 , 000 design pressure. \\
\hline 30 & Cooling Tower & 1 & $14^{\prime} \mathrm{L} \times 244^{\prime} \mathrm{W} \times 20 \mathrm{H}$ & $\begin{array}{l}\text { Flowrate }=5300 \mathrm{gpm} \text {, Hot Water } \mathrm{T}=95^{\circ} \mathrm{F} \text {, Cold Water } \\
\mathrm{T}=80^{\circ} \mathrm{F} \text {, Wet Bul } \mathrm{b}=70^{\circ} \mathrm{F} \text {, Fan HP=75}\end{array}$ \\
\hline 16 & Cooling Tower Water Pump & 1 & $110 \mathrm{BHF}$ & $5,500 \mathrm{gmm}$ \\
\hline 31 & Condensate Water Treatment Unit & 1 & & \\
\hline 32 & Controls and Instrumentation & 1 & & \\
\hline 33 & Switch Gear & 1 & & \\
\hline 34 & Transformer & 1 & & \\
\hline 35 & Data Aquisition System & 1 & & \\
\hline 36 & Natural Gas Surge Vesel & 1 & $3^{\prime}-6 " 0 \times 10^{\prime}-6 " \mathrm{H}$ & Carbon Steel \\
\hline 37 & Condensate Tank & 1 & $4 ' \mathrm{D} \times 12^{\prime} \mathrm{L}$ & Stainless Steel \\
\hline 38 & Condensate Tank Bleed Pump & 1 & $0.5 \mathrm{BHP}$ & $11.2 \mathrm{gpm}$ \\
\hline 39 & Cooling Tower Water Blowdown Pump & 1 & $1 \mathrm{BHF}$ & $25 \mathrm{gpm}$ \\
\hline
\end{tabular}


Appendix B.3

Pre-Conceptual Cost Estimate Bases and Details

for

Zero Emission Steam Technology Research Facility 


\section{A. PROJECT DATA}

Project Location: Lawrence Livermore National Laboratory (LLNL)

Livermore, California.

Project Scope: The project consists of engineering, procurement and construction (EPC); and operation for a Zero Emission Steam Technology (ZEST) Research Facility.

Type of Estimate: Pre-conceptual level cost estimate.

Pricing Level: $\quad$ Third Quarter of FY 2000.

\section{B. CAPITAL COST ESTIMATE BASIS}

\section{Scope Definition}

The scope for this estimate is described as follows:

- Preconceptual design information of the ZEST Research Facility based on Clean Energy Systems, Inc. (CES) and LLNL input

- Preliminary $81 / 2^{\prime \prime} \times 11^{\prime \prime}$ sketches and equipment list for ZEST Research Facility, gas pipeline and injection well systems:

- Process Flow Diagrams

- Equipment List

- Process Building Layout

- Site Facilities Layout

- Pipeline and Well Systems

\section{Process equipment}

Process equipment estimate is based on the equipment list developed in the design study. Budget prices were obtained for most of the commercially available equipment, such as compressors and cooling tower, with the costs of other equipment estimated using previous estimates for similar equipment as a guide, current estimating manuals, and in-house data bases.

Cost of turbine is estimated from unit cost of MW based on historical cost data. Cost of gas generator is provided by CES.

Cost estimate for the oxygen plant is based on subcontract with budget price quoted from vendors. 
Cost of process control is estimated as a factor equal to $15 \%$ of the process equipment cost.

\section{Process Facilities}

Process facilities include the process building and pad for the oxygen plant. The Process Building is a light structure metal building on a concrete pad. Building quantities are estimated based on similar commercial light structure.

\section{LLNL Site Support Facilities}

Support facilities at the LLNL site include the engineering/control building, and yard equipment. The engineering and control building is a prefab modular building. The yard equipment includes cooling tower pad and site security fence.

\section{Site Improvement}

Site improvement cost includes costs for site demolition and site preparation and costs for yard electrical switchgear, duct bank, substation, fire alarm, and utilities tie-in to the site, their design cost, and the costs for licensing and permits. The site improvement cost is furnished by LLNL.

\section{Pipeline and Injection Well Systems}

Cost for the $\mathrm{CO} 2$ pipeline is furnished by LLNL. Costs for the injection well and monitoring wells are furnished by CES.

\section{Oil Field Facilities}

Oil field facilities include the injection pump station with final-stage compressors and monitoring stations. The injection pump station and monitoring stations are metal shed on a concrete pad with a security fence.

\section{Quantity Development and Pricing}

Quantities were factored based on building sizing from the estimates for similar facilities, and priced on current pricing levels.

\section{Manual Labor}

Davis-Bacon manual labor rates for San Francisco Bay area were used. The Workers' Compensation Insurance rates are included in the wage rates. A standard 40 hour work week was used.

\section{State Sales Tax}

A sales tax of $8.25 \%$ is included for materials and equipment. 


\section{Distributable (General Conditions), Overhead and Profit}

Distributable costs include temporary construction facilities, construction equipment, tools, materials, and other distributable support and non-manual labor costs, and field office costs. The distributable and construction contractor's overhead and profit is factored at 30\% of the direct construction costs, and at 15\% of the subcontract equipment. These factors are based on recent evaluation of industrial rates.

Contractor's bond is calculated at $1 \%$ of total construction cost.

\section{Construction management}

Construction management costs, including the construction manager's overhead and profit, was included at 10\% of the construction contractor's costs.

\section{Architect-engineering, and procurement}

Architect-Engineer's design and construction support costs include all functions such as engineering management, project control, all discipline engineering, documentation, quality control, procurement, and support services. The costs were factored at $20 \%$ of the field costs for construction excluding subcontract items.

\section{Project management}

Project management costs are factored at $7.5 \%$ of the field costs.

\section{Escalation}

Costs are estimated at $3^{\text {rd }}$ Quarter of FY 2000 level. Escalation of capital cost to midpoint of construction (March 2004) is also reported with an escalation rate of $10.01 \%$ based on DOE's cost index.

\section{Contingency}

A 35\% contingency allowance is included in the ZEST capital cost.

\section{Exclusions}

1. Cost of land lease of the oil field

2. Research and development costs

3. Royalties

4. DOE Oversight

5. Salvage value from the DC Power Supply Area demolition

6. Facilities removal and site restoration at the LLNL site or oil field after project completion. 


\section{OPERATING COST ESTIMATE BASIS}

The operating cost estimate includes consumables, utilities, operating personnel wages, and operating material expenditures for the ZEST Research Facility operations after plant construction completion.

\section{Consumable Material Cost}

Cost of consumable material for process operations, such as natural gas, is based on current LLNL rates charged to laboratory program. Electricity is based on 4.6 cents per $\mathrm{kWh}$. Natural gas is based on 26 cents per therm unit.

Cost for cooling tower water system treatment chemicals is based on NALCO Chemical Co. quotation for treating the makeup water. This includes all the additives and inhibitors and rental instrument for the package unit.

\section{Utilities and Services Cost}

The operating costs for utilities and services are calculated using the actual rate in the plant site. Basis for these costs are calculated electric power needed to operate the facility.

A laboratory facility charge based on buildings square footage is included for facility maintenance. Process equipment maintenance cost is not included. Costs for water and sanitary sewer are from G\&A expenses and not included in the estimate.

\section{Labor Cost}

The plant will be manned by a combination of research staff and manual operators. For the purposes of this study, it is assumed that the plant operation will be supplemented by two full-time operators. The operators will work a normal 40 hour workweek. Wages for manual operator employee including fringe benefits are based on LLNL wage rate.

\section{Revenue}

Revenue from the sales of electricity generated is based on 3 cents per $\mathrm{kWh}$. The revenue is credited to offset the operation cost. Potential revenue from $\mathrm{CO} 2$ sales is not considered.

\section{Exclusions}

The research staff is excluded from the operating cost estimate. No contingency allowance is included. 


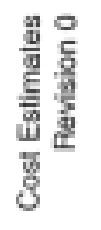

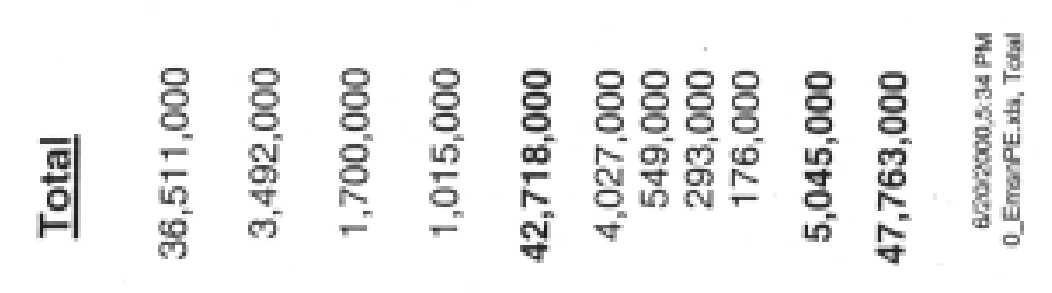






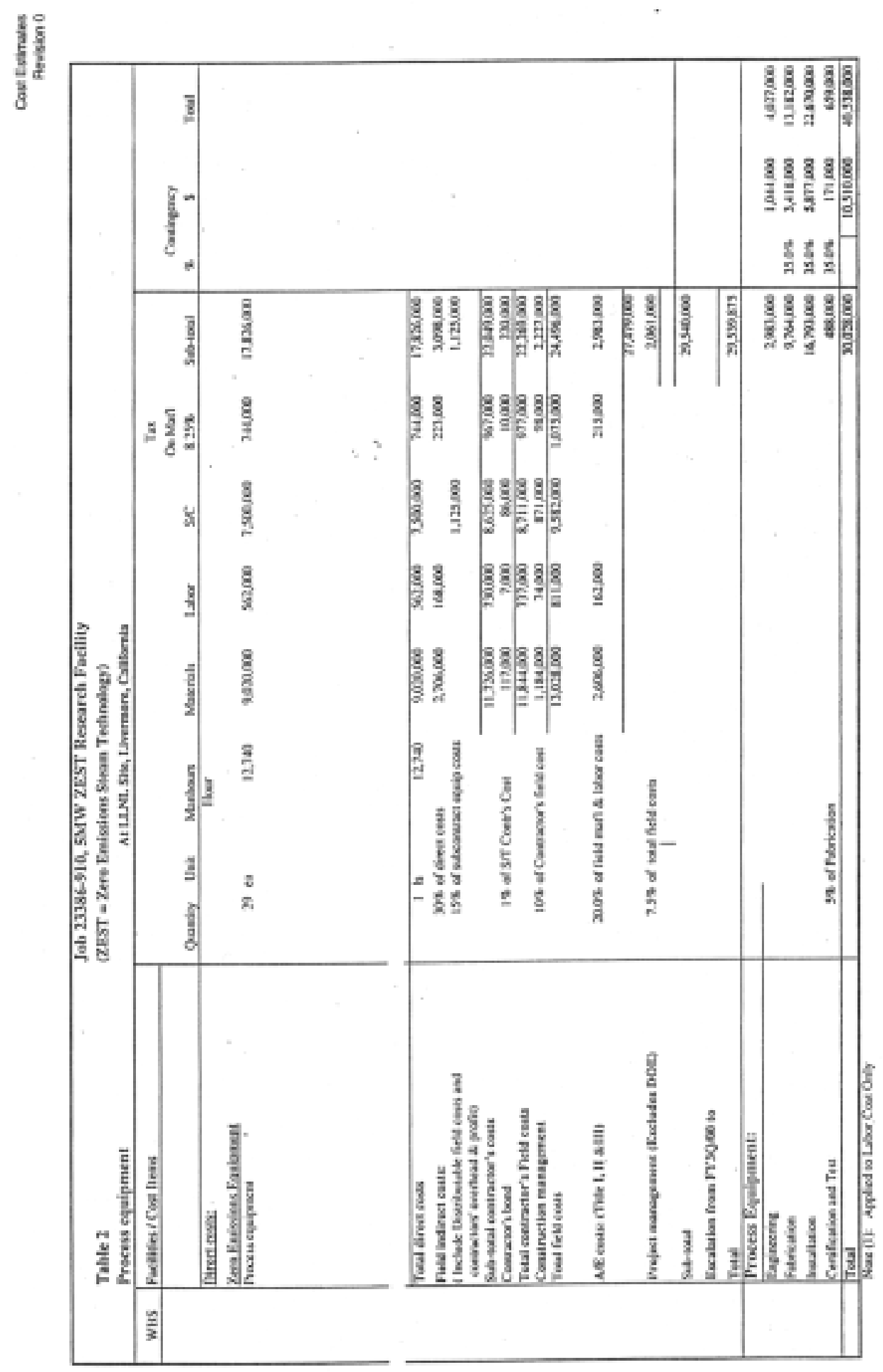

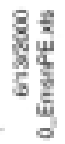


$\frac{2}{8}$

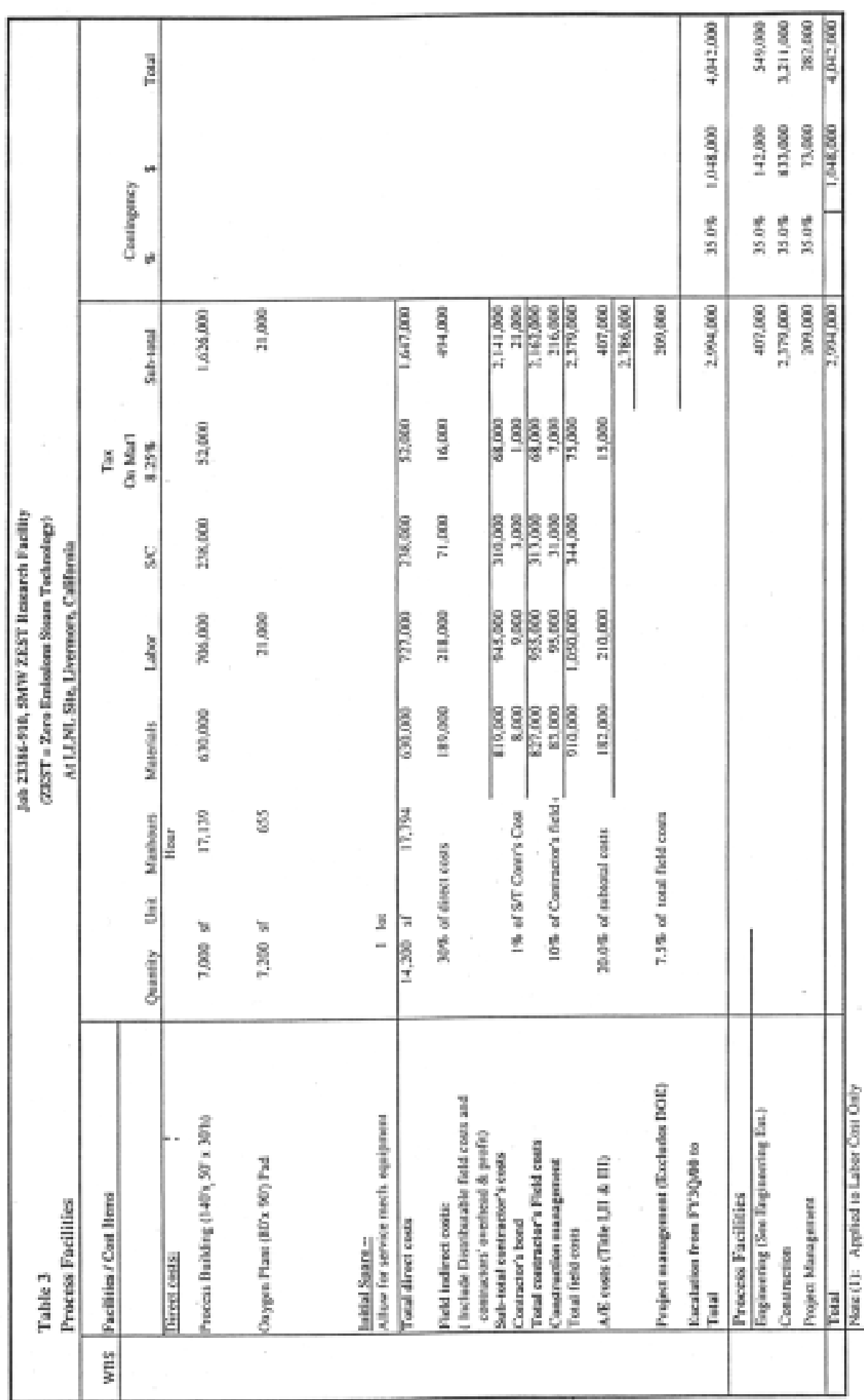

量紫 


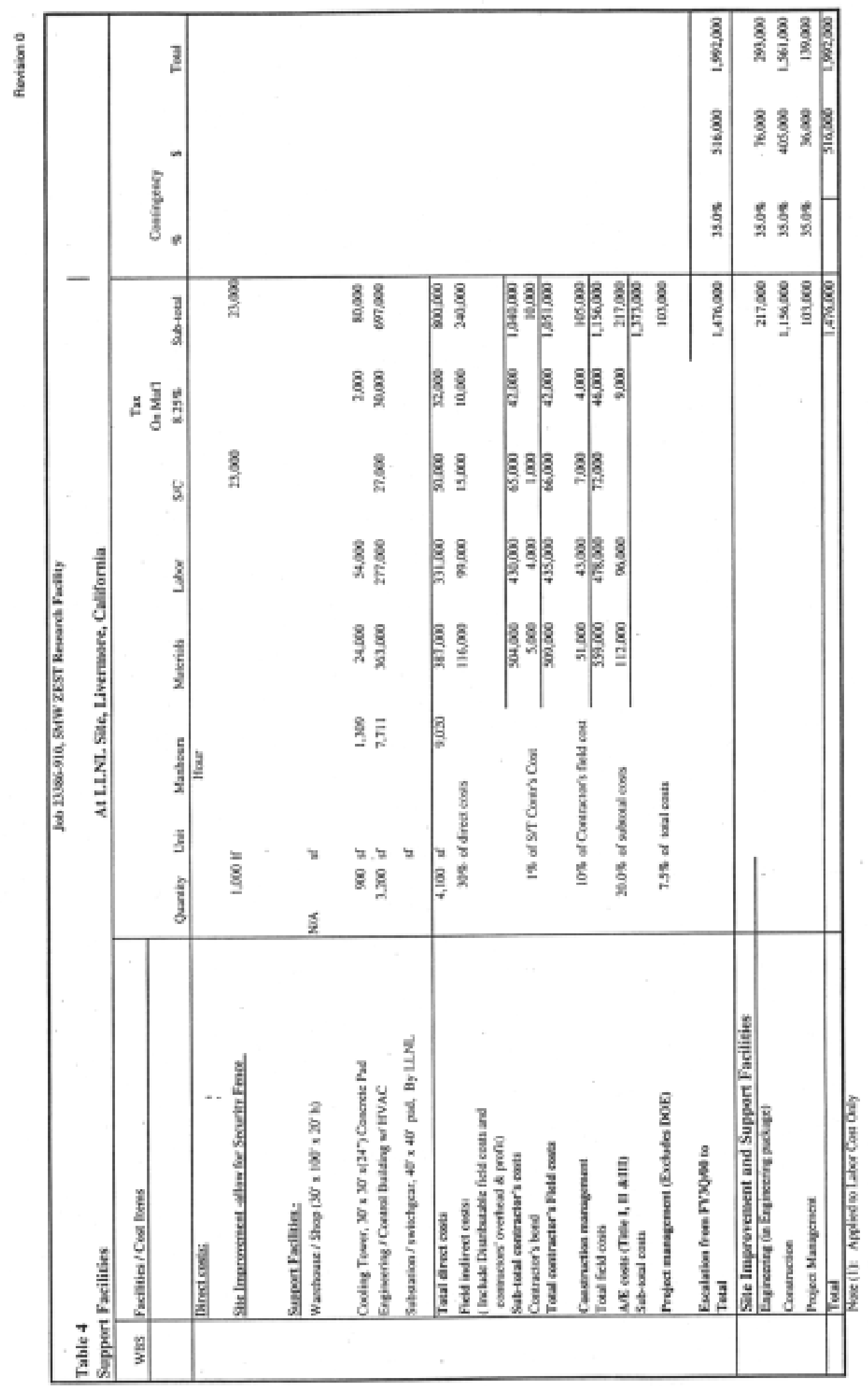




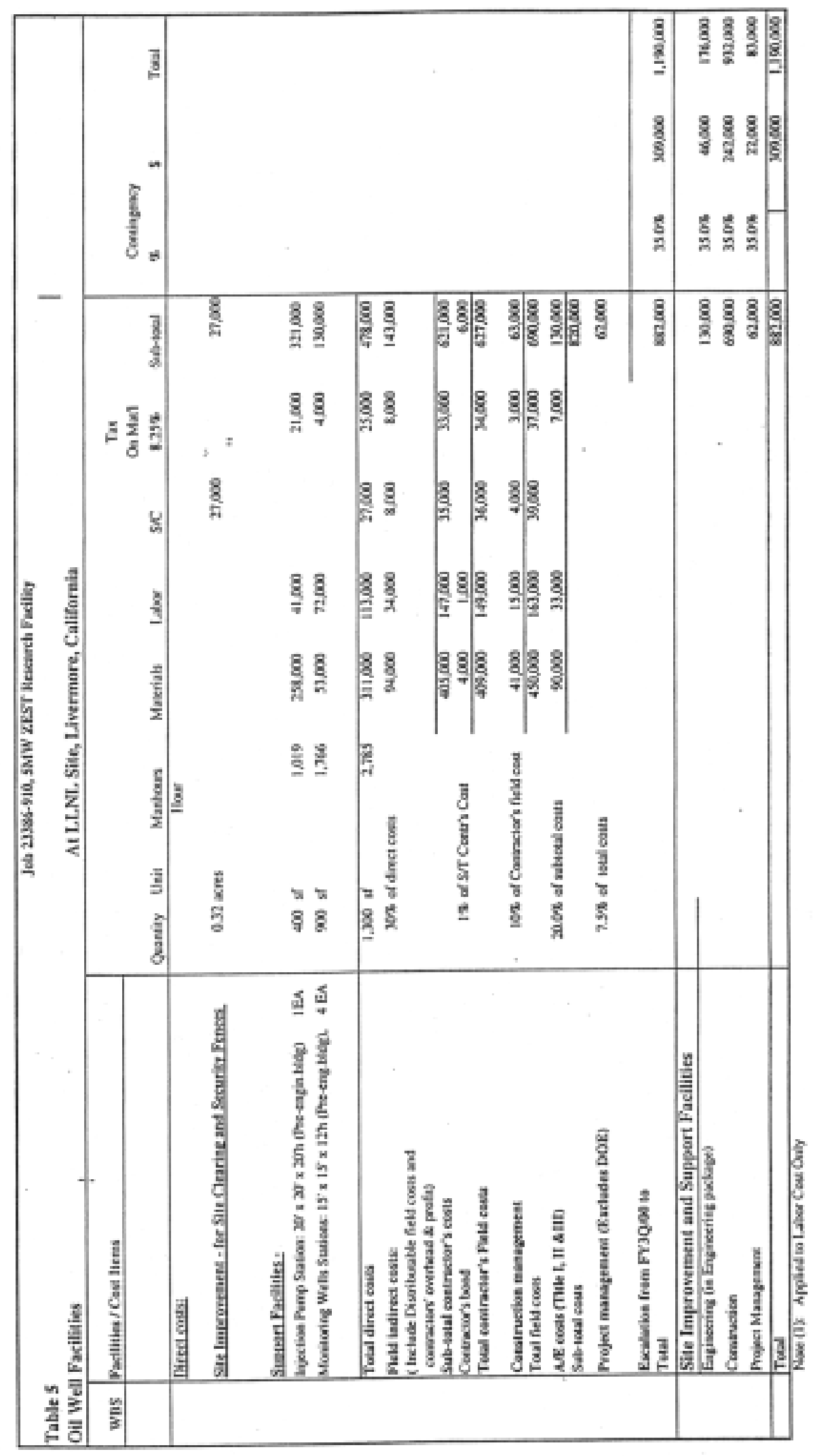

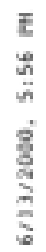




\section{Summary of LLNL Site Preparation and $\mathrm{CO} 2$ Pipeline Costs for ZEST Research Facility}






\section{Summary of Oil Field Well Costs for ZEST Research Facility}

Five wells need to be drilled and completed for the ZEST power plant research facility. One well is an injection well and the other four wells are observation/monitoring wells. The five wells are identified in Table 1 below. Detailed costs of the wells are shown in the attachments. The cost of drilling and completing the five wells is $\$ 2,080,600$.

Each well will require a pad, a small building, electric (AC) power, and security fence. The pad and building of the injection well is larger than the pad and building of the four observation wells. The increased building size is due to the need for a housing of a compressor/pump. This unit is required to bring the pressure of the carbon dioxide to the injection pressure.

Each of the four observation/monitoring wells has a casing size of $85 / 8$ " and depth of 3,200 ft. The surface requirements for each of the four observation/monitoring wells are identical. Electrical power supplied to the building at each of the four observation/monitoring wells should be about $3 \mathrm{KW}$. This power requirement is based on the use of the well as an observation well, and not as a possible production well.

No personnel will be needed on-site for normal operations. Operating control will be at the LLNL ZEST facility and will require approximately 0.2 FTE. No contingencies are included. Unexpected expenses may occur in the drilling and completion of the wells on account of local subsurface geologic variations. Also, included in the cost summary (and attachment) is the cost of one workover. The workover is included to handle unforeseen difficulties once the wells are placed into operation.

Table 1. Summary of Drilling and Completion Costs

\begin{tabular}{|clll|}
\hline Number of Wells & Well Type & AFE Number & Cost \\
\hline 1 & & & \\
4 & Injection, 2,000 ft & LLNL-1 & $\$ 351,800$ \\
& & Observation, 3,200 ft & $\$ 406,700$ \\
& & LLNL-3 & $\$ 406,700$ \\
1 & LLNL-3 & $\$ 406,700$ \\
& Workover & LLNL-3 & $\$ 406,700$ \\
& Total Cost & & $\$ 102,000$ \\
\hline & & & $\$ 2,080,600$ \\
\hline
\end{tabular}




\section{ZEST RESEARCH FACILITY}

ANNUAL OPERATING COST ESTIMATE SUMMARY

Total (\$)



6/20/01 